OAK RIDGE

NATIONAL LABORATORY

MANAGED BY UT-BATTELLE

FOR THE DEPARTMENT OF ENERGY
ORNL/TM-2007/168

Revision 1

\title{
Assessment of Silicon Carbide Composites for Advanced Salt- Cooled Reactors
}

Y. Katoh, D.F. Wilson, C.W. Forsberg Oak Ridge National Laboratory

September 2007

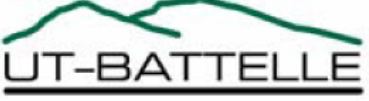


This report was prepared as an account of work sponsored by an agency of the United States Government. Neither the United States government nor any agency thereof, nor any of their employees, makes any warranty, express or implied, or assumes any legal liability or responsibility for the accuracy, completeness, or usefulness of any information, apparatus, product, or process disclosed, or represents that its use would not infringe privately owned rights. Reference herein to any specific commercial product, process, or service by trade name, trademark, manufacturer, or otherwise, does not necessarily constitute or imply its endorsement, recommendation, or favoring by the United States Government or any agency thereof. The views and opinions of authors expressed herein do not necessarily state or reflect those of the United States Government or any agency thereof. 
ORNL/TM-2007/168

\title{
Assessment of Silicon Carbide Composites for Advanced Salt-Cooled Reactors
}

\author{
Y. Katoh*, D.F. Wilson, C.W. Forsberg \\ Oak Ridge National Laboratory \\ Oak Ridge, Tennessee
}

\author{
Contributors \\ Lance L. Snead and David F. Williams \\ Oak Ridge National Laboratory \\ Oak Ridge, Tennessee
}

Date Published: September 2007

\author{
Prepared by \\ OAK RIDGE NATIONAL LABORATORY \\ Oak Ridge, Tennessee 37831 \\ managed by \\ UT-BATTELLE, LLC \\ for the \\ U.S. DEPARTMENT OF ENERGY \\ under contract DE-AC05-00OR22725
}

* P.O.Box 2008, Oak Ridge, TN 37831-6138, Tel. (865) 576-5996, Email: katohy@ornl.gov 



\section{CONTENTS}

Page

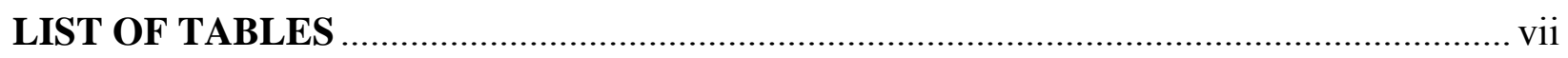

ABBREVIATIONS AND ACRONYMS ...................................................................... ix

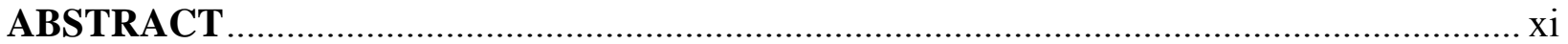

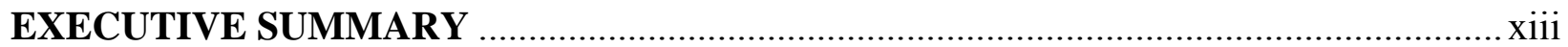

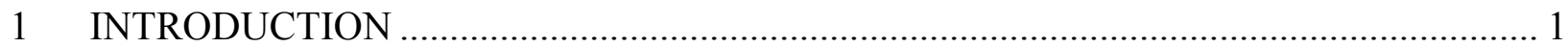

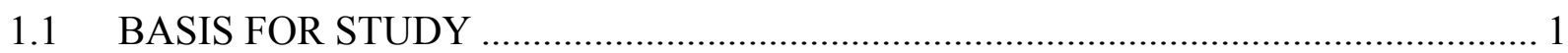

1.2 BASIS FOR SiC EVALUATION ................................................................... 3

2 SiC FOR NUCLEAR APPLICATIONS ….............................................................. 7

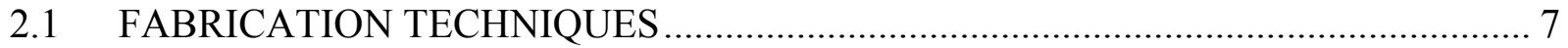

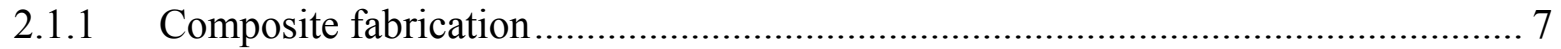

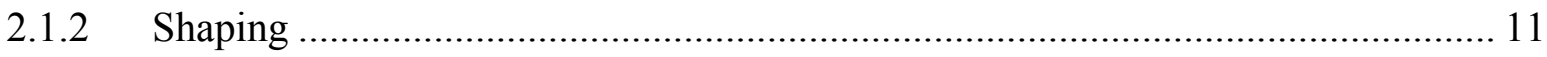

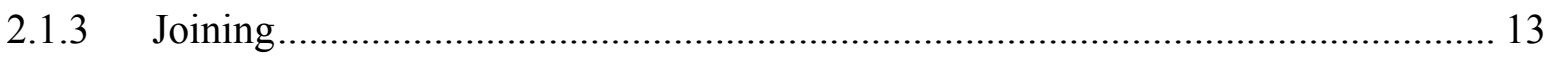

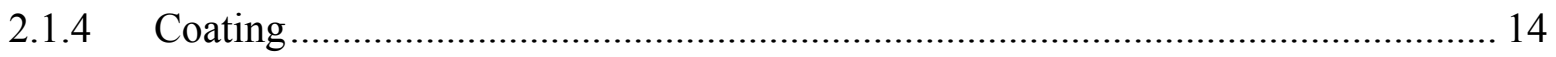

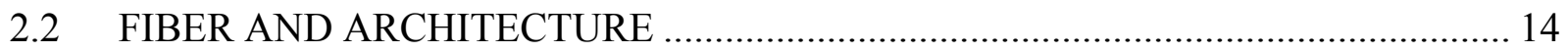

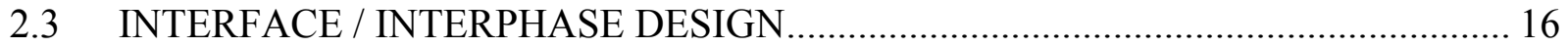

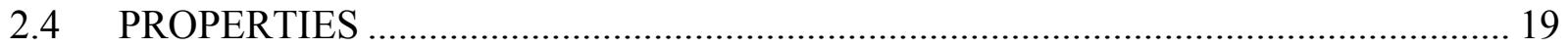

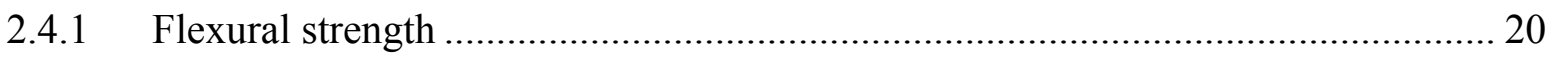

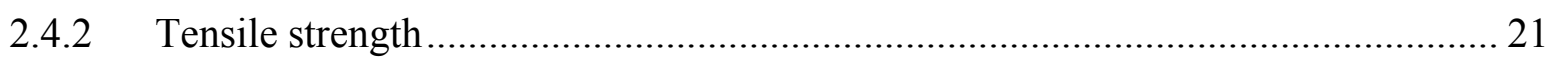

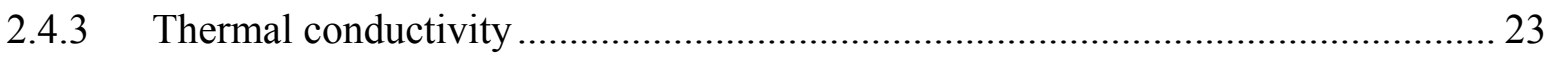

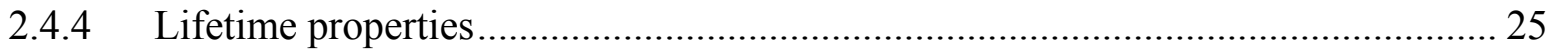

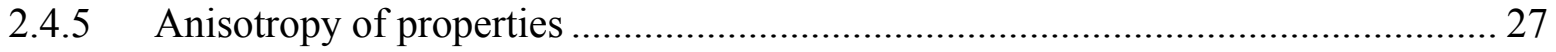

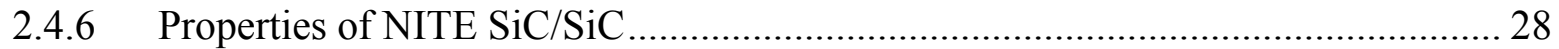

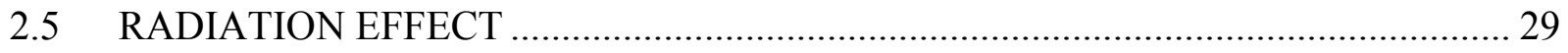

2.5.1 Radiation effect on strength of pure SiC ........................................................ 29

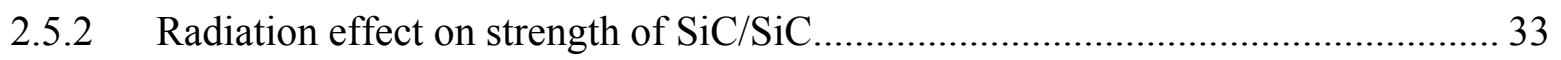

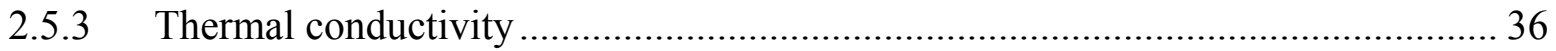

2.5.4 Radiation-induced swelling and microstructure ............................................... 38

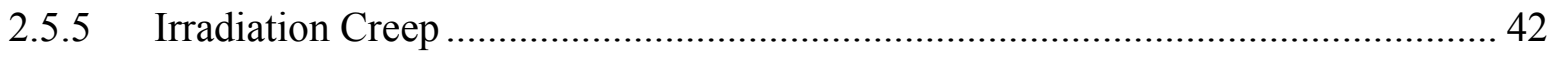

2.5.6 Summary of radiation effect issues.......................................................... 44 


\section{CONTENTS (continued)}

Page

2.6 TEST STANDARDS AND NON-DESTRUCTIVE EVALUATION ....................... 45

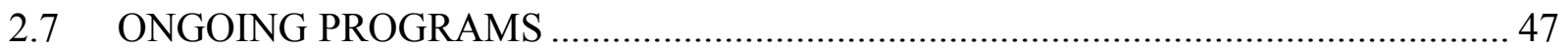

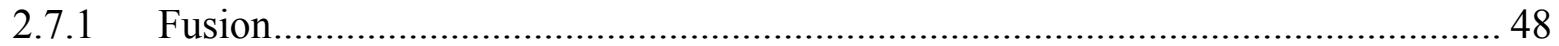

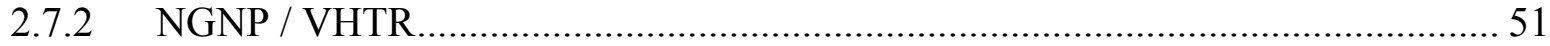

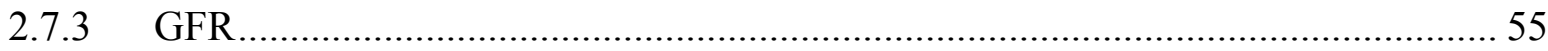

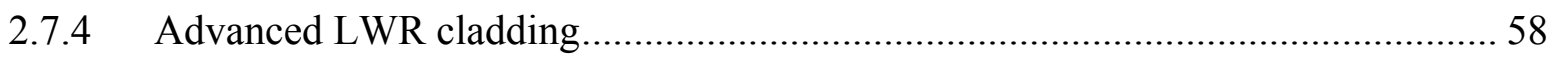

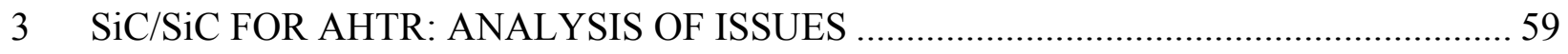

3.1 AHTR STRINGER FUEL COMPONENTS AND REQUIREMENTS ...................... 60

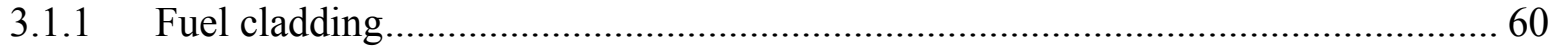

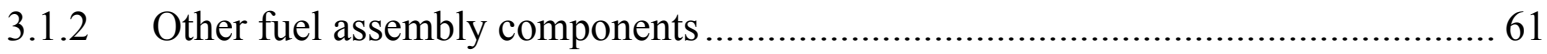

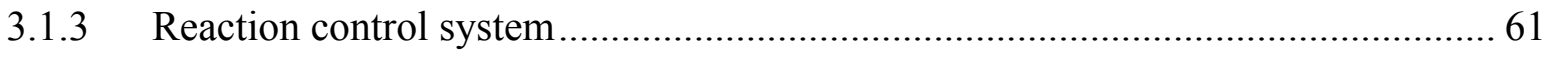

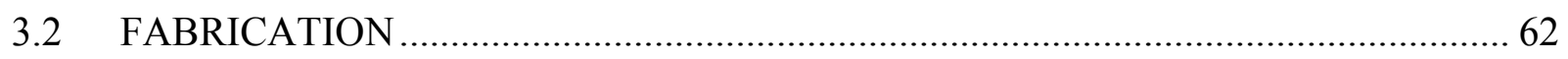

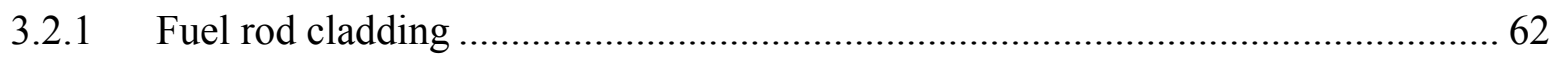

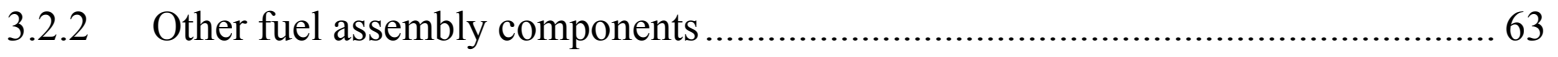

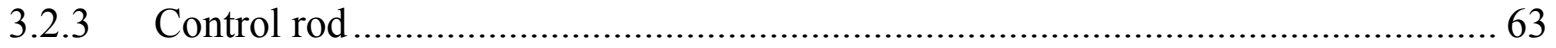

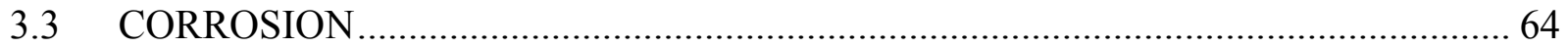

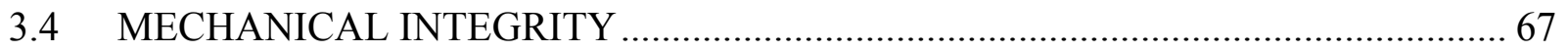

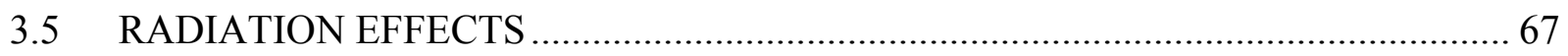

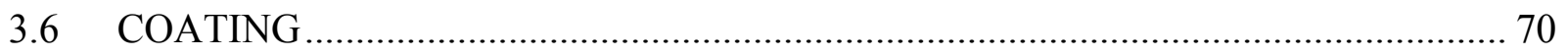

3.7 TEST STANDARDS AND DESIGN CODIFICATION ....................................... 71

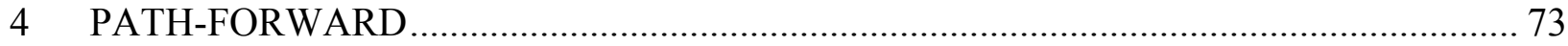

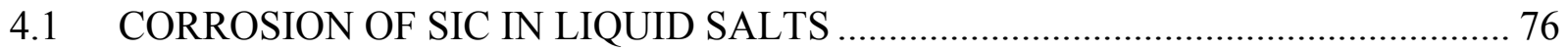

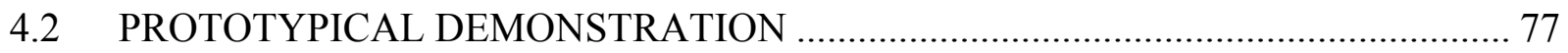

4.3 EFFECTS OF HIGH DOSE IRRADIATION ON FUNDAMENTAL PROPERTIES

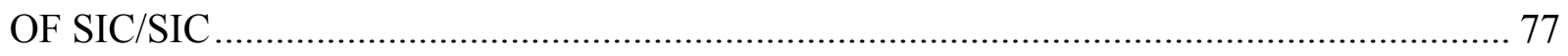

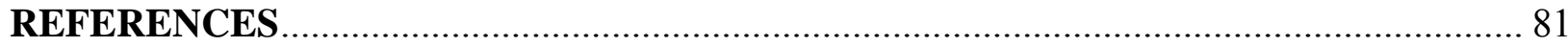




\section{LIST OF FIGURES}

Figure

Page

Figure 1: Examples of components fabrication with CVI SiC/SiC. Left: Tensile test specimens of small diameter, thin wall tubes.(ORNL Gen-IV Materials Program) Right: Rocket nozzle (Courtesy: Hypertherm High-Temperature Composites, Inc.) .... 11

Figure 2: Examples of components fabrication with NITE SiC/SiC (Courtesy: Kyoto University)

Figure 3: Influences of pyrocarbon interphase thickness on mechanical properties of CVI

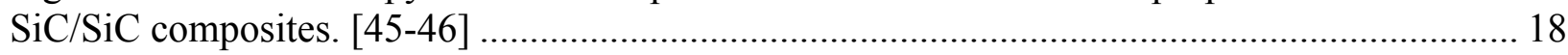

Figure 4: Flexural properties of CVI SiC/SiC. [48] ........................................................... 21

Figure 5: Examples of tensile stress-strain behavior of CVI SiC/SiC (testing procedure involves incremental unloading/reloading sequences to determine the extent of matrix damages and interfacial properties). The labels I - III indicate stages of tensile fracture of the composites in this class; namely I: elastic/reversible deformation, II: matrix micro-crack accumulation, and III: progressive fiber failure. The horizontal shifts are intentional for clarity. [46] ....................... 22

Figure 6: Thermal conductivity of CVI SiC/SiC. [50] .................................................... 23

Figure 7: Strength and thermal property tailoring of 3D SiC/SiC. [50] ................................. 25

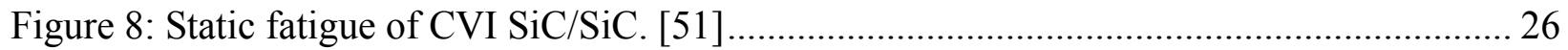

Figure 9: Cyclic fatigue of CVI SiC/SiC. [54] ........................................................... 27

Figure 10: Anisotropy in mechanical properties of 2D SiC/SiC with regard to fiber orientation. [47] 28

Figure 11: Mechanical property of NITE SiC/SiC. [29] ...................................................... 29

Figure 12: Effect of neutron irradiation on fracture strength of high purity CVD SiC. [59]....... 30

Figure 13: Effect of neutron irradiation on statistical fracture strength of high purity CVD SiC.

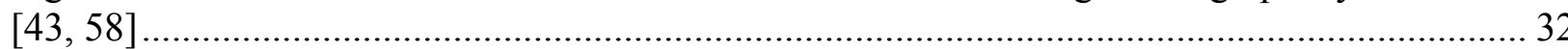

Figure 14: Effect of neutron irradiation on fracture strength of liquid phase sintered SiC. [62].. 33

Figure 15: Effect of neutron irradiation on flexural strength of $\mathrm{SiC} / \mathrm{SiC}$. [70] ........................ 35

Figure 16: Effect of neutron irradiation on tensile properties of $\mathrm{SiC} / \mathrm{SiC}$. [68] ......................... 36

Figure 17: Effect of neutron irradiation on thermal conductivity of $\mathrm{SiC} / \mathrm{SiC}$. [72] ................... 38

Figure 18: Effect of neutron irradiation on saturatable swelling of $\mathrm{SiC} / \mathrm{SiC}$. [80] ..................... 39

Figure 19: Effect of neutron irradiation on unstable swelling of $\mathrm{SiC} / \mathrm{SiC}$. [87] ........................ 41

Figure 20: Microstructural development in high purity CVD SiC during neutron irradiation. [59] 


\section{LIST OF FIGURES (continued)}

Figure

Page

Figure 21: Example of blanket designs assuming use of $\mathrm{SiC} / \mathrm{SiC}$ as structural material. [99, 103]

Figure 22: Examples of blanket designs assuming use of SiC-based flow channel inserts. [23,

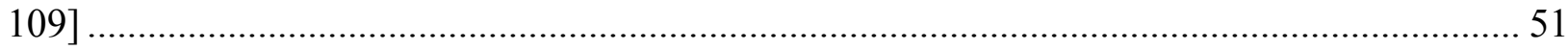

Figure 23: Illustration of reactor vessel and components for GT-MHR. [8] ........................... 53

Figure 24: An example of proposed control rod segment (tubular sleeve, end caps, and articulating joint) made of composite materials. This example assumes the use of $\mathrm{C} / \mathrm{C}$ composite and approximate dimensions of $1 \mathrm{~m}$-long x $10 \mathrm{~cm}$-diameter. ............................................. 54

Figure 25: Spine-based design approach for control rod in Japanese HTTR. [112]................... 54

Figure 26: Sintered SiC fuel matrix element with submillimeter fuel containing channels developed in Japanese NERI program on GFR fuel R\&D.In this figure, process for producing sintered SiC matrix with axial penetrating holes to accommodate fuel micro-rods is shown. [114]

Figure 27: Conceptual illustration of intermediate heat exchanger and heat exchange element

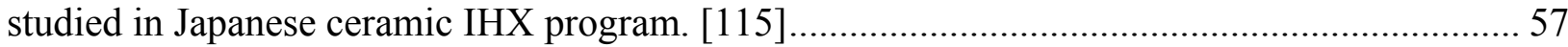

Figure 28: Illustrations of stringer type core and fuel assembly proposed for LS-VHTR. [2]..... 60

Figure 29: Three modes of silicon carbide corrosion in liquid salts. Based on McKee and Chatterji information. [133]

Figure 30: Influences of heat flux and thermal conductivity on magnitude of temperature drop across $\mathrm{SiC} / \mathrm{SiC}$ clad wall with given thickness.

Figure 31: Influence of temperature drop by $200 \mathrm{~K}$ across clad wall on evolution of maximum swelling-induced internal stress in fully constrained clad during operation with three extreme hypothetical irradiation creep cases. Stress magnitude is roughly estimated for Young's modulus $200 \mathrm{GPa}$. Note that understanding of irradiation creep behavior of SiC-based materials is presently very insufficient. [136] 


\section{LIST OF TABLES}

Table

Page

Table 1: Comparison of SiC-based ceramics and composites in various forms. 8

Table 2: Comparison of various process techniques for continuous $\mathrm{SiC}$ fiber, $\mathrm{SiC}$ matrix composites $(\mathrm{SiC} / \mathrm{SiC})$ for nuclear applications..................................................................... 9

Table 3: Typical properties of CVI and NITE SiC/SiC composites. [23] .................................. 10

Table 4: Comparison of various techniques for joining and sealing SiC-based materials. [30-34] 13

Table 5: Generations of SiC-based commercial fibers. [40-42] ………..................................... 16

Table 6: Established and developmental interphases for $\mathrm{SiC} / \mathrm{SiC}$ composites............................... 17

Table 7: Typical mechanical, physical, and lifetime properties of CVI SiC/SiC. [47] ................. 20

Table 8: Summary of neutron irradiation effects on mechanical properties of advanced fiber CVI

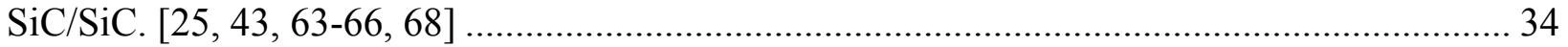

Table 9: Irradiation effect issues in SiC-based ceramics and composites and present status of

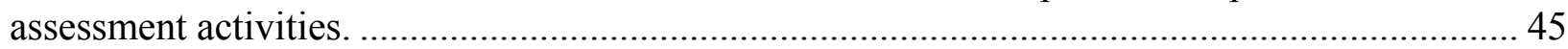

Table 10: ASTM test standards for ceramic matrix composites.................................................. 46

Table 11: NDE techniques for $\mathrm{SiC} / \mathrm{SiC}$ : candidate modalities and main attributes. [97] .............. 47

Table 12: Ongoing $\mathrm{SiC} / \mathrm{SiC} \mathrm{R} \& \mathrm{D}$ activities for nuclear applications and their focuses. .............. 48

Table 13: Fusion blanket designs assuming use of $\mathrm{SiC} / \mathrm{SiC}$. [99, 101-104] ................................ 49

Table 14: Key requirements for $\mathrm{SiC} / \mathrm{SiC}$ for blanket structural and functional applications in

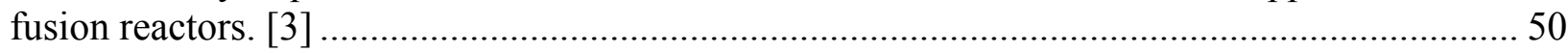

Table 15: Elements of US NGNP Composite R\&D program and comparison with international

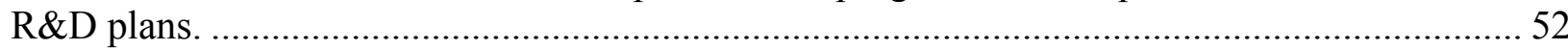

Table 16: Preliminary specifications for Japanese conceptual GFR core with SiC composite

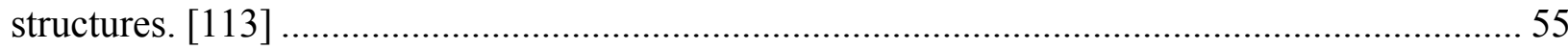

Table 17: Operating conditions and assumed thermal properties for cladding material for

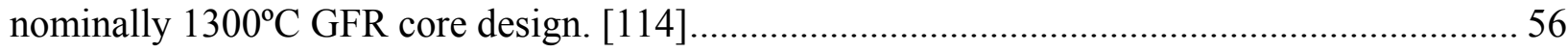

Table 18: Optimum specifications determined for mixed nitride fuel in Japanese GFR fuel

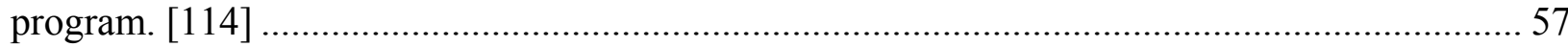

Table 19: Common fabric architectures for fibrous ceramic composites. [121] .......................... 62

Table 20: Critical issues and their relative importance for application of $\mathrm{SiC} / \mathrm{SiC}$ to salt-cooled high temperature reactor fuel cladding. Application temperature and maximum neutron fluence are assumed to be $800^{\circ} \mathrm{C}$ and $30 \mathrm{dpa}$, respectively. 


\section{LIST OF TABLES (continued)}

Table

Page

Table 21: Critical issues and their relative importance for application of $\mathrm{SiC} / \mathrm{SiC}$ to salt-cooled high temperature reactor fuel cladding at temperatures significantly higher than $800^{\circ} \mathrm{C} \ldots \ldots \ldots \ldots . . . .75$

Table 22: Suggested directions of near-term proof-of-principle study for application of SiCbased materials to salt-cooled high temperature reactor fuel cladding.................................... 75 


\section{ABBREVIATIONS AND ACRONYMS}

AGR

AHTR

ALWR

ARIES

ASME

ASTM

BSR

$\mathrm{C} / \mathrm{C}$

CTE

CVD

CVI

DCLL

DPA

EBC

FCI

GFR

GIF

GT-MHR

HCCB

HFIR

HTGR

HTTR

IHX

ITER

JMTR

LPS

LSI

LS-VHTR

LWR
Advanced Gas-cooled Reactor

Advanced High-Temperature Reactor

Advanced Light-Water Reactor

Advanced Reactor Innovation and Evaluation Studies

American Society of Mechanical Engineers

American Society for Testing and Materials, ASTM International

Bend Stress Relaxation

Continuous Carbon fiber-reinforced Carbon-matrix composite

Coefficient of Thermal Expansion

Chemical Vapor Deposition

Chemical Vapor Infiltration

Dual-Cooled Lead-Lithium

Displacement-per-atom

Environmental Barrier Coating

Flow Channel Insert

Gas-cooled Fast Reactor

Generation-IV International Forum

Gas-Turbine Modular Helium Reactor

Helium-Cooled Ceramic Breeding

High Flux Isotope Reactor

High Temperature Gas-cooled Reactor

High Temperature Test Reactor

Intermediate Heat Exchanger

International Thermonuclear Experimental Reactor

Japan Materials Test Reactor

Liquid-Phase Sintering

Liquid Silicon Infiltration

Liquid-Salt-cooled Very High-Temperature Reactor

Light Water Reactor 


\section{ABBREVIATIONS AND ACRONYMS (continued)}

$\begin{array}{ll}\text { MI } & \text { Melt-Infiltration } \\ \text { NDE } & \text { Non-Destructive Evaluation } \\ \text { NGNP } & \text { Next Generation Nuclear Power } \\ \text { NITE } & \text { Nano-Infiltration and Transient Eutectic-phase } \\ \text { ORNL } & \text { Oak Ridge National Laboratory } \\ \text { PBMR } & \text { Pebble-Bed Modular Reactor } \\ \text { PCS } & \text { Polycarbosilane } \\ \text { PIE } & \text { Post-Irradiation Examination } \\ \text { PIP } & \text { Polymer Impregnation and Pyrolysis } \\ \text { PLS } & \text { Proportional Limit Stress } \\ \text { PPCS } & \text { Power Plant Conceptual Study } \\ \text { PTCS } & \text { Polytitanocarbosilane } \\ \text { PyC } & \text { Pyrolytic Carbon, Pyrocarbon } \\ \text { R\&D } & \text { Research and Development } \\ \text { RS } & \text { Reaction Sintering } \\ \text { SCC } & \text { Stress-Corrosion Cracking } \\ \text { SCG } & \text { Slow Crack Growth } \\ \text { SCLL } & \text { Self-Cooled Lead-Lithium } \\ \text { SiC } & \text { Silicon Carbide } \\ \text { SiC/SiC, SiC } / \text { /SiC } & \text { SiC continuous fiber-reinforced SiC matrix composite } \\ \text { SNF } & \text { Spent Nuclear Fuel } \\ \text { TBM } & \text { Test Blanket Module } \\ \text { TEP } & \text { Transient Eutectic-Phase } \\ \text { UTS } & \text { Ultimate Tensile Stress } \\ \text { VHTR } & \text { Very High Temperature Reactor }\end{array}$




\begin{abstract}
The Advanced High-Temperature Reactor (AHTR) is a new reactor concept that uses a liquid fluoride salt coolant and a solid high-temperature fuel. Several alternative fuel types are being considered for this reactor. One set of fuel options is the use of pin-type fuel assemblies with silicon carbide ( $\mathrm{SiC}$ ) cladding. This report provides (1) an initial viability assessment of using $\mathrm{SiC}$ as fuel cladding and other in-core components of the AHTR, (2) the current status of SiC technology, and (3) recommendations on the path forward.

Based on the analysis of requirements, continuous SiC fiber-reinforced, chemically vaporinfiltrated $\mathrm{SiC}$ matrix (CVI SiC/SiC) composites are recommended as the primary option for further study on AHTR fuel cladding among various industrially available forms of SiC. Critical feasibility issues for the SiC-based AHTR fuel cladding are identified to be (1) corrosion of SiC in the candidate liquid salts, (2) high dose neutron radiation effects, (3) static fatigue failure of $\mathrm{SiC} / \mathrm{SiC}$, (4) long-term radiation effects including irradiation creep and radiation-enhanced static fatigue, and (5) fabrication technology of hermetic wall and sealing end caps. Considering the results of the issues analysis and the prospects of ongoing $\mathrm{SiC}$ research and development in other nuclear programs, recommendations on the path forward is provided in the order or priority as: (1) thermodynamic analysis and experimental examination of $\mathrm{SiC}$ corrosion in the candidate liquid salts, (2) assessment of long-term mechanical integrity issues using prototypical component sections, and (3) assessment of high dose radiation effects relevant to the anticipated operating condition.
\end{abstract}


This page is intentionally left blank. 


\section{EXECUTIVE SUMMARY}

The Advanced High-Temperature Reactor (AHTR) is a new reactor concept that uses a liquid fluoride salt coolant and a solid high-temperature fuel. Several alternative fuel types are being considered for this reactor. One set of fuel options is the use of pin-type fuel assemblies with silicon carbide ( $\mathrm{SiC}$ ) cladding. This report provides (1) an initial viability assessment of using $\mathrm{SiC}$ for fuel cladding and other incore components of the AHTR, (2) the current status of $\mathrm{SiC}$ technology, and (3) recommendations on the path forward.

\section{Basis for Consideration of Pin-Type Fuel Assemblies.}

The initial concept of the AHTR was similar to a high-temperature gas-cooled reactor (HTGR) or very high temperature reactor (VHTR) except that a low-pressure liquid-salt-coolant replaced the high-pressure helium coolant. The AHTR is a graphite-moderated reactor with a thermal neutron spectrum that is almost identical to high-temperature helium-cooled reactors. Depending upon design goals, peak temperatures can vary from 700 to $1000^{\circ} \mathrm{C}$. The baseline concept uses graphite-matrix coated-particle fuel in the form of a prismatic block. The fuel, except for some dimensional changes in coolant channels and fuel loading, is essentially identical to the fuel that has been used in several helium-cooled high-temperature reactors.

The initial AHTR studies were done with graphite-matrix coated-particle fuel based on several considerations. The fuel has been demonstrated in two high-temperature helium-cooled reactors; (1) the Fort St. Vrain that was built in the United States and later decommissioned and (2) the operating Japanese High-Temperature Test Reactor. The graphite-matrix fuel is compatible with the liquid-salt coolant. Last, the U.S. experience base for high-temperature reactor fuels is the graphite-matrix coated-particle prismatic fuel.

These studies showed that the AHTR (1) was technical viable, (2) could potentially have major safety advantages with the use of passive and inherent structures, systems, and components and (3) had the potential for lower capital costs than traditional light water reactors. The lower capital costs are primarily a consequence of using a low-pressure, high-volumetricheat-capacity, low-chemically-reactive, high-temperature, liquid coolant that reduces equipment and plant size.

After the initial viability studies, a second set of trade studies were initiated to understand the range of potentially viable AHTR designs. These trade studies included evaluations of alternative fuel forms, different liquid-salt coolants, and alternative safety systems. The goals of 
these studies were to identify the most promising AHTR concepts in terms of (1) economics, (2) safety, (3) fuel cycles [sustainability, non-proliferation, etc.], and (4) minimization of development costs. Studies were conducted at Oak Ridge National Laboratory, the University of California at Berkeley, Areva NP, Argonne National Laboratory, Idaho National Laboratory, and the University of Wisconsin. The studies identified and examined three fuel configurations that corresponded to the three fuel configurations that have been used in high-temperature reactors: (1) prismatic-block graphite-matrix, coated-particle fuel, (2) pebble-bed graphite-matrix, coatedparticle fuel, and (3) pin-fuel assemblies.

Among the three fuel configurations, the pin-type fuel assembly has several potential advantages relative to coated-particle fuel in the AHTR. Preliminary evaluations by Areva NP indicate the potential for lower fuel fabrication costs. If the pin assembly contained uranium oxide or another ceramic, the fuel assemble could have a higher loading of uranium compared to a coated-particle fuel. This would allow for lower fuel enrichments or higher burnups. A pin-type fuel assemble separates the graphite from the fuel. This greatly reduces the spent nuclear fuel (SNF) volume if the SNF is directly disposed of as waste. If the SNF is to be reprocessed, a pintype assemble could be processed in the same way that light-water reactor fuel assembles are reprocessed. Last, a series of neutronic studies indicate that such a fuel may enable relatively efficient burning of actinides.

In parallel with the fuel trade studies, there were a series of evaluations of alternative decayheat removal systems. The new decay-heat removal systems that were identified and analyzed showed lower peak fuel temperature under severe accident conditions. These developments indicate that the same safety goals defined for an AHTR with coated-particle fuel can now be potentially met at lower temperatures with a pin-type fuel assemblies. Developments in AHTR safety systems partly opened the door to alternative fuel types.

The considerations above indicated the need to consider in further depth the feasibility and viability of a pin-type fuel assembly for the AHTR. It has many advantages; but, it is not a demonstrated fuel type. The central technical challenge is the choice of clad and structural materials for the fuel assembly.

\section{Basis for Consideration of SiC for Pin-Type Fuel Assemblies}

The AHTR with a pin-type fuel assembly has multiple materials requirements for fuel clad, fuel assembly components, and other core components. These requirements include the ability to withstand very high temperatures, radiation resistance, compatibility with the liquid salt, and 
mechanical requirements, in addition to the availability and reasonable economy. The only hightemperature reactor fuels that have been fully developed and qualified are those that use a carbon matrix - the prismatic and pebble bed fuels. However, there are major questions about the viability of carbon-based materials for large pin-type fuel assemblies in liquid-salt systems. Alternative materials are needed if pin-type fuel assembles are to be considered.

There are many potential candidate materials. However, the development of a new clad and core material is an extremely difficult, time consuming, and expensive task. As a consequence, there are strong incentives to examine available and more mature materials. An initial examination indicated that $\mathrm{SiC}$ is a potential candidate material. It is being examined first based on the considerations of (1) the research and development of $\mathrm{SiC}$ as a fuel clad and structural material in several types of reactors, (2) experience by the British Advanced-Gas Reactor (AGR) program for development of $\mathrm{SiC}$ as a clad material for new generation of higher-temperature AGRs, and (3) experience in salt systems indicating that $\mathrm{SiC}$ should be compatible with liquid salts.

$\mathrm{SiC}$ is considered promising for various nuclear applications, primarily because it is the only refractory ceramic which has demonstrated an inherent tolerance against heavy irradiation by energetic neutrons. The energy systems which are presently studying $\mathrm{SiC}$ in various forms (or $\mathrm{SiC}$-based materials) for potential application in fuel/core/radiation environments include the helium-cooled very high temperature reactor (VHTR), the gas-cooled fast reactor (GFR), the advanced light water reactor (ALWR), and both the magnetic- and inertial-confinement fusion. Benefits, other than radiation resistance, of using $\mathrm{SiC}$ for nuclear applications come from its excellent mechanical properties and chemical inertness up to well beyond the upper temperature limits for typical metallic superalloys, attractive nuclear properties (low neutron-induced activation and low decay heat), and the availability in various forms including high fracture toughness composites.

\section{SiC Technology}

SiC-based materials are industrially available in various forms. Selection of appropriate forms is based upon consideration of baseline material properties and availability of components in suitable shapes and sizes. For the fuel cladding application, because the primary requirements include mechanical strength, fracture toughness, thermal conductivity, and availability in long, small-diameter tubes, a continuous $\mathrm{SiC}$ fiber-reinforced $\mathrm{SiC}$ matrix composite ( $\mathrm{SiC} / \mathrm{SiC}$ composite) will be the most adequate form. The cladding application may require an additional 
measure to secure hermeticity against fission gas permeation, because $\mathrm{SiC} / \mathrm{SiC}$ composites are not necessarily gas-tight.

$\mathrm{SiC} / \mathrm{SiC}$ composites are available in various combinations of the reinforcing fiber, the matrix densification process, and the interphase (material used for an interlayer between the fiber and the matrix). Properties including those closely related with the critical feasibility issues for the AHTR application are strongly affected by selection of the composites' constituents and the matrix densification technique. Near-stoichiometric and fully-crystallized fibers, or the Generation III SiC fibers, are necessary for AHTR because fibers in other classes are not radiation resistant. As the matrix densification process, chemical vapor infiltration should be chosen as the reference (again because of proven radiation resistance), where nano-infiltration and transient eutectic-phase (NITE) process as a potential alternative. Pyrolytic carbon interphase and more advanced interphases comprising carbon and $\mathrm{SiC}$ are considered adequate for AHTR, provided that $\mathrm{SiC}$ is chemically compatible with the coolant.

Some of the general critical properties for fission core components are common or intrinsic to $\mathrm{SiC}$ as a substance, while others are to some extent specific to materials in certain forms, with certain constituents, and in certain shapes and architectures. The properties inherent to SiC are mostly related with corrosion and radiation effect, such as radiation-induced swelling, irradiation creep, and radiation-induced thermal conductivity degradation. On the other hand, the properties which substantially vary depending on materials within "SiC" category, including strength, fracture toughness, thermal conductivity, and fatigue, were assessed for the reference $\mathrm{SiC} / \mathrm{SiC}$ composites with the Generation III SiC fibers, pyrolytic carbon interphase, and chemically vapor-infiltrated $\mathrm{SiC}$ matrices.

Critical feasibility issues for the potential application of SiC-based materials to AHTR fuel cladding and other core components were identified as follows.

- Corrosion: While the majority of work in the literature on silicon carbide corrosion in liquid salts is with salts other than halides, the sodium sulfate corrosion information in combination with the information from previous works on halides indicates the potential viability of $\mathrm{SiC}$. However, the information is insufficient to state that $\mathrm{SiC}$ is a clearly viable clad option for the AHTR under the specific conditions that are expected. There are significant issues that must be evaluated for the use of fluoride salts with $\mathrm{SiC}$.

- High dose radiation effect: The reference $\mathrm{SiC} / \mathrm{SiC}$ composites are considered highly tolerant against neutron irradiation at temperatures of current interest, however, the highest dose those materials have ever been irradiated to and tested is so far slightly more 
than $10 \mathrm{dpa}$, which may be substantially below the anticipated dose in AHTR. It will be critically important to confirm the fundamental radiation stability to higher doses. Moreover, issues associated with potentially high internal stress due to thermal conductivity degradation and differential swelling are critical to fuel cladding.

- Slow crack growth failure: Slow crack growth, or static fatigue, will likely dictate the mechanical integrity of $\mathrm{SiC} / \mathrm{SiC}$ fuel cladding. In case any of the anticipated stress components may reach 30 to $50 \%$ of the proportional limit stress, which is extremely likely, mechanical integrity may become a critical feasibility/design issue. These are also strongly related with the radiation effects on $\mathrm{SiC} / \mathrm{SiC}$ including radiation creep, radiationassisted/enhanced static fatigue, thermal conductivity change, and radiation-induced strength modification.

- Long-term radiation effects: Assuming the internal pressurization by fuel swelling and/or fission gas production as the primary source of mechanical loading onto the fuel cladding, irradiation creep and static fatigue may lead to unacceptable cross-sectional deformation. Moreover, rupture failure leads to a loss of fission product confinement. Therefore, understanding irradiation creep and irradiated static fatigue are both critically important technical issues.

- Hermeticity/fabrication technology: Potential requirements of seal tightness against fission gas permeation is an obvious challenge and critical for $\mathrm{SiC} / \mathrm{SiC}$ cladding. It is possible that an additional measure for securing gas tightness has to be taken. Such measures include but are not limited to the additional CVD SiC coating and metal lining inside the tube. Hermetic sealing or joining at the both ends of the cladding tube is an additional technical issue that has to be addressed.

At this moment, it is not possible to determine if all of these issues are truly critical to the technical feasibility of the SiC-based AHTR fuel/core concept or some are more like design issues for which design solutions exist, and if so to what extent.

\section{Recommendations}

Based on the analysis of critical feasibility issues, The following conclusions were reached regarding the directions of the near-term proof-of-principle study for potential application of SiC-based materials to AHTR are recommended. The recommendations are for the fuel cladding application and are listed in the order of priority. 
- Corrosion of $\mathrm{SiC}$ in candidate liquid salt: Work needs to be performed to create a good thermodynamic foundation for the evaluation of silicon carbide in liquid fluoride salts with respect to the basicity/acidity of the salt and low partial oxygen pressures that are to be expected in reactor systems. Experimental data need to be generated to support the thermodynamic analyses and to shed light on the corrosion effects in systems with varying temperatures. Appropriate thermodynamic data enables evaluation of performance for a wide range of conditions.

- Prototypical demonstration: The real critical issue in this category is the time-dependent damaging and fracture due to very slow crack growth during the prolonged service. However, such damage processes are highly dependent on the architectural design of the component. Hence, prototypical components need to be designed and fabricated with $\mathrm{SiC} / \mathrm{SiC}$ composite in the most promising architecture, and need to be evaluated for lifetime-limiting properties including stress rupture and static fatigue in prototypical conditions including the liquid salt environment.

- High dose radiation effect: Experimental data need to be generated to study if $\mathrm{SiC} / \mathrm{SiC}$ components maintain fundamental integrity to doses and at temperatures beyond current experience and relevant to the AHTR. Dependable capability to estimate the temperature distribution changes and their consequence on the secondary stresses in fuel cladding needs to be established. Moreover, both the irradiation creep and the in-pile static fatigue behaviors of $\mathrm{SiC}$ in the medium to high dose regimes are need to be understood.

The above recommendations assume that the remaining critical issues are to be addressed in other on-going national or international programs which deal with various technical issues for nuclear applications of SiC-based materials. Therefore, it will be important to maintain awareness on technical and programmatic developments in those programs and stay being able to adjust to potential changes in their directions and scopes. 


\section{INTRODUCTION}

This study is an initial examination of the viability of using silicon carbide ( $\mathrm{SiC}$ ) as a fuel clad and component material in the liquid-salt-cooled Advanced High-Temperature Reactor (AHTR). The report reviews the literature to determine what is known and what is not known in the context of using $\mathrm{SiC}$ for this application. Recommendations are made on the path forward to determine the viability of $\mathrm{SiC}$ for this application. The recommendations include the types of $\mathrm{SiC}$ to consider for this application, the constraints and limitations, and a prioritized list of tasks to determine viability.

\subsection{BASIS FOR STUDY}

The Advanced High-Temperature Reactor (AHTR) is a new reactor concept that uses a liquid fluoride salt coolant and a solid high-temperature fuel. The reactor has a thermal neutron spectrum that is almost identical to high-temperature helium-cooled reactors. Depending upon design goals, peak temperatures can vary from 700 to $1000^{\circ} \mathrm{C}$. The baseline concept uses graphite-matrix coated-particle fuel in the form of a prismatic block. The fuel, except for some dimensional changes in coolant channels and fuel loading, is essentially identical to the fuel that has been used in several helium-cooled high-temperature reactors. A series of neutronic, thermohydraulic, and refueling studies indicate the technical viability of an AHTR with this fuel type. [1]

The initial AHTR studies were done with this fuel form based on several considerations. The fuel has been demonstrated in two high-temperature helium-cooled reactors; (1) the Fort St. Vrain that was built in the United States and later decommissioned and (2) the operating Japanese High-Temperature Test Reactor. The graphite-matrix fuel is compatible with the liquidsalt coolant. Lastly, the U.S. experience base for high-temperature reactor fuels is the graphitematrix coated-particle prismatic fuel.

These studies showed that the AHTR (1) is technically viable, (2) could potentially have major safety advantages with the use of passive and inherent structures, systems, and components and (3) has the potential for lower capital costs than traditional light water reactors. The lower capital costs are primarily a consequence of using a low-pressure, high-volumetricheat-capacity, low-chemically-reactive, high-temperature, liquid coolant that reduces equipment and plant size. 
After the initial viability studies, a second set of trade studies were initiated to understand the range of potentially viable AHTR designs. These trade studies included examination of alternative fuel forms, the basis for selection of a specific fluoride salt, and evaluations of alternative safety systems. The goals of these studies were to identify the most promising AHTR concepts in terms of (1) economics, (2) safety, (3) fuel cycles [sustainability, non-proliferation, etc.], and (4) minimization of development costs. Studies were conducted at Oak Ridge National Laboratory, the University of California at Berkeley, Areva NP, Argonne National Laboratory, Idaho National Laboratory, and the University of Wisconsin. The studies identified and examined three fuel configurations that correspond to the three fuel configurations that have been used in high-temperature reactors.

- Prismatic-block graphite-matrix, coated particle fuel. This is the base case.

- Pebble-bed graphite-matrix, coated particle fuel. This is the same fuel type as the prismatic fuel; but it is in a different geometry. This option would simplify refueling and has several other advantages. There are neutronic design constraints with this fuel on the reactor design because the fuel to moderator ratio is partly fixed in a pebble bed reactor.

- Pin-fuel assemblies. The carbon-dioxide-cooled, graphite-moderated British Advanced Gas Reactor (AGR) uses a pin fuel assembly. A similar core design could be used for an AHTR, provided materials compatible with the liquid salts were chosen.

In the 1960s, the British built a series of AGR power plants. These are high-temperature reactors with a graphite moderator and pin-type fuel assemblies. The pins are made of stainless steel with uranium dioxide fuel. Multiple pins are assembled as a fuel assembly that is about a meter in length. Up to eight fuel assemblies are connected together as a stringer that is placed in a channel within the graphite core. The height of the AGR core makes it difficult to fabricate and use pins the full height of the reactor core - thus the connection of multiple bundles into a stringer. This feature and many other features of the AGR would likely be adopted for a pin-type fuel in an AHTR because of similar engineering constraints associated with graphite-moderated reactors with pin-type fuel assembles.

The pin-type fuel assembly has several potential advantages relative to coated-particle fuel in the AHTR. Preliminary evaluations by Areva NP indicate the potential for lower fuel fabrication costs.[2] If the pin assembly contained uranium oxide or another ceramic, the fuel assembly 
could have a higher loading of uranium compared to a coated-particle fuel. This would allow for lower fuel enrichments or higher burnups. A pin-type fuel assembly separates the graphite from the fuel. This greatly reduces the spent nuclear fuel (SNF) volume if the SNF is directly disposed of as waste. If the SNF is to be reprocessed, a pin-type assemble could be processed in the same way that light-water reactor fuel assembles are reprocessed. Last, a series of neutronic studies indicate that such a fuel may enable relatively efficient burning of actinides.

In parallel with the fuel trade studies, there were a series of evaluations of alternative decayheat removal systems. The new decay-heat removal systems that were identified and analyzed showed lower peak fuel temperature under severe accident conditions. These developments indicate that the same safety goals defined for an AHTR with coated-particle fuel can now be potentially met at lower temperatures with a pin-type fuel assemblies. Developments in AHTR safety systems have partly opened the door to alternative fuel types.

The above considerations indicated the need to consider in further depth the feasibility and viability of a pin-type fuel assembly for the AHTR. It has many advantages; but, it is not a demonstrated fuel type. The central technical challenge is the choice of clad and structural materials for the fuel assembly.

\subsection{BASIS FOR SiC EVALUATION}

The AHTR with a pin-type fuel assembly has multiple materials requirements for fuel clad, fuel assembly components, and other core components. These requirements include the ability to

withstand very high temperatures, radiation resistance, compatibility with the liquid salt, and mechanical requirements, as well as availability and reasonable economics. The only hightemperature reactor fuels that have been fully developed and qualified are those that use a carbon matrix - the prismatic and pebble bed fuels. However, there are major questions about the viability of carbon-based materials for large pin-type fuel assemblies in liquid-salt systems. Alternative materials are needed if pin-type fuel assembles are to be considered.

There are many potential candidate materials. However, the development of a new clad and core material is an extremely difficult, time consuming, and expensive task. As a consequence, there are strong incentives to first examine available and mature materials. An initial examination indicated that $\mathrm{SiC}$ is a potential candidate material. It is being examined first based on the following considerations. 
- Experience. There are multiple programs underway to develop $\mathrm{SiC}$ as a fuel clad and structural material in several types of reactors. This includes the use of $\mathrm{SiC}$ in the Next Generation Nuclear Plant (a helium-cooled very high-temperature reactor), gascooled fast reactors, light-water reactors, and fusion machines. In both the gas-cooled fast reactors and the light-water reactors, it is proposed to use $\mathrm{SiC}$ for fuel claddingthe same primary mission as proposed for the AHTR. These ongoing programs imply that if SiC is suitable, much of the development work can be shared.

- AGR. The British AGR program began development of $\mathrm{SiC}$ as a clad material for new generation of higher-temperature AGRs. This program included fuel irradiations. The program, as far as it went, was successful. The program was shut down when a decision was made to cancel the development of all advanced reactors in Great Britain. That decision was partly a consequence of the discovery of large natural gas deposits found in the North Sea. The AHTR with pin-type fuel assembles has a core design very similar to the British AGR with many of the same constraints and requirements. These similarities provide incentives to consider $\mathrm{SiC}$ for the AHTR.

- Salt experience. There is limited information indicating that $\mathrm{SiC}$ should be compatible with liquid salts.

Silicon carbide is not a single material. It is a class of materials that can be produced in different forms by different methods with different impurities and/or second phases. Some of those impurities and second phases are known to be incompatible with salt coolants while others should be compatible with salt coolants. It is similar to the use of nickel alloys with liquid salts. Some nickel alloys are extremely corrosion resistant while other alloys are not corrosion resistant (Note: most nickel alloys perform poorly in high-radiation fields and thus are not usually used for fuel cladding). The practical implications are that one must examine the requirements and the various types of $\mathrm{SiC}$ to make initial selections of $\mathrm{SiC}$ for possible use as a clad material before further analysis and testing can be initiated.

Objectives of this work were to evaluate potentials, identify suitable forms, and identify critical feasibility issues for $\mathrm{SiC}$ as the fuel cladding and core materials for the AHTR, ultimately to provide recommendations for the path-forward of critical viability evaluation. For these purposes, an extensive survey of research and development (R\&D) activities of SiC for nuclear and fusion applications was conducted. The status of SiC R\&D and the present understanding of $\mathrm{SiC}$ properties and behavior, particularly in nuclear environments, are reviewed in Chapter 2. Based on the review and the known or likely requirements for application in the AHTR fuel 
assembly, potential critical issues for $\mathrm{SiC}$ are analyzed in Chapter 3. Finally, recommendations for the path-forward toward the assessment of critical viability issues are provided in Chapter 4 . 
This page is intentionally left blank. 


\section{SiC FOR NUCLEAR APPLICATIONS}

Among various refractory engineering materials, silicon carbide $(\mathrm{SiC})$ based ceramics and composites, often specifically continuous $\mathrm{SiC}$-fiber reinforced $\mathrm{SiC}$-matrix $(\mathrm{SiC} / \mathrm{SiC})$ composites, have been studied and developed for fusion and advanced fission energy applications. Benefits of using $\mathrm{SiC}$-based material for nuclear applications come from the attractive properties of $\mathrm{SiC}$; namely the excellent irradiation tolerance and safety features such as the inherent low activation/low decay heat properties and low tritium permeability, in addition to the other wellperceived thermo-physical/chemical properties [3-6]. Benefiting from non-nuclear programs that pursued issues such as manufacturing technology and testing development, the research and development (R\&D) efforts in fusion energy and nuclear materials programs have been focusing on the essential feasibility issues, such as the fundamental performance of $\mathrm{SiC} / \mathrm{SiC}$ composites under neutron irradiation and the development of radiation-resistant composite materials. As the fundamental radiation performance was being positively addressed, $R \& D$ programs have been initiated aiming at the well-defined evaluation of $\mathrm{SiC} / \mathrm{SiC}$ composites and the designing of components out of them, for example, in support of the Test Blanket Module (TBM) development for ITER [7] and VHTR [8]. In this chapter, the present status of SiC ceramic and composite $R \& D$ for nuclear and fusion applications is reviewed in terms of fabrication techniques, reinforcing fiber development, composite design, typical properties, radiation effects, test standards, and non-destructive evaluation.

\subsection{FABRICATION TECHNIQUES}

\subsubsection{Composite fabrication}

SiC-based ceramics and composites are available in various forms including monolithic ceramics, continuous fiber reinforced composites, bonded fiber ceramics, chopped fiber composites, and particulate-reinforced composites. Those materials are compared in Table 1 for industrial availability, typical production routes, and typical values of fundamental properties. Monolithic $\mathrm{SiC}$ is commercially available as catalogue products from a number of venders; however, it is inherently a brittle ceramic which provides relatively low fracture toughness $(\sim 3.5$ MPa- $\mathrm{m}^{1 / 2}$ ) among various engineering ceramics. Because of the low fracture toughness and the small fracture strain, monolithic $\mathrm{SiC}$ is very difficult to be made into shapes such as thin-walled tubular products with sufficient strength and structural integrity. 
Table 1: Comparison of SiC-based ceramics and composites in various forms.

\begin{tabular}{|c|c|c|c|c|}
\hline & Monolithic SiC & $\begin{array}{c}\text { Continuous Fiber } \\
\mathrm{SiC} / \mathrm{SiC}\end{array}$ & $\begin{array}{c}\text { SiC Bonded Fiber } \\
\text { Ceramic }\end{array}$ & $\begin{array}{c}\text { Chopped Fiber } \\
\text { SiC/SiC }\end{array}$ \\
\hline $\begin{array}{l}\text { Commercial } \\
\text { availability }\end{array}$ & Catalogue products & $\begin{array}{l}\text { Routine custom- } \\
\text { order products }\end{array}$ & $\begin{array}{l}\text { Routine custom- } \\
\text { order products }\end{array}$ & $\begin{array}{l}\text { Non-routine } \\
\text { custom-order } \\
\text { products }\end{array}$ \\
\hline $\begin{array}{c}\text { Production methods } \\
\text { suitable for nuclear } \\
\text { application }\end{array}$ & $\mathrm{CVD}^{1}$ & $\mathrm{CVI}^{2}\left(\mathrm{NITE}^{3}\right)$ & Hot-press & CVI (, NITE) \\
\hline $\begin{array}{c}\text { Typical fracture / } \\
\text { cracking stress at RT- } \\
1000^{\circ} \mathrm{C}\end{array}$ & $\begin{array}{l}\text { Flexural stress } \\
300-500 \mathrm{MPa}\end{array}$ & $\begin{array}{l}\text { Tensile matrix } \\
\text { cracking stress } \\
100-200 \mathrm{MPa}\end{array}$ & $\begin{array}{l}\text { Tensile initial } \\
\text { cracking stress } \\
\sim 100 \mathrm{MPa}\end{array}$ & Data not available \\
\hline $\begin{array}{c}\text { Typical fracture } \\
\text { toughness }\end{array}$ & $\mathrm{K}_{\mathrm{Ic}} \sim 3.5 \mathrm{MPa}-\mathrm{m}^{1 / 2}$ & $\begin{array}{cl}\mathrm{K}_{\mathrm{Ic}} \\
20-30 \mathrm{MPa}-\mathrm{m}^{1 / 2}\end{array}$ & Data not available & Data not available \\
\hline $\begin{array}{c}\text { Max. operating } \\
\text { temperature in inert } \\
\text { environment }\end{array}$ & $\sim 1800^{\circ} \mathrm{C}$ & $\sim 1600^{\circ} \mathrm{C}$ & $\sim 1600^{\circ} \mathrm{C}$ & $\sim 1600^{\circ} \mathrm{C}$ \\
\hline $\begin{array}{c}\text { Typical thermal } \\
\text { conductivity at } 800^{\circ} \mathrm{C} \\
\text { in transverse direction }\end{array}$ & $\sim 100 \mathrm{~W} / \mathrm{m}-\mathrm{K}$ & $\sim 15 \mathrm{~W} / \mathrm{m}-\mathrm{K}$ & $\sim 30 \mathrm{~W} / \mathrm{m}-\mathrm{K}$ & Data not available \\
\hline
\end{tabular}

1) Chemical Vapor Deposition, 2) Chemical Vapor Infiltration, 3) Nano-Infiltration and Transient Eutectic-phase process

Continuous fiber composites $(\mathrm{SiC} / \mathrm{SiC})$ are industrially the most matured form of composites. In this report it is assumed that the fuel cladding will require continuous fiber composites or $\mathrm{SiC} / \mathrm{SiC}$ instead of other forms of $\mathrm{SiC}$, due to several essential requirement factors (however, most of the assessments are common to different forms of SiC-based ceramics and composites). $\mathrm{SiC}$ bonded fiber composite is commercially available as Tyrannohex ${ }^{\mathrm{TM}}$ from Ube Industries, LTd., Japan[9]. Tyrannohex ${ }^{\mathrm{TM}}$ is a potential alternative to $\mathrm{SiC} / \mathrm{SiC}$ for various nuclear applications. Chopped fiber composites and particulate-reinforced composites are unsuitable for fuel cladding fabrication for similar reasons with monolithic ceramics.

Properties critical to feasibility of SiC-based ceramic composites to various nuclear applications strongly depend on the fabrication routes. Processing routes presently available for industrial production of $\mathrm{SiC}$ composites are chemical vapor infiltration (CVI) [10], nanoinfiltration and transient eutectic-phase process (NITE) [11-13], melt-infiltration (MI, or occasionally termed reaction sintering, RS, or liquid silicon infiltration, LSI) [14], and polymerimpregnation and pyrolysis (PIP) [15]. Typical attributes for these processing routes are compared in Table 2. 
Table 2: Comparison of various process techniques for continuous SiC fiber, SiC matrix composites (SiC/SiC) for nuclear applications.

\begin{tabular}{|c|c|c|c|c|}
\hline $\begin{array}{c}\text { Matrix densification } \\
\text { process }\end{array}$ & $\begin{array}{c}\text { Pyrolytic reaction } \\
\text { of gaseous } \\
\text { precursor(s) }\end{array}$ & $\begin{array}{c}\text { Pressurized } \\
\text { transient eutectic } \\
\text { phase sintering }\end{array}$ & $\begin{array}{c}\text { Pyrolytic reaction } \\
\text { of polymer } \\
\text { precursor(s) }\end{array}$ & $\begin{array}{c}\text { Direct reaction of } \\
\text { molten silicon and } \\
\text { solid carbonaceous } \\
\text { precursor }\end{array}$ \\
\hline $\begin{array}{c}\text { Typical matrix } \\
\text { composition }\end{array}$ & $\begin{array}{c}\text { High purity beta- } \\
\text { phase SiC }\end{array}$ & $\begin{array}{c}\text { Beta-phase SiC }+ \\
\text { small amount of } \\
\text { yttria-alumina } \\
\text { oxide }\end{array}$ & $\begin{array}{c}\text { Nanocrystalline } \\
\text { SiCO }\end{array}$ & $\begin{array}{c}\text { Beta-phase SiC }+ \\
\text { fair amount of } \\
\text { metallic Si }\end{array}$ \\
\hline Radiation stability & Stable & Stable & Unstable & Unstable \\
\hline Strength & High & High & Low & Pigh \\
\hline Thermal conductivity & Fair & Goor & High \\
\hline $\begin{array}{c}\text { Shaping technology } \\
\text { for thin-wall tubes }\end{array}$ & Established & Being developed & Established & Established \\
\hline $\begin{array}{c}\text { Commercial } \\
\text { availability }\end{array}$ & $\begin{array}{c}\text { Available from } \\
\text { multiple US } \\
\text { venders }\end{array}$ & $\begin{array}{c}\text { Available from US } \\
\text { sales representative }\end{array}$ & $\begin{array}{c}\text { Available from } \\
\text { multiple US } \\
\text { venders }\end{array}$ & $\begin{array}{c}\text { Available from US } \\
\text { venders }\end{array}$ \\
\hline
\end{tabular}

Notes: 1) Data available up to $\sim 12 \mathrm{dpa}$ at $\left.<\sim 800^{\circ} \mathrm{C}, 2\right)$ Data available up to $\sim 4$ dpa at $\sim 1000^{\circ} \mathrm{C}$

The recent $\mathrm{SiC} / \mathrm{SiC}$ development for nuclear environments has been directed toward stoichiometric, high purity, and fully crystalline $\mathrm{SiC}$ as the primary constituents, namely fibers and matrices [16]. This direction is based on the demonstrated radiation instability of common matrix second phases such as metallic silicon in the reaction-bonded matrices [17], sintering agent represented by boron in hot-pressed $\mathrm{SiC}$ [18], and the amorphous Si-C-O commonly obtained through preceramic polymer routes [19]. Therefore, CVI, which essentially is chemical vapor deposition of $\mathrm{SiC}$ onto reinforcing fiber surfaces, has been an obvious selection of the matrix densification technique for the feasibility studies on $\mathrm{SiC} / \mathrm{SiC}$ for nuclear applications [10, 20]. Furthermore, CVI is an industrially established technique for fabrication of $\mathrm{SiC} / \mathrm{SiC}$ components in various sizes and shapes and for various property requirements.

The Nano-Infiltration and Transient Eutectic-phase (NITE) process was developed by employing the liquid phase sintering (LPS) for silicide ceramics with a small amount of oxide additives. The development and fundamental characterization of the early-grade NITE SiC/SiC are summarized elsewhere $[11,13,21]$. NITE $\mathrm{SiC} / \mathrm{SiC}$ is anticipated to be a potential alternative to $\mathrm{CVI} \mathrm{SiC/SiC}$, because the matrix consists mostly of highly crystallized beta-phase SiC. Based on achievement by the laboratory grade development, pilot commercial grade (PG) production was recently initiated [22]. During the PG productions, process improvement for higher density and improved strength was achieved. 
Typical thermal and mechanical properties for CVI and NITE SiC/SiC are summarized in Table 3. Thermal properties for CVI SiC/SiC in Table 3 will be appropriate for use in technical feasibility assessment. More details will be discussed in later section. On the other hand, strength properties shown are for fast fracture (strain rate on the order of $10^{-3} \mathrm{~s}^{-1}$ ), hence they may be substantially different from the appropriate design stresses for applications which require reliability during long term services. Design stress issues are also discussed in later sections in association with the fatigue phenomena and slow crack growth.

Table 3: Typical properties of CVI and NITE SiC/SiC composites. [23]

\begin{tabular}{lcccc}
\hline \multirow{2}{*}{ Key properties } & \multirow{2}{*}{ Unit } & \multicolumn{3}{c}{ Typical Property Values } \\
\cline { 3 - 5 } & & 2D CVI & 3D CVI & UD C/P NITE \\
\hline Thermal conductivity, through-thickness & {$[\mathrm{W} / \mathrm{m}-\mathrm{K}]$} & & & \\
$\quad$ Non-irradiated, $500^{\circ} \mathrm{C}$ & & $\sim 15$ & $25-40$ & $15-40$ \\
$\quad$ Non-irradiated, $1000^{\circ} \mathrm{C}$ & & 10 & $20-30$ & $10-30$ \\
Irradiated, $500^{\circ} \mathrm{C}$ & & $2-3^{*}$ & $5-8^{*}$ & - \\
Irradiated, $1000^{\circ} \mathrm{C}$ & $4-6^{*}$ & $12-18^{*}$ & - \\
\hline Tensile properties & & & & \\
Ultimate tensile stress, $500-1000^{\circ} \mathrm{C}$ & {$[\mathrm{MPa}]$} & $\sim 300$ & $100-200$ & $300-400$ \\
Matrix cracking stress, $500-1000^{\circ} \mathrm{C}$ & {$[\mathrm{MPa}]$} & $\sim 150$ & - & $200-250$ \\
Modulus, $500-1000^{\circ} \mathrm{C}$ & {$[\mathrm{GPa}]$} & $\sim 250$ & $\sim 200$ & $300-400$ \\
\hline
\end{tabular}

*Based on model calculation.

Neither polymer impregnation and pyrolysis nor melt-infiltration is not presently attracting much attention for nuclear applications due to the recognized significant challenges for materials obtained through these processes $[15,24]$. For the PIP, radiation instability of the amorphous silicoxycarbide matrices has been anticipated. The matrices produced by the PIP method can be crystallized and made into near-stoichiometric SiC by combined very high temperature treatment and use of polymer precursors for near-stoichiometric $\mathrm{SiC}[15,25]$. However, high temperaturepyrolyzed PIP composites were then fabricated using several different precursors, leading to a conclusion that the loss of matrix integrity due to severe micro-cracking upon crystallization is a major issue [26]. This problem may possibly be overcome by employing precursors which shrink two-dimensionally into films surrounding fibers, instead of being severely cracked threedimensionally upon ceramization [27]. As to the MI, a fine-tuned "reaction sintering (RS)" technique has been developed to produce monolithic $\mathrm{SiC}$ with the minimal amount of unreacted silicon which is finely distributed as a scattered second phase [28]. The most anticipated issues for conventional MI SiC were high temperature and irradiation instability of the networked silicon [24]. 


\subsubsection{Shaping}

CVI SiC/SiC components are typically fabricated by matrix densification through chemical vapor deposition onto fiber preforms. The fiber preforms are made through weaving (2D, 3D, etc.), braiding, filament winding, and various other methods. Different preforming methods results in different fiber reinforcement structures which are called "architecture." The preforms are often supported by mandrels or other custom-fabricated supporting structures, usually made of coefficient of thermal expansion (CTE)-matched graphite, during the early or all period of CVI processing. Therefore, shapes consisting of walls and/or tubes are most easily made. AsCVI'ed components are often machined to target dimensions depending on the required dimensional precision, hence the preform shaping process is called "near-net shaping". Examples of $\mathrm{CVI} \mathrm{SiC/SiC} \mathrm{components} \mathrm{made} \mathrm{on} \mathrm{braided} \mathrm{tubular} \mathrm{preforms} \mathrm{are} \mathrm{shown} \mathrm{in} \mathrm{Figure} \mathrm{1.} \mathrm{The} \mathrm{photo}$ on the left shows 6 inch-long, a half inch outer diameter tubular tensile test specimens produced in bi-axial braiding architecture for evaluation in the US NGNP Composite R\&D Program. The photo on the right shows an example of CVI SiC/SiC nozzle for an aeronautic propulsion system, demonstrating the ability to shape varying diameter tubes with the tri-axial braiding architecture. The maximum size of the components which can be produced by CVI will be limited by the furnace size or the requirement of homogeneity over the component body. Typical manufacturers readily produce $\mathrm{CVI} \mathrm{SiC} / \mathrm{SiC}$ components with lengths up to $\sim 1$ meter. It is believed that production of substantially larger components is possible by a few industries in the world.
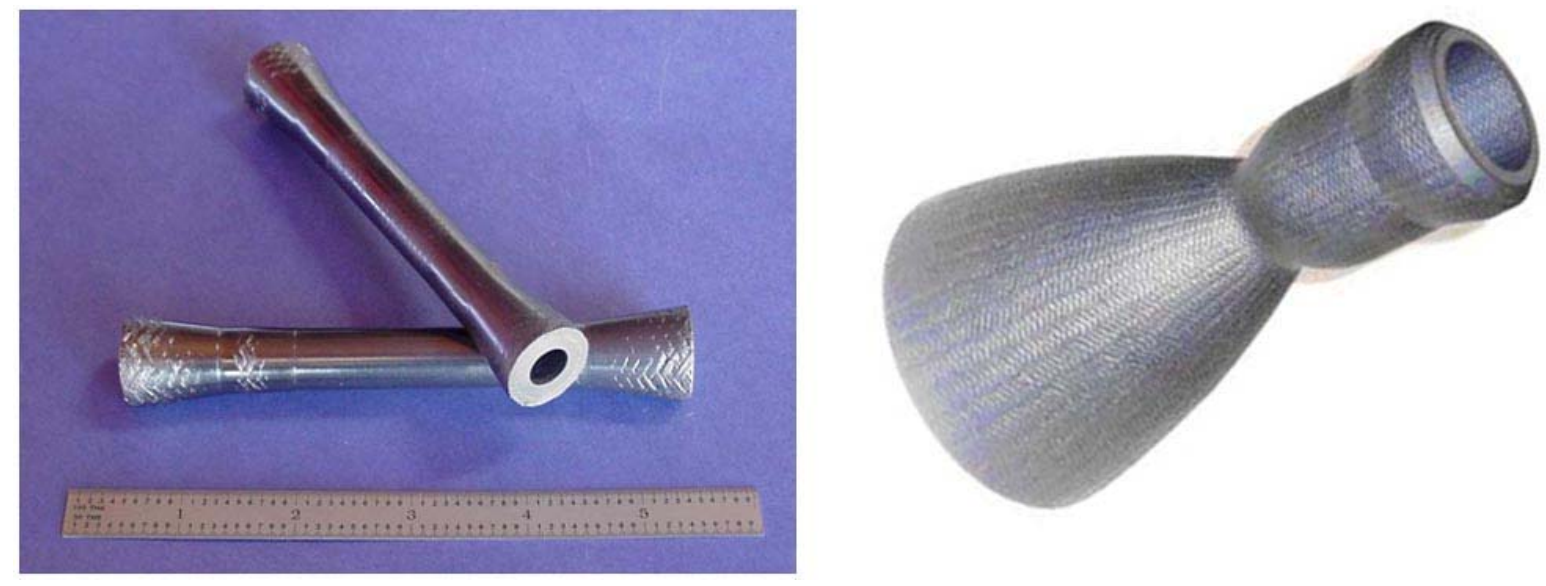

Figure 1: Examples of components fabrication with CVI SiC/SiC. Left: Tensile test specimens of small diameter, thin wall tubes.(ORNL Gen-IV Materials Program) Right: Rocket nozzle (Courtesy: Hypertherm High-Temperature Composites, Inc.) 
Near net-shaping techniques for NITE SiC/SiC have also been demonstrated [22]. As shown in Figure 2, small (10mm inner diameter) tubes were successfully fabricated with the fiber angle of $\pm 15^{\circ}$ and $\pm 30^{\circ}$ in the filament winding architecture. The density of these tubes reached 3.02 $\mathrm{g} / \mathrm{cm}^{3}$, which is close to $3.08 \mathrm{~g} / \mathrm{cm}^{3}$ for the commercial flat plate materials of NITE SiC/SiC. Diametral ring compression strength is reported to be $108 \mathrm{MPa}$. Also, $200 \mathrm{~mm}$ diameter cylinders for GFR fuel compartment were produced with a wall thickness of $3 \mathrm{~mm}$. However, because the production of NITE $\mathrm{SiC} / \mathrm{SiC}$ requires pressurization by hot-pressing or pseudo isostatic hot pressing, the tubes length has so far been limited to $<10$ times the inner diameter. Production of longer tubes has been demonstrated by interconnecting the NITE $\mathrm{SiC} / \mathrm{SiC}$ short tubes by the NITE Joint method [29].

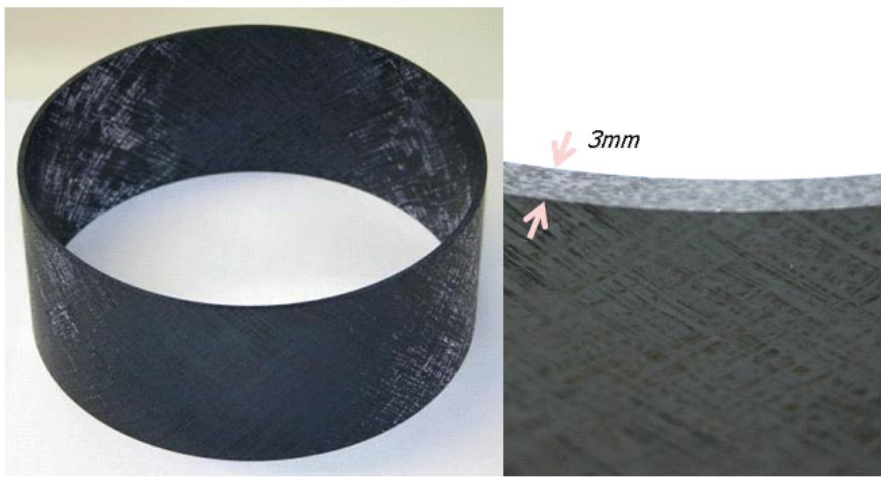

$12 \mathrm{~mm}$-OD tubes of NITE $\mathrm{SiC} / \mathrm{SiC}$ developed for fuel cladding

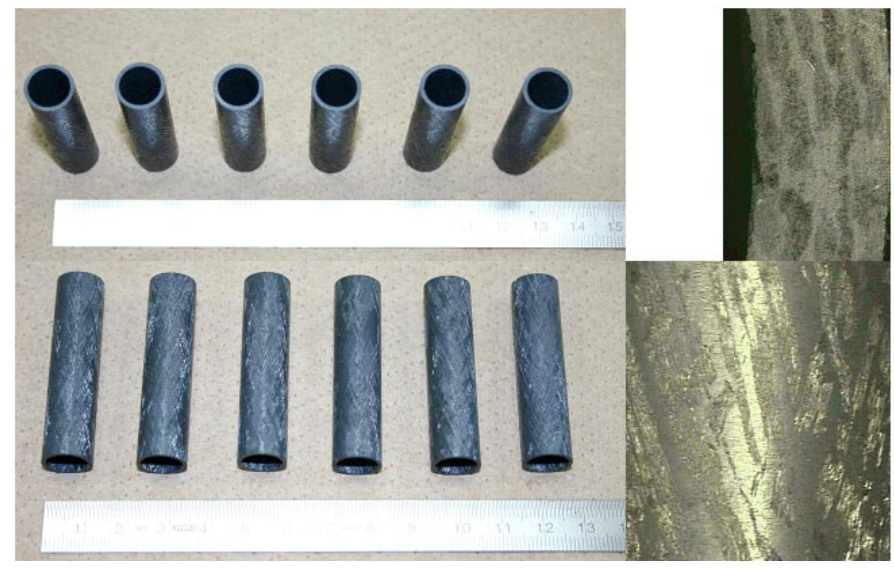

Screw fastening interconnect and manifold for small diameter tubes made of NITE SiC/SiC

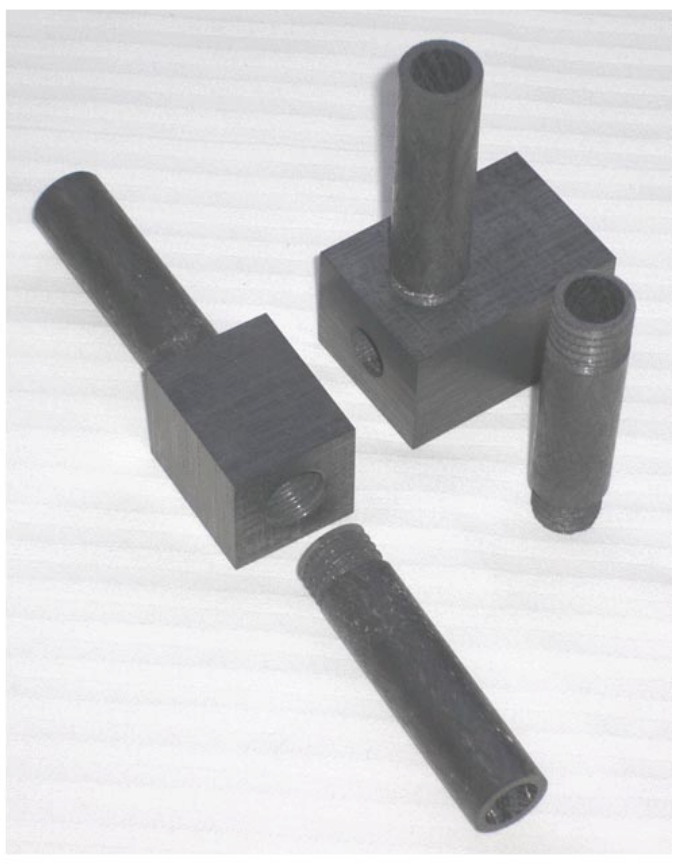

Figure 2: Examples of components fabrication with NITE SiC/SiC (Courtesy: Kyoto University) 


\subsubsection{Joining}

Self-joining $\mathrm{SiC}$ and/or $\mathrm{SiC} / \mathrm{SiC}$ is among the major near-term technical objectives for nuclear ceramics R\&D. Presently several joining methods, including diffusion bonding (by various approaches), transient eutectic phase (TEP) joining, and selective area CVD, are considered promising for radiation services. Methods for joining $\mathrm{SiC}$ to $\mathrm{SiC}$ are summarized in Table 4 with the reported typical joint strength, anticipated radiation stability of the joint, and the sites of ongoing or recent $\mathrm{R} \& \mathrm{D}$ activities.

Table 4: Comparison of various techniques for joining and sealing SiC-based materials. [30-34]

\begin{tabular}{|c|c|c|c|c|c|c|c|}
\hline & $\begin{array}{c}\text { Diffusion } \\
\text { bonding }\end{array}$ & $\begin{array}{c}\text { Transient } \\
\text { eutectic- } \\
\text { phase } \\
\text { joining }\end{array}$ & $\begin{array}{c}\text { Glass- } \\
\text { ceramics } \\
\text { Joining }\end{array}$ & Brazing & $\begin{array}{c}\text { Reaction } \\
\text { bonding }\end{array}$ & $\begin{array}{c}\text { Polymer } \\
\text { joining }\end{array}$ & $\begin{array}{c}\text { Selective } \\
\text { area CVD }\end{array}$ \\
\hline $\begin{array}{c}\text { Typical or } \\
\text { reported } \\
\text { strength }\end{array}$ & $\begin{array}{c}\sim 150 \mathrm{MPa} \\
\text { shear }\end{array}$ & $\begin{array}{c}\sim 250 \mathrm{MPa} \\
\text { tensile }\end{array}$ & $\begin{array}{c}\sim 250 \mathrm{MPa} \\
\text { flexural }\end{array}$ & $\mathrm{n} / \mathrm{a}$ & $\begin{array}{c}\sim 30 \mathrm{MPa} \\
\text { shear }\end{array}$ & $\begin{array}{c}\sim 10 \mathrm{MPa} \\
\text { shear }\end{array}$ & $\mathrm{n} / \mathrm{a}$ \\
\hline $\begin{array}{c}\text { Radiation } \\
\text { stability }\end{array}$ & $\begin{array}{c}\text { Expectedly } \\
\text { Good }\end{array}$ & $\begin{array}{c}\text { Expectedly } \\
\text { Good }\end{array}$ & $\begin{array}{c}\text { Positive } \\
\text { result from } \\
\text { EU } \\
\text { Extremat } \\
\text { program }\end{array}$ & $\begin{array}{c}\text { Expectedly } \\
\text { poor }\end{array}$ & $\begin{array}{c}\text { Expectedly } \\
\text { poor }\end{array}$ & $\begin{array}{c}\text { Expectedly } \\
\text { poor }\end{array}$ & Good \\
\hline $\begin{array}{c}\text { On-going / } \\
\text { recent R\&D }\end{array}$ & $\begin{array}{c}\text { NASA, } \\
\text { Bettis, } \\
\text { EU fusion }\end{array}$ & $\begin{array}{c}\text { Kyoto } \\
\text { Univ., etc. }\end{array}$ & $\begin{array}{c}\text { Polytech. } \\
\text { Torino }\end{array}$ & Snecma & NASA & PNNL, etc. & $\begin{array}{c}\text { Univ. } \\
\text { Conn, etc. }\end{array}$ \\
\hline
\end{tabular}

The diffusion bonding is typically facilitated by inserting thin metallic foil(s) between the joining surfaces of SiC. Metals like titanium [30] and molybdenum [31] have successfully been applied as the filler material. The TEP joining takes advantage of reduced melting temperature for particular silica-bearing oxide systems (such as yttria-alumina-silica) to develop SiC-based joint material through the solution and re-precipitation process. The NITE joint belongs to this category, in which the joint material is ideally identical with the matrix material for the NITE $\mathrm{SiC} / \mathrm{SiC}$ [32]. The selective area CVD is obviously the method that produces most radiation resistant joint of $\mathrm{SiC}$ [33]. Glass-ceramics joining is studied in the European Extremat program and positive results on low dose radiation performance are reportedly obtained [34]. 
General issues for joining ceramics for nuclear applications include those associated with CTE mismatch, radiation stability and other performances of joint materials and interfaces, and practical applicability of the joining methods limited by requirements of temperature, pressure, and atmosphere for successful joining. Joint of pure, crystalline $\mathrm{SiC}$, such as obtained by selected area CVD, eliminates the first two issues but the third issue is often a problem. Joints incorporating non-SiC second phases or insufficiently crystallized $\mathrm{SiC}$ phases will have to be thoroughly studied for the first two issues.

\subsubsection{Coating}

Oxidation resistance of $\mathrm{SiC}$ relies on the formation of a stable protective layer of silica, which is an oxidation product of $\mathrm{SiC}$. Therefore, in the active oxidation condition in which the silica layer does not form or is readily removed, $\mathrm{SiC}$ can undergo substantial corrosion. Details of $\mathrm{SiC}$ corrosion is discussed in Section 3.3.

Detrimental effects of corrosion of $\mathrm{SiC}$ can be minimized by applying appropriate environmental barrier coating (EBC). EBC for SiC has extensively been studied for combustor and leading edge applications. Such EBC's typically comprise multiple layers of ceramics incorporating yttria, hafnia, and other rare earth oxides. However, oxide ceramics are considered unstable in liquid salts.

On the other hand, carbon is generally stable in fluoride salts even at very high temperatures. Graphite and carbon composites are often coated with pyrolytic $\mathrm{SiC}$ in order to add oxidative resistance. It is technically feasible to apply coating with carbon on SiC. CTE of isotropic graphite can be tailored to match with the CTE of SiC. However, there are critical issues for carbon as the protective coating on $\mathrm{SiC}$ for nuclear applications. Those issues will be identified in Section 3.6.

\subsection{FIBER AND ARCHITECTURE}

In $\mathrm{SiC} / \mathrm{SiC}$ composites, fiber, matrix, and interphase (interfacial substance between the fibers and the matrices) are the three constituents and are equally important. Fibers primarily carry the load, while the matrix primarily transfers the load to fibers. Silicon carbide fibers are commercially processed through many different routes. The most widely studied, developed and 
commercialized $\mathrm{SiC}$ fiber is derived from the polymer precursor process first introduced by Yajima [35]. The fibers are commercially available under the trade name of Nicalon ${ }^{\mathrm{TM}}$ (Nippon Carbon Co., Tokyo, Japan), Tyranno ${ }^{\mathrm{TM}}$ (Ube Industries, Ltd., Ube, Japan), and Sylramic ${ }^{\mathrm{TM}}$ (COI Ceramics, Inc., Salt Lake City). The first stage of the fiber process involves the low-temperature melt-spinning of the polycarbosilane (PCS) or polytitanocarbosilane (PTCS) polymer. These spun fibers, which are in the green state, are then stabilized by elevated temperature exposure to oxygen and successively ceramized in an inert atmosphere to a final temperature of $\sim 1300^{\circ} \mathrm{C}$. It is important to note that due to the presence of excess oxygen and carbon, these fibers are more correctly classified as SiC-based fibers, rather than SiC fibers. Nicalon ${ }^{\mathrm{TM}}$ NL-200 and Tyranno $^{\mathrm{TM}}$ LoxM belong to this fiber category, or Generation-I SiC fibers, comprising a dispersion of beta-SiC crystallites of a few nanometers in size embedded in a continuum glassy silicon oxycarbide matrix $\left(\mathrm{Si}_{-}-\mathrm{O}_{\mathrm{x}}-\mathrm{C}_{\mathrm{y}}\right.$, where $\mathrm{x}+\mathrm{y}$ is approximately 4). The Generation-I SiC fibers are highly unstable in radiation environment because further cross-linking takes place during irradiation.

The Nicalon ${ }^{\mathrm{TM}}$ fiber's thermomechanical properties have been improved by altering the method of cross-linking the spun polymer. Rather than curing the PCS in air, the polymer is subjected to ionizing radiation in an inert environment. This process reduces the atomic oxygen content from to less than $1 \%$ and is the process with which Hi-Nicalon ${ }^{\mathrm{TM}}$, or Generation-II SiC fiber, is made [36]. The average $\mathrm{SiC}$ crystallite size for this product increases by more than a factor of two over the ceramic grade fiber, and the elastic modulus undergoes a large increase while the strength decreases slightly. The density of the Hi-Nicalon fiber is also increased from $2.55 \mathrm{~g} / \mathrm{cm}^{3}$ (NL-200) to $2.74 \mathrm{~g} / \mathrm{cm}^{3}$, which is approximately $85 \%$ theoretical SiC density. Radiation stability of the Generation-II SiC fibers has been improved over that of the previous generation fibers, however, it exhibits serious radiation instability due to the presence of large amount of excess carbon.

Further improvement in the $\mathrm{SiC}$ fibers has been achieved. The Hi-Nicalon ${ }^{\mathrm{TM}}$ process has been taken a step further, by incorporating decarburization process in an hydrogen environment, with the introduction of Hi-Nicalon ${ }^{\mathrm{TM}}$ Type-S SiC fiber with a near theoretical density fiber and very low excess carbon and oxygen [37]. At the same time, the Tyranno ${ }^{\mathrm{TM}} \mathrm{SA} 3$ fiber was developed through a very different route of sintering with aluminum addition to the original polymer precursor, which resulted in similarly very low contents of excess carbon and oxygen [38]. Moreover, the Sylramic ${ }^{\mathrm{TM}} \mathrm{SiC}$ fiber was developed also by applying sintering technique but with an addition of boron to the polytitanocarbosilane polymer precursor [39]. All three SiC fibers, categorized as the Generation-III SiC fibers, are characterized by near-stoichiometry, high 
crystallinity (crystallite sizes 50 to $200 \mathrm{~nm}$ ), and low excess carbon and oxygen contents. It has been demonstrated that the Hi-Nicalon ${ }^{\mathrm{TM}}$ Type $\mathrm{S}$ and Tyranno ${ }^{\mathrm{TM}} \mathrm{SA} 3$ fibers are highly resistant to neutron irradiation. A comparison of the properties of the various generations and brand SiCbased fibers is given in Table 5 [40-42].

Table 5: Generations of SiC-based commercial fibers. [40-42]

\begin{tabular}{|c|c|c|c|c|c|c|}
\hline & $\begin{array}{c}\text { Nicalon NL- } \\
200\end{array}$ & $\begin{array}{c}\text { Tyranno } \\
\text { LoxM }\end{array}$ & Hi-Nicalon & $\begin{array}{c}\text { Hi-Nicalon } \\
\text { Type S }\end{array}$ & Tyranno SA3 & Sylramic \\
\hline $\begin{array}{l}\text { Chemical } \\
\text { composition }\end{array}$ & $\begin{array}{l}\mathrm{SiC}_{1.31} \\
12 \% \mathrm{O}\end{array}$ & $\begin{array}{c}\mathrm{SiC}_{1.36} \\
11 \% \mathrm{O} 2 \% \mathrm{Ti}\end{array}$ & $\begin{array}{l}\mathrm{SiC}_{1.39} \\
0.5 \% \mathrm{O}\end{array}$ & $\begin{array}{l}\mathrm{SiC}_{1.05} \\
0.2 \% \mathrm{O}\end{array}$ & $\begin{array}{l}\mathrm{SiC}_{1.07} \\
2 \% \mathrm{Al}\end{array}$ & $\begin{array}{c}\mathrm{SiC} \\
\mathrm{TiB}_{2}, \mathrm{~B}\end{array}$ \\
\hline $\begin{array}{c}\text { Fiber } \\
\text { diameter } \\
\text { (um) }\end{array}$ & 14 & 11 & 14 & 11 & 7.5 & 10 \\
\hline $\begin{array}{l}\text { Number of } \\
\text { filaments }\end{array}$ & 500 & 800 & 500 & 500 & 1600 & 800 \\
\hline $\begin{array}{c}\text { Tensile } \\
\text { strength } \\
\text { (GPa) }\end{array}$ & 3.0 & 3.3 & 2.8 & 2.6 & 2.8 & 3.2 \\
\hline $\begin{array}{l}\text { Tensile } \\
\text { modulus } \\
(\mathrm{GPa})\end{array}$ & 220 & 190 & 270 & 420 & 380 & 380 \\
\hline $\begin{array}{c}\text { Elongation } \\
(\%)\end{array}$ & 1.4 & 1.8 & 1.0 & 0.6 & 0.7 & 0.8 \\
\hline $\begin{array}{l}\text { Density } \\
(\mathrm{g} / \mathrm{cc})\end{array}$ & 2.55 & 2.48 & 2.74 & 3.10 & 3.10 & 3.1 \\
\hline $\begin{array}{c}\text { Thermal } \\
\text { conductivity } \\
(\mathrm{W} / \mathrm{m}-\mathrm{K})\end{array}$ & $\begin{array}{c}3.0(\mathrm{RT}) \\
2.2\left(500^{\circ} \mathrm{C}\right)\end{array}$ & $1.4(\mathrm{RT})$ & $\begin{array}{c}7.8(\mathrm{RT}) \\
10\left(500^{\circ} \mathrm{C}\right)\end{array}$ & $\begin{array}{c}18(\mathrm{RT}) \\
16\left(500^{\circ} \mathrm{C}\right)\end{array}$ & $65(\mathrm{RT})$ & 46 (RT) \\
\hline
\end{tabular}

\subsection{INTERFACE / INTERPHASE DESIGN}

The roles of interphase in ceramic matrix composites are to transfer load between the fibers and matrices when the composites are structurally intact, and to accommodate energy dissipation and the pseudo-ductile deformation through debonding and sliding once the matrix developed micro-cracks. Development of appropriate interphase takes very substantial R\&D effort, not only because the fibers and the interphase have to be compatible with the interphase application process and matrix densification process, respectively, but also it requires extensive research to develop optimum functions for a particular fiber-interphase-matrix system. Several interphases presently employed or being developed for $\mathrm{SiC} / \mathrm{SiC}$ are compared in Table 6 . 
Table 6: Established and developmental interphases for $\mathrm{SiC} / \mathrm{SiC}$ composites.

\begin{tabular}{|c|c|c|c|c|c|}
\hline & $\begin{array}{c}\text { Pyrolytic } \\
\text { Carbon }\end{array}$ & $\begin{array}{c}\text { SiC/PyC } \\
\text { Multilayer }\end{array}$ & $\begin{array}{c}\text { Pseudo-porous } \\
\text { SiC }\end{array}$ & BN & Monazite \\
\hline $\begin{array}{c}\text { Status of } \\
\text { development }\end{array}$ & $\begin{array}{c}\text { Industrially } \\
\text { established }\end{array}$ & $\begin{array}{c}\text { Industrially } \\
\text { established }\end{array}$ & $\begin{array}{c}\text { Industrially } \\
\text { established }\end{array}$ & $\begin{array}{c}\text { Industrially } \\
\text { established }\end{array}$ & Developmental \\
\hline $\begin{array}{c}\text { Oxidation } \\
\text { resistance }\end{array}$ & Poor & Fair & Poor & Fair & Good \\
\hline $\begin{array}{c}\text { Fiber coating } \\
\text { technique }\end{array}$ & CVD & CVD & CVD & CVD & Slurry dipping \\
\hline $\begin{array}{c}\text { Radiation } \\
\text { stability }\end{array}$ & Fair & Good & $\begin{array}{c}\text { No data } \\
\text { available }\end{array}$ & Poor & $\begin{array}{c}\text { No data } \\
\text { available }\end{array}$ \\
\hline
\end{tabular}

Presently, pyrolytic carbon (often termed pyrocarbon or "PyC") is most commonly used and extensively studied as the material for interphase in $\mathrm{SiC} / \mathrm{SiC}$. Pyrocarbon typically has a structure of glassy or turbostratic carbon and are produced by thermal decomposition of hydrocarbon gases such as methane or propane. The pyrocarbon interphase can easily be applied in an isothermal, isobaric CVI configuration onto the fiber surfaces as a coating. Since the oxidation resistance of pyrocarbon interphase will not be a critical issue for $\mathrm{SiC} / \mathrm{SiC}$ for salt-cooled reactor application, pyrocarbon may be an appropriate interphase for reference materials to be used in the feasibility study phase.

The $\mathrm{SiC} / \mathrm{PyC}$ multilayered interphase is composed of repeating layers of very thin pyrocarbon and thicker $\mathrm{SiC}$ phases. It is a variation of pyrocarbon interphase, because only the innermost pyrocarbon interphase layer contributes to the fast fracture mechanical properties of the composites. Outer pyrocarbon layers in the multilayered interphase are known to provide extended life in oxidative environments, whereas other potential benefits have not been demonstrated.

The $\mathrm{BN}$ interphase is also industrially established for $\mathrm{SiC} / \mathrm{SiC}$. The $\mathrm{BN}$ interphase provides enhanced oxidative resistance, which will not be a benefit for use in liquid salt. It has been proven that the burn-up of boron does serious harm to the composite strength [43]. Oxide ceramics, represented by various monazites, are considered potential novel interphase materials for ceramic matrix composites. Compatibility with the SiC fibers and the matrix deposition processes is a present issue for monazite interphases [44].

An example of interphase optimization is adjusting the interphase thickness for the optimum composite mechanical properties. However, as shown in Figure 3, fast fracture strength of CVI $\mathrm{SiC} / \mathrm{SiC}$ composites with the Generation-III SiC fibers appeared insensitive to the pyrocarbon interphase thickness in a broad thickness range [45-46]. This is an additional benefit of using the 
Generation-III SiC fibers, because the interphase may be optimized for other properties such as high dose radiation resistance and fatigue / creep lifetime. For example, very thin pyrocarbon interphase in $\mathrm{SiC} / \mathrm{SiC}$ can be self-sealed with silica in a low oxygen activity environment.
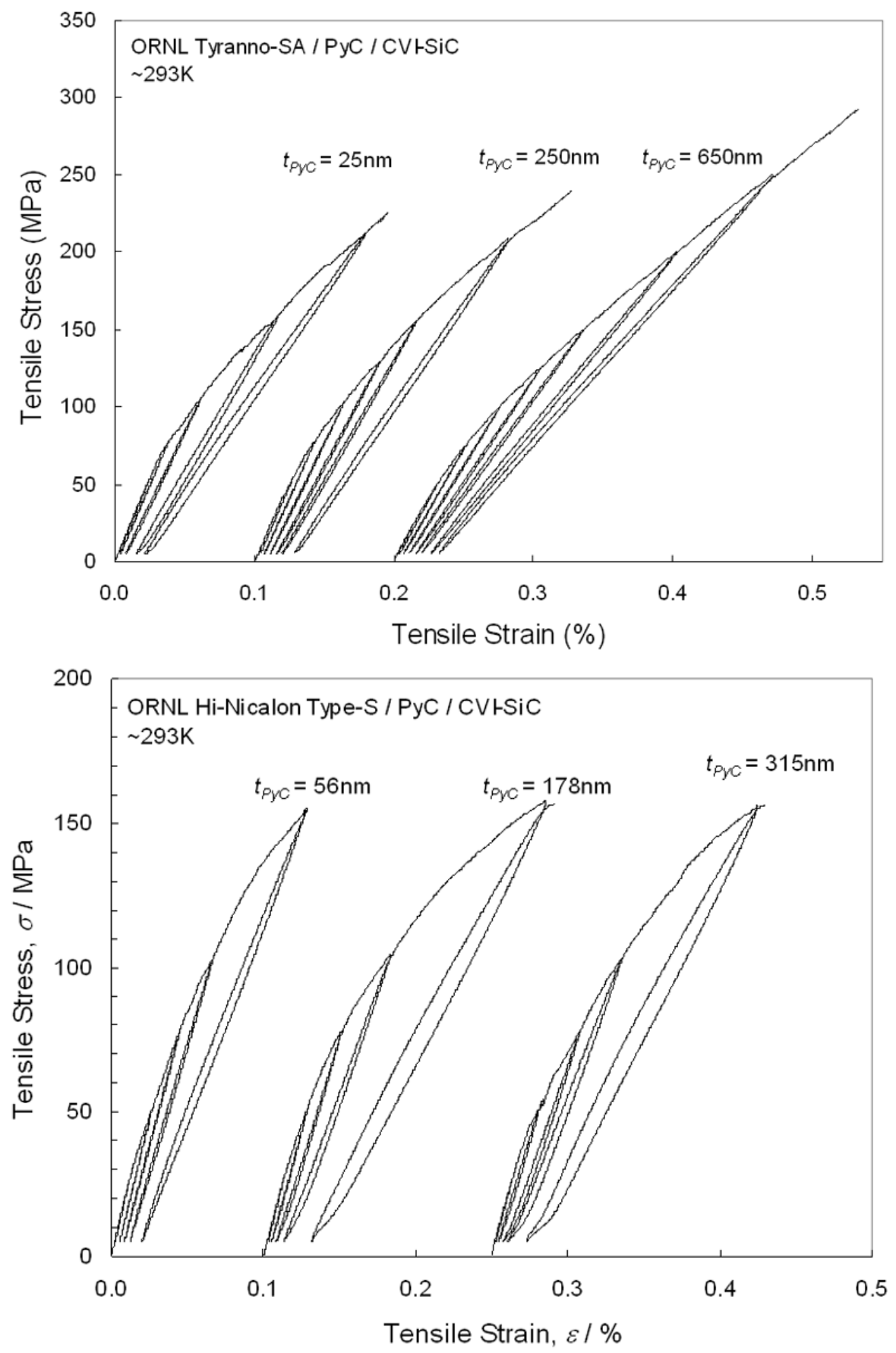

Figure 3: Influences of pyrocarbon interphase thickness on mechanical properties of CVI $\mathrm{SiC} / \mathrm{SiC}$ composites. [45-46] 


\subsection{PROPERTIES}

Properties of continuous fiber composite materials are generally anisotropic and dependent on the architecture and the properties of constituents. In other words, composite properties can generally be adjusted, to a limited extent, to meet the design requirements. However, because the fiber and the matrix have to be made of stoichiometric, crystalline $\mathrm{SiC}$ for the assumed application in this report, the properties of those main composite constituents may not be adjusted. Therefore, it is adequate here that the composite properties are determined primarily by its architecture. In Table 7, various mechanical, physical, and lifetime properties for the Generation-III $\mathrm{SiC}$ fiber, CVI $\mathrm{SiC}$ composites are compared for several representative architectures and orientations. Although the data availability is rather limited, it can be seen that most properties are not very strongly dependent on architecture or orientation, except for the fracture properties. Note that the apparent differences in transverse thermal conductivity are not inherent to the different in architecture but more strongly depend on the characteristics of interlaminar pores. Also it is important to note that these properties are substantially different from those for composites with previous generations $\mathrm{SiC}$ fibers, for which much more complete properties data bases are available. 
Table 7: Typical mechanical, physical, and lifetime properties of CVI SiC/SiC. [47]

\begin{tabular}{|c|c|c|c|c|c|}
\hline & & $2 \mathrm{D} 0 / 90^{\circ}$ & $2 \mathrm{D} \pm 45^{\circ}$ & $\begin{array}{l}\text { Braiding, bi- } \\
\text { axial } \pm 55^{\circ}\end{array}$ & $\begin{array}{l}\text { Braiding, tri- } \\
\quad \text { axial }\end{array}$ \\
\hline In-plane tensile proportional limit stress & $\mathrm{MPa}$ & $100-150^{1)}$ & $100-150^{1)}$ & $70-150^{1)}$ & $\sim 100^{1)}$ \\
\hline In-plane tensile strength & $\mathrm{MPa}$ & $250-400^{1)}$ & $\sim 200^{1)}$ & $100-300^{1)}$ & $\sim 150^{1)}$ \\
\hline In-plane tensile modulus & $\mathrm{GPa}$ & $200-300^{1)}$ & $200-300^{1)}$ & $200-300^{1)}$ & $200-300^{1)}$ \\
\hline Poisson's ratio & & $0.2^{1)}$ & $0.2^{1)}$ & $0.2^{1)}$ & - \\
\hline Trans-thickness tensile strength & $\mathrm{MPa}$ & $\sim 20^{2)}$ & $\sim 20^{2)}$ & $\sim 20^{4)}$ & $\sim 20^{4)}$ \\
\hline In-plane flexural proportional limit stress & $\mathrm{MPa}$ & $300-500^{4)}$ & - & - & - \\
\hline In-plane flexural strength & $\mathrm{MPa}$ & $500-800^{4)}$ & - & - & - \\
\hline In-plane shear proportional limit stress & $\mathrm{MPa}$ & $\sim 40^{5)}$ & $\sim 40^{5)}$ & - & - \\
\hline In-plane shear strength & $\mathrm{MPa}$ & $\sim 100^{5)}$ & $\sim 120^{5)}$ & - & - \\
\hline Interlaminar shear strength & $\mathrm{MPa}$ & $\sim 40^{5}$ & $\sim 40^{5)}$ & - & - \\
\hline Fracture toughness & ${\mathrm{MPa}-\mathrm{m}^{1 / 2}}^{2}$ & $20-30^{2)}$ & $\sim 20^{2)}$ & $20-30^{1)}$ & $\sim 20^{1)}$ \\
\hline $\begin{array}{c}\text { Cyclic fatigue run-out stress } \\
\left(1000^{\circ} \mathrm{C} \text { in argon, tension-tension }\right)\end{array}$ & MPa & $\sim 70^{5)}$ & - & - & - \\
\hline $\begin{array}{l}\text { Critical rupture stress } \\
\left(1200^{\circ} \mathrm{C} \text { in air, tension }\right)\end{array}$ & MPa & $<50^{5)}$ & - & - & - \\
\hline Mass density & $\mathrm{g} / \mathrm{cm}^{3}$ & $2.6-2.8^{1)}$ & $2.6-2.8^{1)}$ & $2.6-2.8^{1)}$ & $2.6-2.8^{1)}$ \\
\hline Thermal conductivity, in-pane & $\mathrm{W} / \mathrm{m}-\mathrm{K}$ & $\begin{array}{c}\sim 30(\mathrm{RT})^{2)} \\
\sim 18\left(800^{\circ} \mathrm{C}\right) \\
\end{array}$ & \begin{tabular}{|c|}
$\sim 30(\mathrm{RT})^{2)}$ \\
$\sim 18\left(800^{\circ} \mathrm{C}\right)$ \\
\end{tabular} & $\begin{array}{c}40(\mathrm{RT})^{1)} \\
\sim 25\left(800^{\circ} \mathrm{C}\right) \\
\end{array}$ & $\begin{array}{c}\sim 40(\mathrm{RT})^{1)} \\
\sim 25\left(800^{\circ} \mathrm{C}\right) \\
\end{array}$ \\
\hline Thermal conductivity, transverse & $\mathrm{W} / \mathrm{m}-\mathrm{K}$ & $\begin{array}{c}\sim 15(\mathrm{RT})^{2)} \\
\sim 10\left(800^{\circ} \mathrm{C}\right)\end{array}$ & $\begin{array}{c}\sim 15(\mathrm{RT})^{2)} \\
\sim 10\left(800^{\circ} \mathrm{C}\right)\end{array}$ & $\begin{array}{l}\sim 35(\mathrm{RT})^{1)} \\
\sim 20\left(800^{\circ} \mathrm{C}\right)\end{array}$ & $\begin{array}{c}\sim 25(\mathrm{RT})^{1)} \\
\sim 18\left(800^{\circ} \mathrm{C}\right)\end{array}$ \\
\hline Thermal expansion $\left(0-1000^{\circ} \mathrm{C}\right)$ & $\mathrm{ppm} / \mathrm{K}$ & $\sim 4.5^{3)}$ & $\sim 4.5^{3)}$ & $\sim 4.5^{3)}$ & $\sim 4.5^{3)}$ \\
\hline
\end{tabular}

* Materials are Hi-Nicalon ${ }^{\mathrm{TM}}$ Type-S, 150nm pyrocarbon interphase, CVI SiC matrix composites unless otherwise noted.

1) Data obtained in U.S. Gen-IV NGNP Composite R\&D Program and affiliated SBIR programs.

2) Data obtained in Fusion Advanced Materials Program for materials in the same class.

3) Intrinsic properties for crystalline, stoichiometric SiC. Confirmative data exist.

4) Values guessed by the authors based on data for similar materials.

5) Data for CG-Nicalon ${ }^{\mathrm{TM}}$, pyrocarbon interphase, CVI SiC matrix composites.

\subsubsection{Flexural strength}

Historically, the flexural test has been most frequently used to evaluate the strength of ceramic composites. The primary reason for the heavy utilization of flexural test is that it requires only very simple testing procedures and relatively small, simple-shaped specimens. An ASTM test standard exists for flexural testing of continuous fiber ceramic composites. In Figure 4, typical flexural stress-strain behavior of the Generation III CVI SiC/SiC is presented [48]. In this example, the materials are CVI composites with varied pyrocarbon interphase thickness and are reinforced with plain-weave Tyranno ${ }^{\mathrm{TM}} \mathrm{SA} 3$ fabrics and are tested in the $0 / 90^{\circ}$ orientation. The composites exhibits 500 - $800 \mathrm{MPa}$ ultimate flexural stresses with the proportional limit stresses typically $\sim 70 \%$ of the ultimate stresses. The flexural strengths measured for fiber composites are generally substantially greater than the tensile strength. This is generally 
explained that the neutral plane in the flexural specimen shifts toward the compressive side as the extensive cracking proceeds on the tensile side. Hence the apparent maximum stress becomes greater than the true stress near the tensile surface. Moreover, very large apparent failure strains are often exhibited in a flexural loading configuration as in Figure 4, because the preceding delamination failure allows large bending without complete fiber fracture. Because of these reasons, flexural strength data for ceramic composites should be used only for preliminary evaluation or when the stress states in the flexural test is relevant to the anticipated failure mode in specific applications.

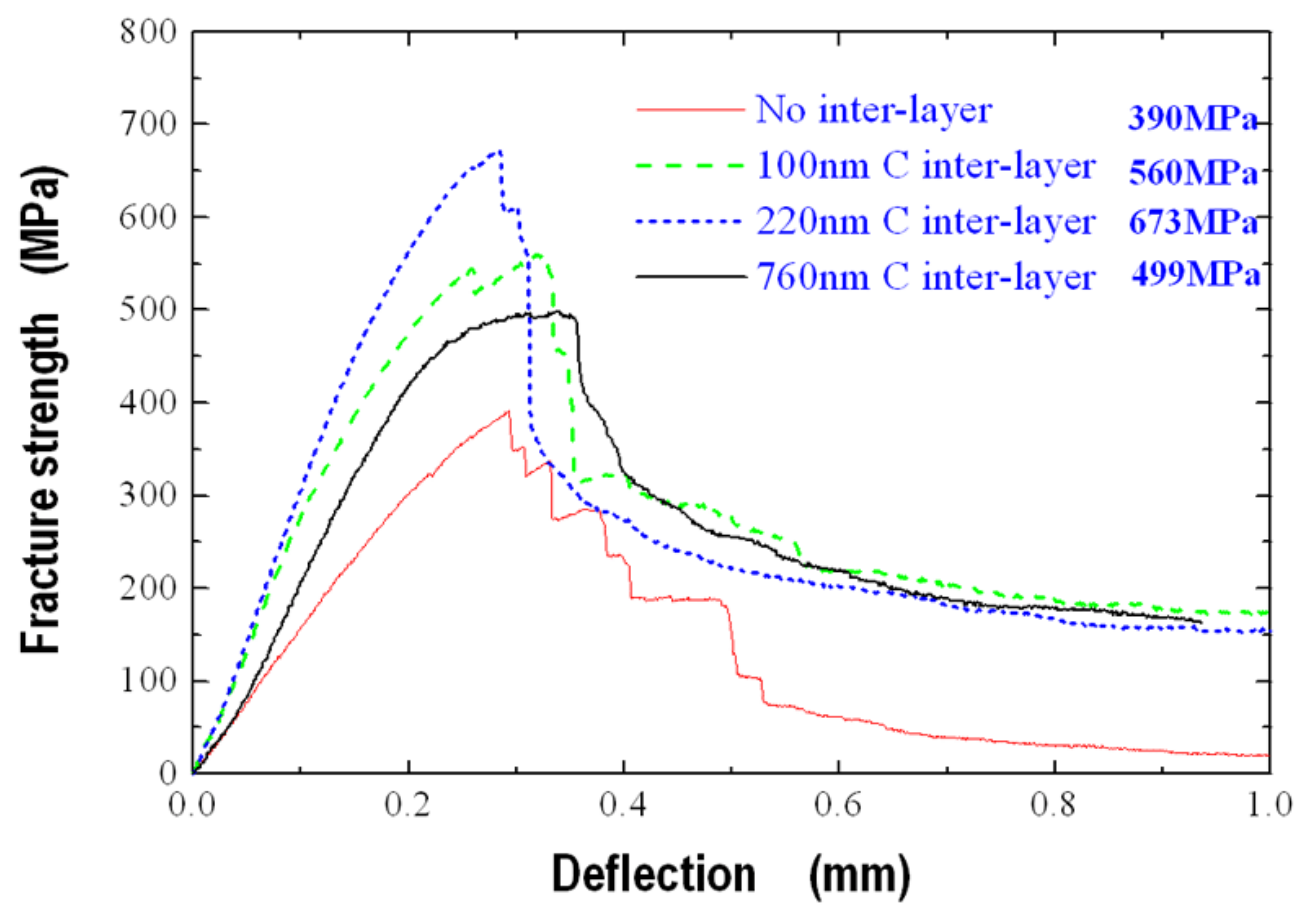

Figure 4: Flexural properties of CVI SiC/SiC. [48]

\subsubsection{Tensile strength}

Because of the above-stated shortcomings regarding general validity of the strength data obtained by flexural tests, it is highly desirable that the baseline strength data are obtained by tensile testing for ceramic composites. ASTM test standards exist for tensile testing of continuous fiber ceramic composites at ambient and elevated temperatures. Moreover, test techniques using small tensile specimens were recently established. In Figure 5, examples of stress-strain behavior of the Generation III CVI SiC/SiC are presented [46]. In these examples, 
the materials are CVI composites with thin $(<100 \mathrm{~nm})$ pyrocarbon interphases and are reinforced with plain-weave Tyranno ${ }^{\text {TM }}$ SA3 or Hi-Nicalon ${ }^{\text {TM }}$ Type-S fabrics and are tested in the $0 / 90^{\circ}$ orientation at ambient and elevated temperatures. The testing procedure employed involves incremental unloading/reloading sequences in order to determine the extent of matrix damages and interfacial properties [49]. The labels I, II, and III indicate stages of elastic/reversible deformation, matrix microcrack accumulation, and progressive fiber failure, respectively. The end of Stage I implies the initiation of matrix cracking and/or crack opening and the corresponding stress is termed proportional limit stress (PLS). The ultimate tensile stress (UTS) and PLS for the Generation III CVI SiC/SiC is typically $250-400 \mathrm{MPa}$ and $100-150 \mathrm{MPa}$, respectively. The tensile behavior at $1300^{\circ} \mathrm{C}$ in Figure 5 indicates the lack of strength decrease at the test temperature as compared with ambient temperature (strain was not correctly measured in that work at $1300^{\circ} \mathrm{C}$ ).

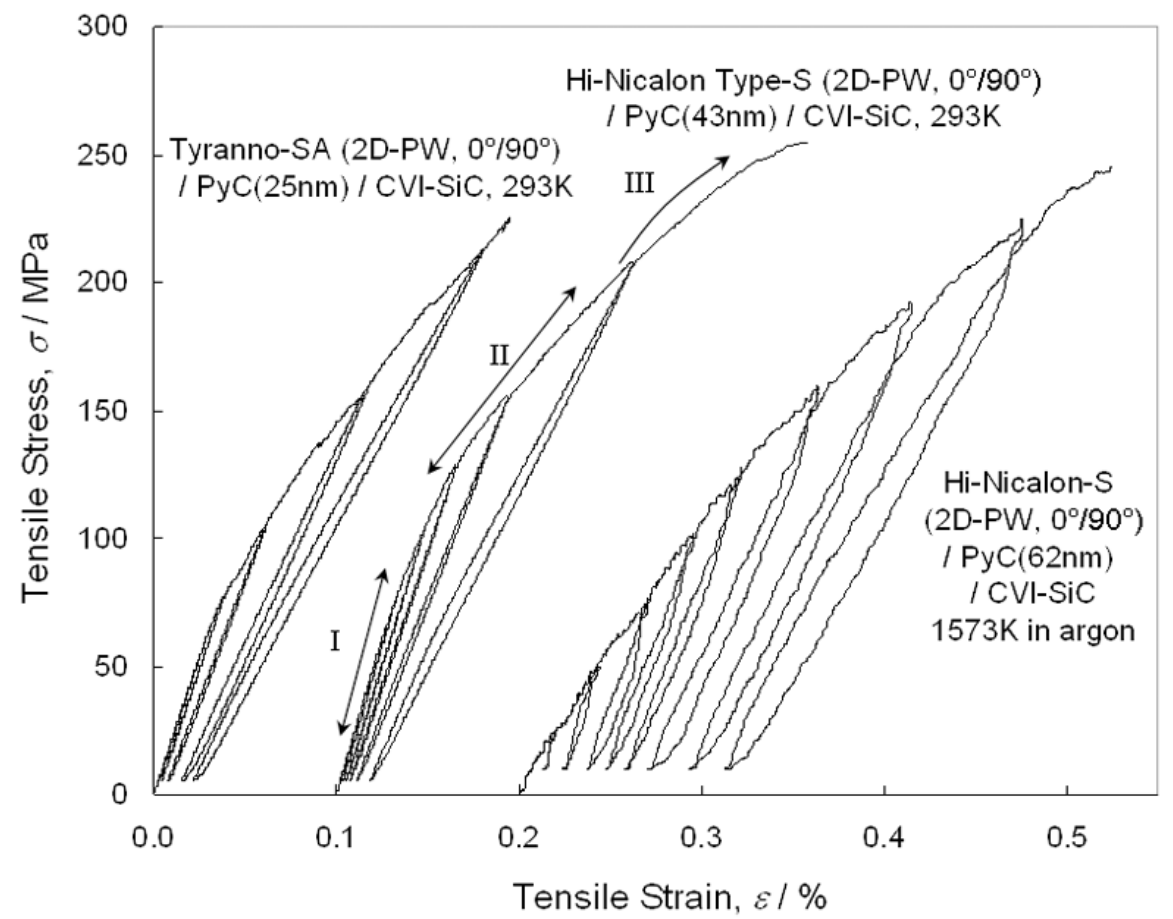

Figure 5: Examples of tensile stress-strain behavior of CVI SiC/SiC (testing procedure involves incremental unloading/reloading sequences to determine the extent of matrix damages and interfacial properties). The labels I - III indicate stages of tensile fracture of the composites in this class; namely I: elastic/reversible deformation, II: matrix micro-crack accumulation, and III: progressive fiber failure. The horizontal shifts are intentional for clarity. [46] 


\subsubsection{Thermal conductivity}

High thermal conductivity is preferred for most thermostructural applications, because it often lowers the highest temperature in the components, lowers thermal stress, and reduces thermal shock and/or thermal stress loads. These will be important considerations for use of $\mathrm{SiC} / \mathrm{SiC}$ as the fuel cladding.

Thermal conductivity in $\mathrm{SiC} / \mathrm{SiC}$ is usually highly anisotropic depending on architecture. It is governed by the thermal conductivity, volume fraction, shape, and orientation of the fibers, matrix, interphases, and pores. Typical thermal conductivities for the Generation III CVI $\mathrm{SiC} / \mathrm{SiC}$ in two-dimensional and orthogonal three-dimensional architectures are shown as a function of temperature in Figure 6, where experimental data are compared with the model simulation [50].

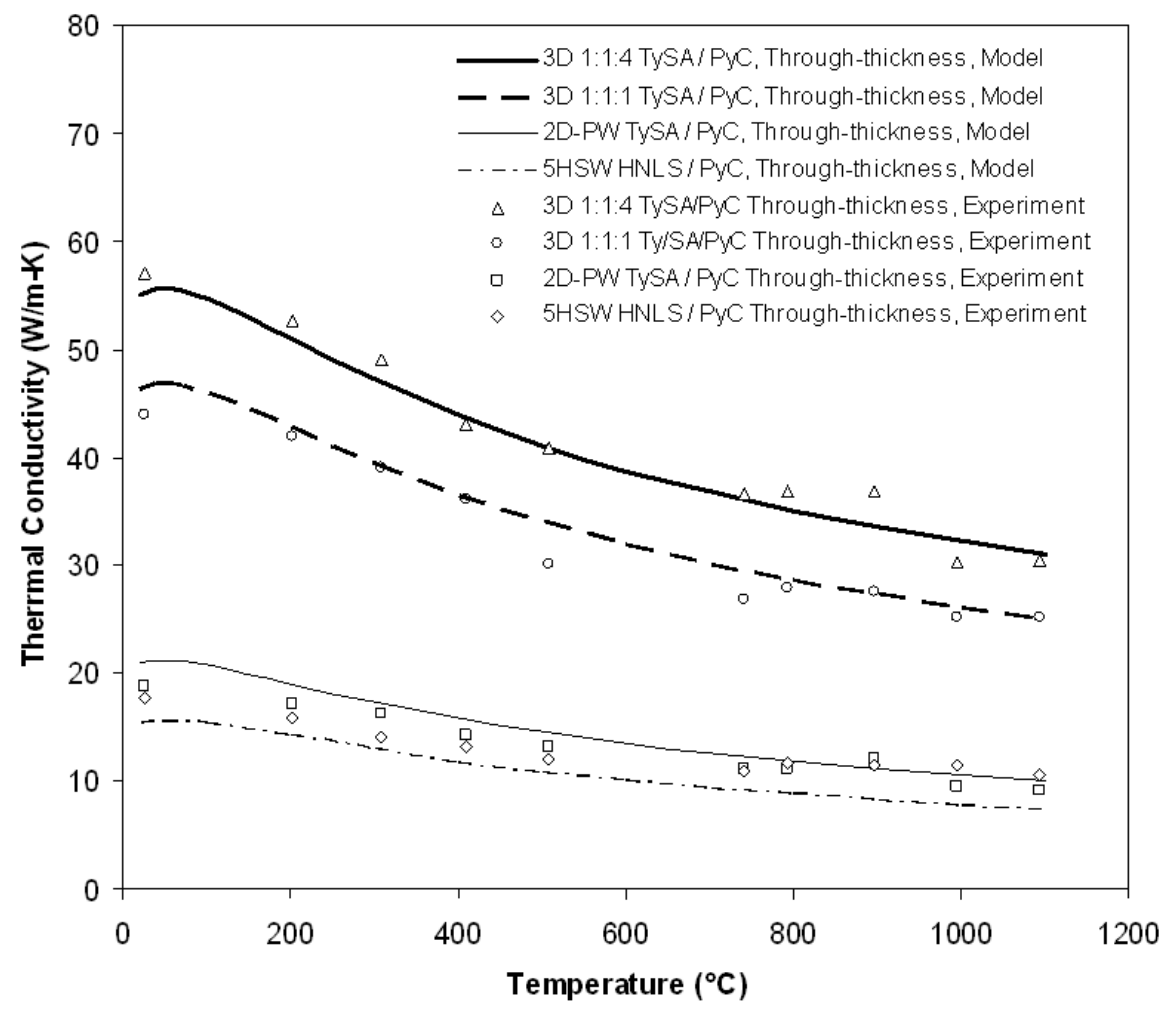

Figure 6: Thermal conductivity of CVI SiC/SiC. [50] 
Thermal conductivity of CVI SiC matrix with hypothetical full density is often assumed to be $50-70 \mathrm{~W} / \mathrm{m}-\mathrm{K}$. Among the Generation III SiC fibers, Tyranno ${ }^{\mathrm{TM}} \mathrm{SA} 3$ gives the highest thermal conductivity of $\sim 65 \mathrm{~W} / \mathrm{m}-\mathrm{K}$ at ambient temperature, as compared to $\sim 18 \mathrm{~W} / \mathrm{m}-\mathrm{K}$ for HiNicalon ${ }^{\mathrm{TM}}$ Type-S. Therefore, thermal conductivity of $\mathrm{SA} 3 \mathrm{CVI} \mathrm{SiC} / \mathrm{SiC}$ in major fiber directions falls in a 40 to $60 \mathrm{~W} / \mathrm{m}-\mathrm{K}$ range, and somewhat lower for Type-S CVI SiC/SiC. The low conductivity for the Type-S fiber is due to the presence of high concentration impurity and the smaller grain sizes. Thermal conductivity of $\mathrm{SiC} / \mathrm{SiC}$ in lay-up type architectures (e.g., twodimensional and braiding) in the transverse, or trans-thickness, direction is usually much lower than in in-plane directions. This is primarily because of the presence of interlaminar pores which are in planar shapes and are oriented so that transverse heat transport is effectively disrupted. Typical transverse thermal conductivity of two-dimensional and braided $\mathrm{SiC} / \mathrm{SiC}$ wall is $15-20$ $\mathrm{W} / \mathrm{m}-\mathrm{K}$ at ambient and $10-15 \mathrm{~W} / \mathrm{m}-\mathrm{K}$ at $800^{\circ} \mathrm{C}$. It is important to note that neutron irradiation reduces the thermal conductivity of ceramics including $\mathrm{SiC}$ very effectively (see discussion in Section 2.5). The transverse thermal conductivity will also be reduced substantially when interlaminar cracks are introduced.

Constitutive modeling of thermal conductivity in $\mathrm{SiC} / \mathrm{SiC}$ has been advanced during the last few years, and fairly sophisticated predictive capability is now developed including irradiation effect. In Figure 7, thermal conductivity and thermal stress are calculated for varied transverse fiber fractions in orthogonally three-dimensional Tyranno ${ }^{\mathrm{TM}} \mathrm{SA} 3 \mathrm{CVI} \mathrm{SiC} / \mathrm{SiC}$ and presented [50]. 

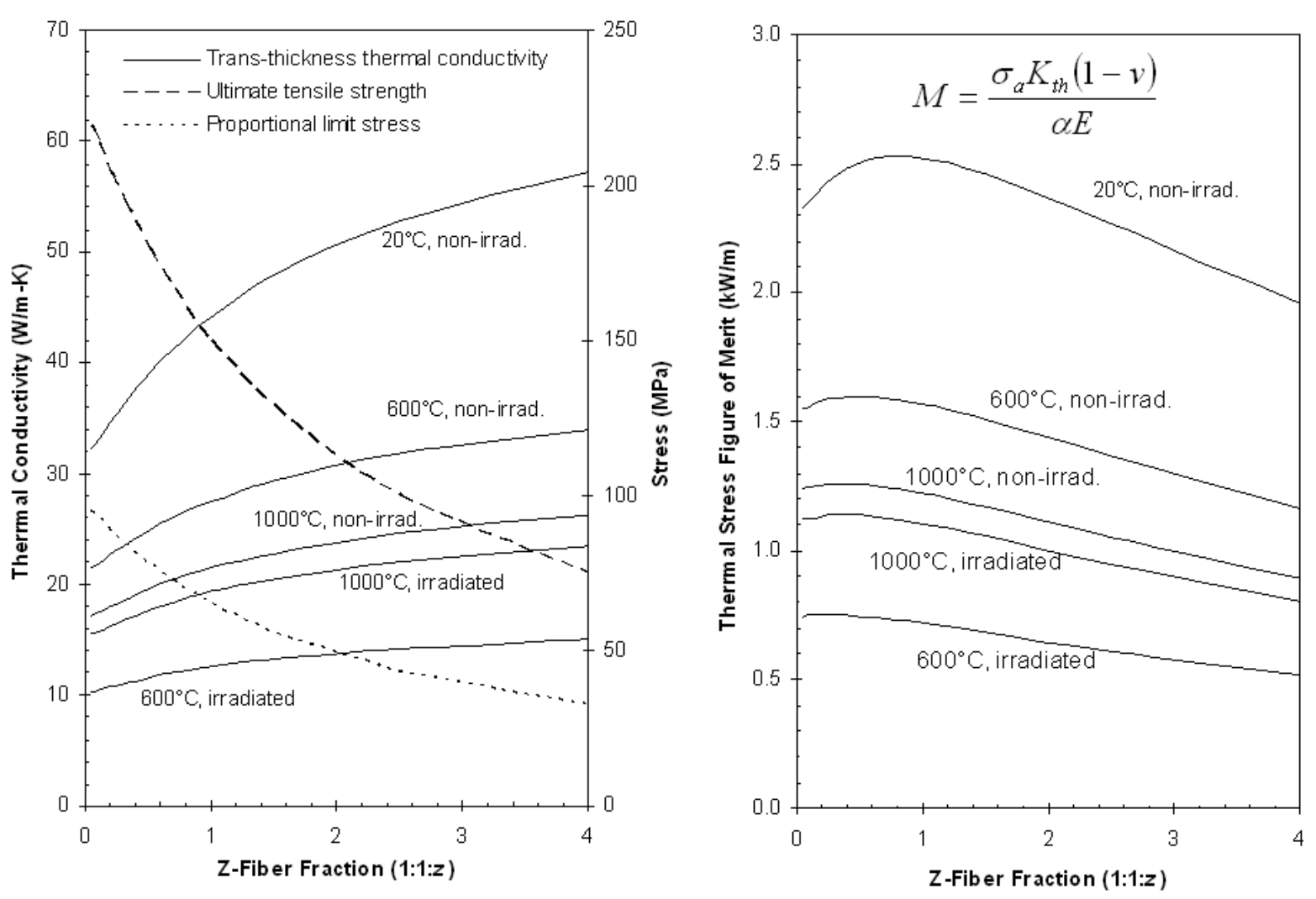

Figure 7: Strength and thermal property tailoring of 3D SiC/SiC. [50]

\subsubsection{Lifetime properties}

Fatigue properties are important to determine the both the static and cyclic design stresses for ceramic composites. The static fatigue is deterioration of materials due to crack extension under static loading, whereas the cyclic fatigue occurs under repeating dynamic loading environments. The static fatigue in ceramic composites is often misconstrued as creep. Slow crack growth (SCG), or stress corrosion cracking (SCC), is an environmentally assisted form of the static fatigue (although environmentally assisted and non-assisted crack growth may not be clearly separated). Studies on fatigue or crack growth properties of the Generation III SiC fiber CVI $\mathrm{SiC} / \mathrm{SiC}$ have been extremely limited. Therefore, such properties for $\mathrm{SiC} / \mathrm{SiC}$ are briefly discussed below using data published for previous generation materials.

Static fatigue lifetime of $\mathrm{SiC} / \mathrm{SiC}$ exhibits a negative correlation with the magnitude of applied stress above the stress at which matrix microcracking is introduced. Hence it often can be fit to a Larson-Miller expression, although the adequacy of the Larson-Miller fitting has not yet demonstrated. The Larson-Miller law will be useful once established, however, will require a 
large amount of experimental data to establish. Moreover, a prudent consideration of environment effect will be required. In Figure 8, static fatigue property of Hi-Nicalon ${ }^{\mathrm{TM}} \mathrm{CVI}$ $\mathrm{SiC} / \mathrm{SiC}$ is shown in a Larson-Miller plot [51]. The material studied in the work of Figure 8 exhibits an apparent PLS of approximately $150 \mathrm{MPa}$. It is important to note that the static fatigue failure occurs at stress levels lower than PLS. The reason is that PLS does not represent the stress at which the first matrix cracking occurs but is the stress at which detectable crack opening occurs. A very limited work on static fatigue of Tyranno ${ }^{\mathrm{TM}}-\mathrm{SA} 3 \mathrm{CVI} \mathrm{SiC} / \mathrm{SiC}$ has been performed by Riccardi et al to confirm the same trend [52].

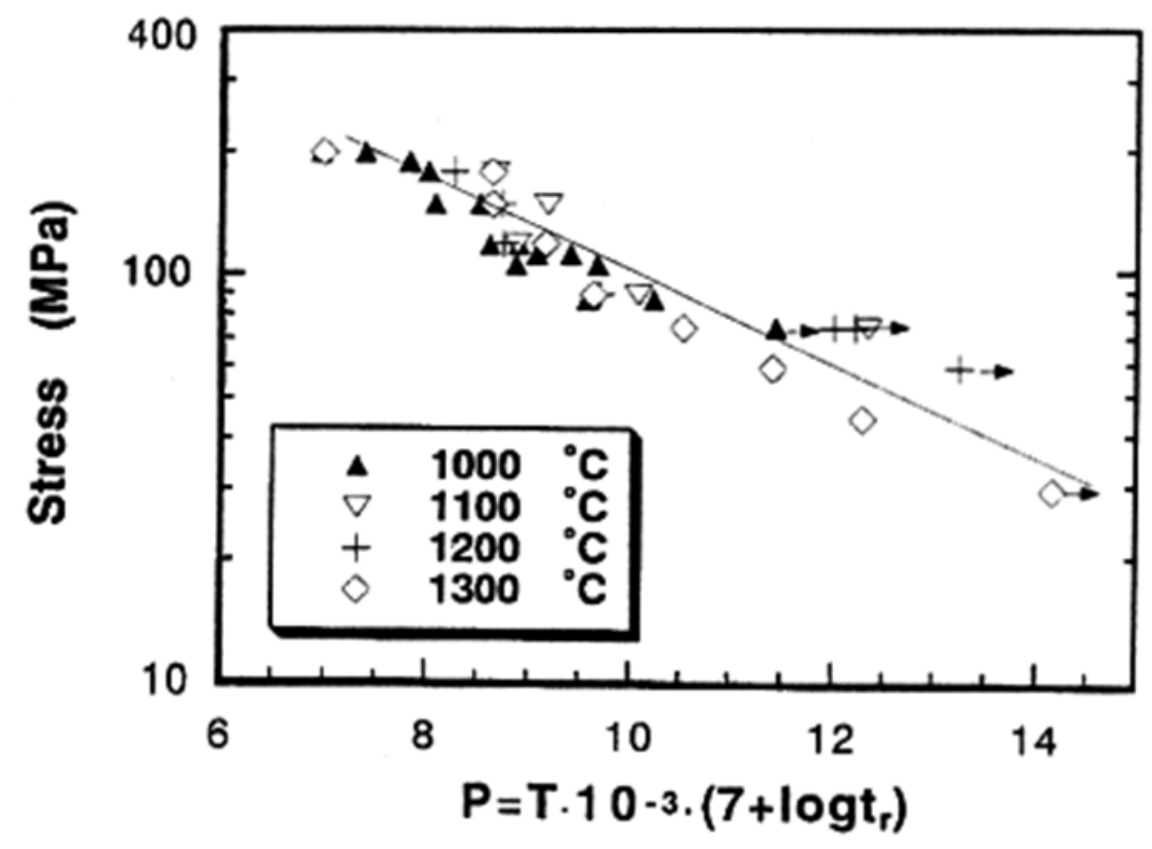

Figure 8: Static fatigue of CVI SiC/SiC. [51]

Static fatigue due to the environmentally assisted SCG is often an issue for $\mathrm{SiC} / \mathrm{SiC}$ for use in oxidative environments. It has been proposed that the SCG is enabled by recession of interphase and/or creep, degradation, or rupture of fibers [53]. On the other hand, the liquid salt environment may be unique for that it may attack $\mathrm{SiC}$ (though it seems to depend on quality of $\mathrm{SiC}$ ) rather than carbon interphase. The effect of liquid salt environment on $\mathrm{SCG}$ of $\mathrm{SiC} / \mathrm{SiC}$ is unknown.

The cyclic fatigue limit stress for $\mathrm{SiC} / \mathrm{SiC}$ may be substantially higher than the static fatigue limit. The stress - number of cycles $(\mathrm{S}-\mathrm{N})$ relationship determined for a material very similar to 
the one used in the work of Figure 8 is presented in Figure 9 [54]. It is noted that the cyclic fatigue limit stress in Figure 9 is about $\sim 140 \mathrm{MPa}$, whereas the static fatigue limit stress in Figure 8 appears approximately $70 \mathrm{MPa}$ at $<1200^{\circ} \mathrm{C}$. To the contrary, a very limited work on cyclic fatigue of Tyranno ${ }^{\text {TM}}$-SA3 CVI SiC/SiC performed by Riccardi et al implies the cyclic fatigue limit stress similar to the static fatigue stress [52]. This area needs more work for clarification.

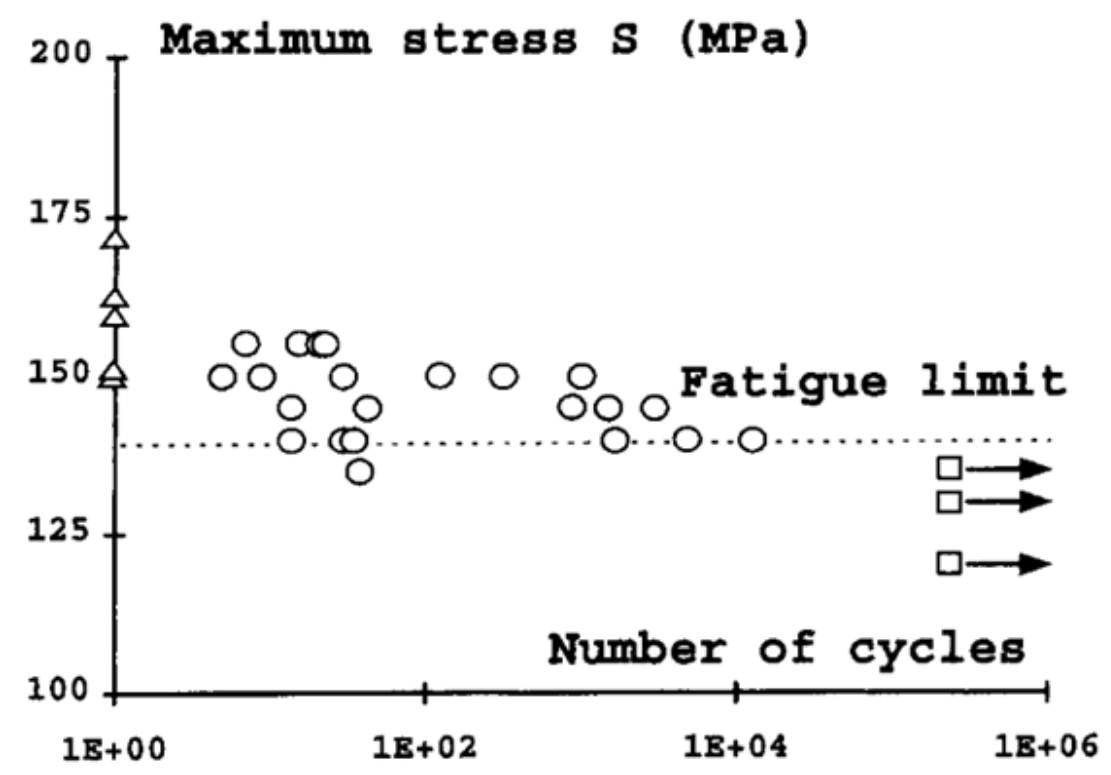

Figure 9: Cyclic fatigue of CVI SiC/SiC. [54]

\subsubsection{Anisotropy of properties}

One of the important design aspects for the use of tubular composites is fiber architecture to ensure the best optimized margins against stresses generated by mechanical loading or thermal expansion in the axial and hoop directions, i.e., anisotropy issue. The anisotropy is obviously the most pronounced for unidirectional architecture. Multi-axial fiber reinforcement is often applied to relief composite anisotropy. There have been studies on anisotropic tensile properties of the previous generation $\mathrm{SiC} / \mathrm{SiC}$ composites [55-56]. Recently, a limited study on anisotropic mechanical properties of the Generation III CVI SiC/SiC was performed [47].

The work is briefly summarized in Figure 10, showing tensile PLS and ultimate stress with respect to the off-axis loading angle. Key crack initiation mechanisms are supposed to be 1) transverse cracking perpendicular to the fiber longitudinal direction, i.e., matrix cracking, 2) in- 
plane shear cracking within the fiber bundles along the longitudinal fibers, and 3) interlaminar shear cracking along the longitudinal fibers by fiber detachment. For off-axis tension, the applied stress can be separated into three stress elements: tensile stresses in the longitudinal fiber direction, in the transverse fiber direction, and in-plane shear stress on the plane parallel to the longitudinal fiber direction. The map indicates that cracking and failure occur when any of the stress components exceed the critical cracking and failure stresses in the respective mode.
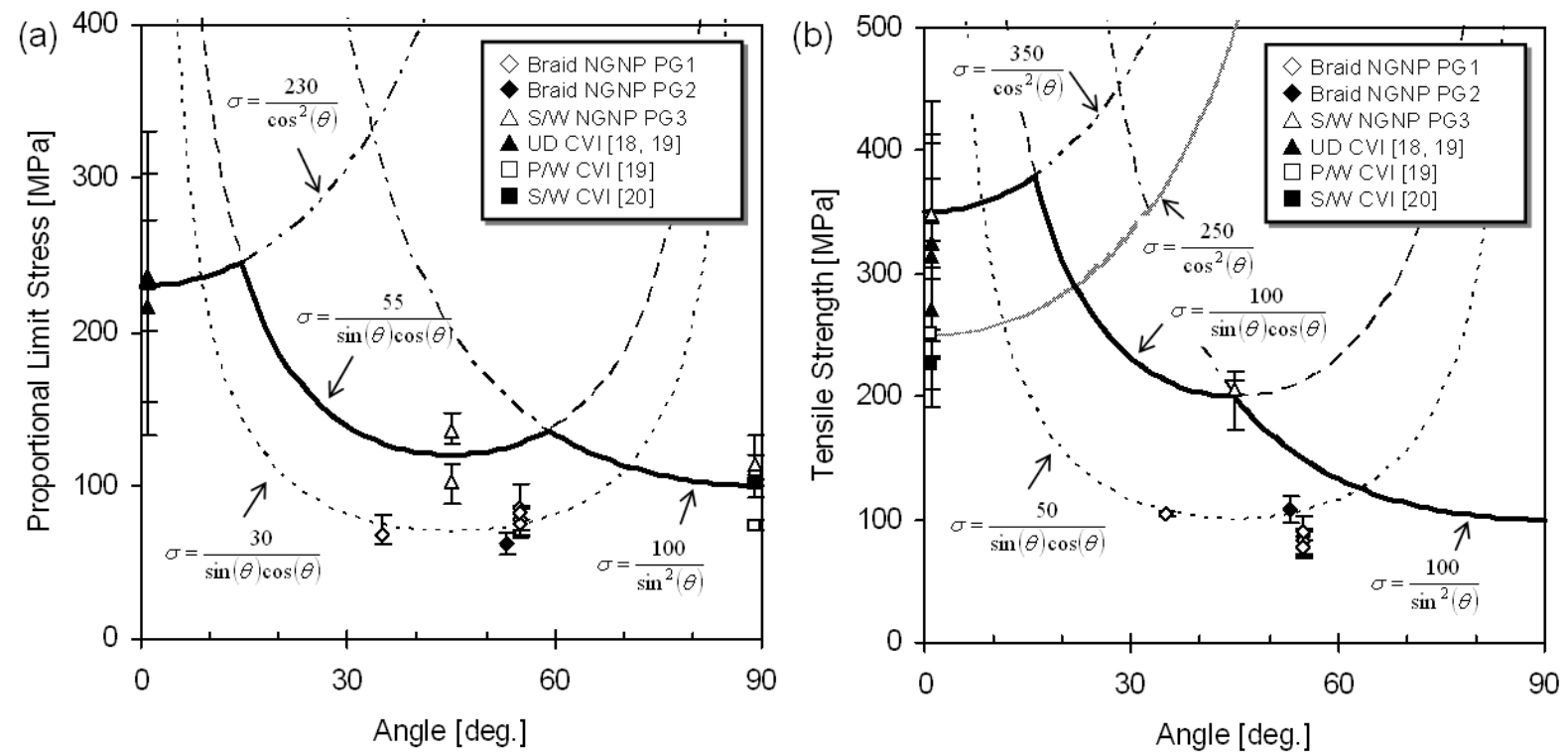

Figure 10: Anisotropy in mechanical properties of 2D $\mathrm{SiC} / \mathrm{SiC}$ with regard to fiber orientation. [47]

\subsubsection{Properties of NITE SiC/SiC}

As discussed above, NITE $\mathrm{SiC} / \mathrm{SiC}$ is a potential alternative to $\mathrm{CVI} \mathrm{SiC} / \mathrm{SiC}$. NITE $\mathrm{SiC} / \mathrm{SiC}$ is attractive in terms of strength, thermal conductivity, gas tightness, etc., but is on the other hand less mature as an industrial material. Extensive characterization of the NITE $\mathrm{SiC} / \mathrm{SiC}$ is being performed in Japanese GFR and nuclear heat exchanger programs. A comparison of NITE $\mathrm{SiC} / \mathrm{SiC}$ with $\mathrm{CVI} \mathrm{SiC/SiC}$ for baseline properties was provided in Table 3. Ambient temperature tensile property of the pilot commercial grade NITE $\mathrm{SiC} / \mathrm{SiC}$ is shown in Figure 11 [22]. The NITE $\mathrm{SiC} / \mathrm{SiC}$ possesses a near-full density matrix of beta-phase $\mathrm{SiC}$ and a small amount of products from the oxide additives. Therefore, it can be considered to be a similar material to CVI $\mathrm{SiC} / \mathrm{SiC}$ except for lack of the high matrix porosity. The less porous matrix provides higher 
strength, higher thermal conductivity, (both in an ideal condition,) and higher composite modulus.

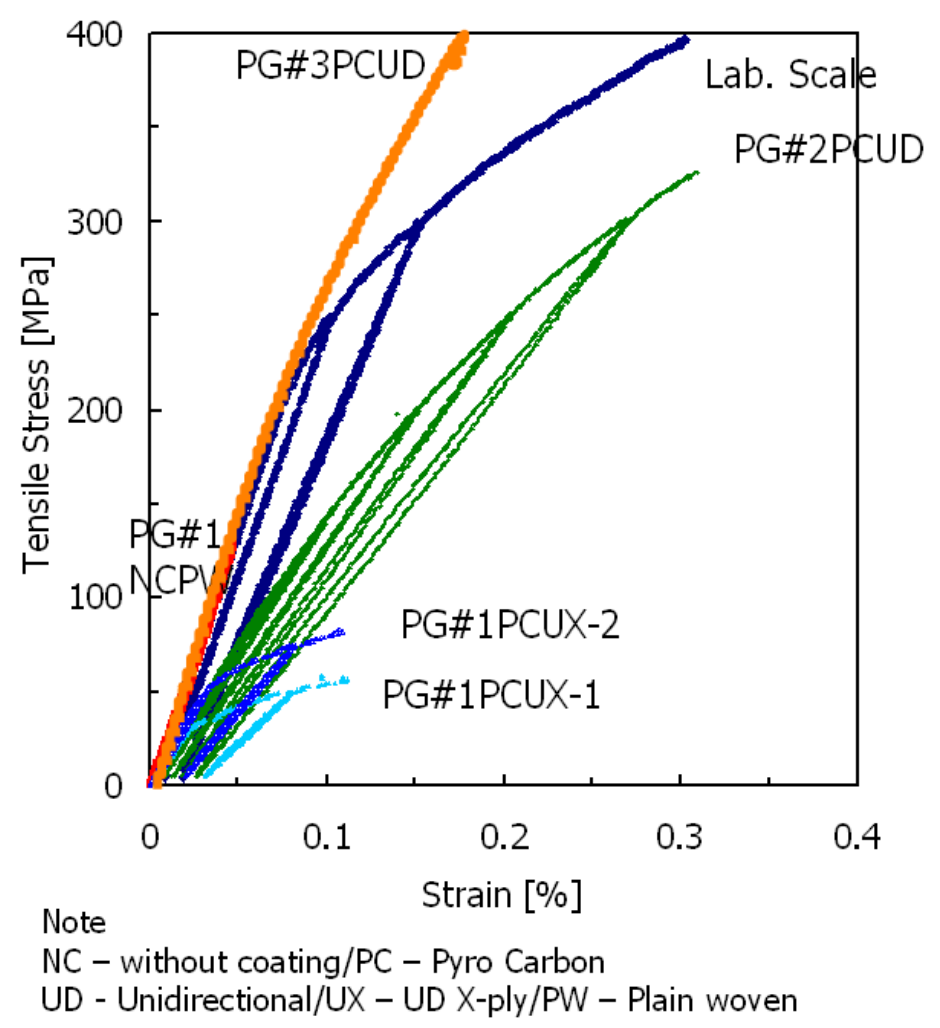

Figure 11: Mechanical property of NITE SiC/SiC. [29]

\subsection{RADIATION EFFECT}

\subsubsection{Radiation effect on strength of pure SiC}

Because the matrix and fiber constituents for the Generation III CVI SiC/SiC consist of betaprimarily phase $\mathrm{SiC}$, the effect of neutron irradiation on the mechanical properties of monolithic beta-SiC is among the most important issues to understand irradiation effects on composites. For example, the matrix-cracking stress for $\mathrm{SiC} / \mathrm{SiC}$ composites, which is related to both static and dynamic fatigue limits, can be subject to irradiation effect through modification of fracture energy and elastic moduli of the composites' constituents [57]. 
There have been several studies on the effect of neutron irradiation on the strength of high purity beta-SiC made through chemical vapor deposition. Generally, the high purity CVD SiC exhibits excellent neutron irradiation resistance [58]. The irradiation effect on flexural strength of Roam and Haas CVD SiC in a fluence range of 0.15-18.7 dpa is summarized in Figure 12 [59]. Note that $1 \mathrm{dpa}$ approximately corresponds to a fast neutron fluence $1 \times 10^{25} \mathrm{n} / \mathrm{m}^{2}(\mathrm{E}>0.1$ $\mathrm{MeV}$ ) in HFIR flux trap, although the conversion factor varies depending on neutron spectrum. Irradiation-induced strengthening seems to be significant at 573-1273 K. There a few reported data points which imply potential deteriorating effect of irradiation. Such deterioration is considered exceptional and is supposed to have been caused by the second phase inclusion in the material used. Unfortunately, details of the material were not given in the original literature [60]. Relatively large scatter in flexural strength of brittle ceramics is inevitable, since the fracture strength is determined by the effective fracture toughness, morphology and characteristics of the flaw that caused the fracture. Irradiation possibly modifies both the flaw characteristics and the fracture toughness, through potential surface modification, relaxation of the machining-induced local stress, modifications of elastic properties and fracture energy.

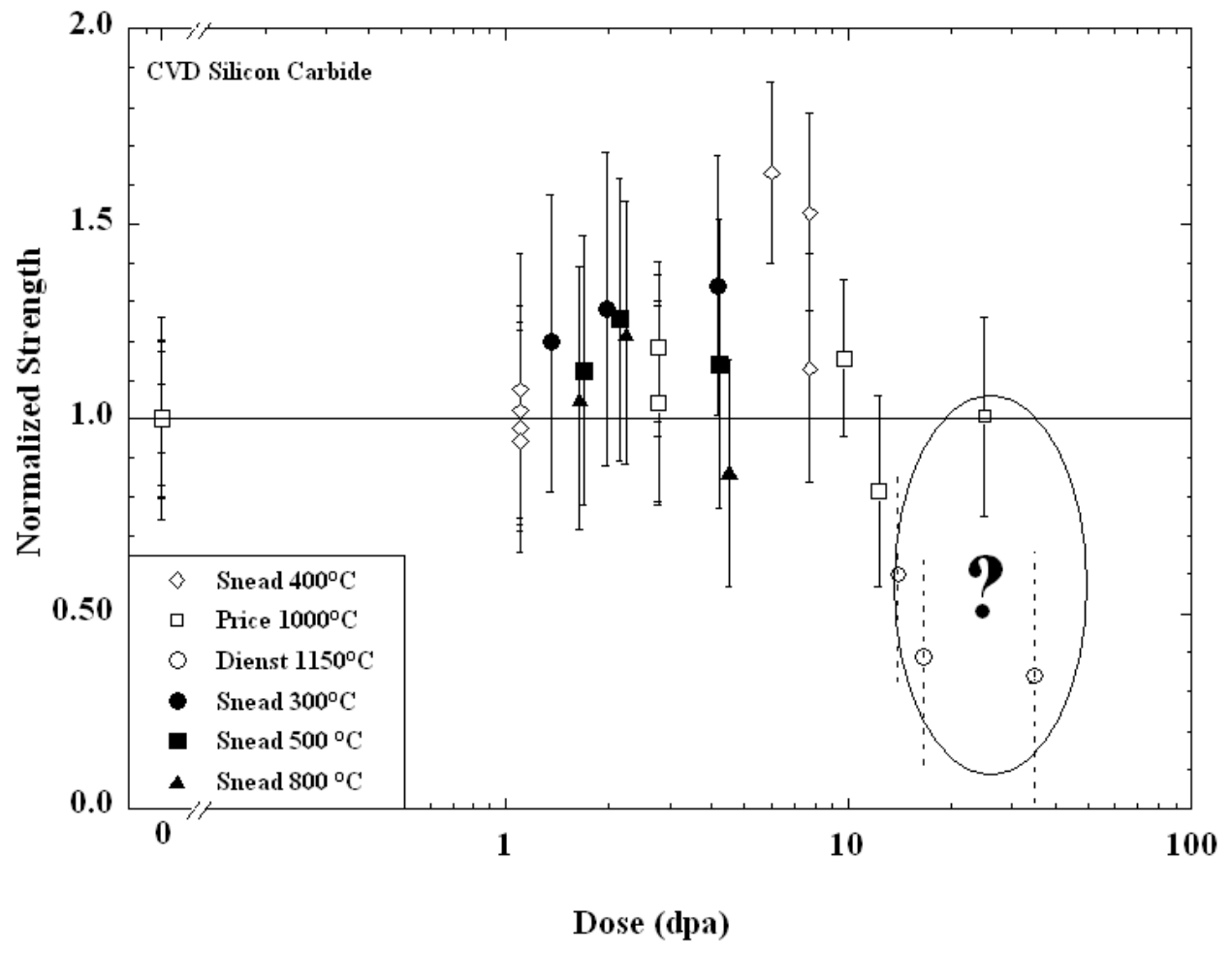

Figure 12: Effect of neutron irradiation on fracture strength of high purity CVD SiC. [59] 
A change in the Weibull statistics, indicating a higher scatter in as-irradiated flexural strength has been observed, though the point could not be made convincingly due to limitations in the number of tests observed. In the earliest work known to the authors, Sheldon [61] noted a 14\% decrease in crushing strength of highly irradiated CVD SiC shells with an increase of the coefficient of variation from $8 \%$ to $14 \%$. Price [17] performed the 4-point flexural test with relatively thin $(\sim 0.6 \mathrm{~mm})$ strips of CVD SiC deposited onto a graphite substrate. In his work the flexural strength following an $\sim 9.4 \times 10^{25} \mathrm{n} / \mathrm{m}^{2}(\mathrm{E}>0.1 \mathrm{MeV})$ irradiation was unchanged within the statistical scatter, but the scatter itself increased from about $10 \%$ to $30 \%$ of the mean flexural strength as described assuming a normal distribution. Unfortunately, there was not sufficient number of samples in Price's work to infer Weibull parameters.

The statistically meaningful data-sets on the effect of flexural strength of CVD SiC have been reported by Newsome [43] and Katoh [58]. Figure 13 shows a compilation Weibull plot of flexural strength of non-irradiated and irradiated Rohm \& Haas CVD SiC taken from the two separate irradiation experiments carried out by the two authors. The sample population was in excess of 30 for each case. In Figure 13(a) the data was arranged by irradiation temperature including data for non-irradiated and 1.5-4.6 $\times 10^{26} \mathrm{n} / \mathrm{m}^{2}(\mathrm{E}>0.1 \mathrm{MeV})$ dose range. It is apparent that Weibull modulus decreased by irradiation and seemingly dependent on irradiation temperature.

Statistical scatter in fracture stress of brittle materials often increases due to harsh handling of the samples. Unfortunately, it is often inevitable to introduce undesired edge flaws during the capsule disassembly and handling of ceramic samples in a hot cell in neutron irradiation experiments. The work of Katoh, on identical material and irradiated at the same temperature as the Newsome work, is at a slightly higher irradiation dose than the data of Newsome. As seen in Figure 13(b) the effect on the Weibull modulus undergoes a similar trend to that of Newsome, though the modulus for the $773 \mathrm{~K}$ irradiation of Katoh is not in agreement, actually showing a slight increase. Given the data discussed on the effect of irradiation on the Weibull modulus and scale parameter of CVD SiC bend bars, it is clear that the material is somewhat strengthened whereas the effect of irradiation on the Weibull modulus of fracture stress remains unclear. 

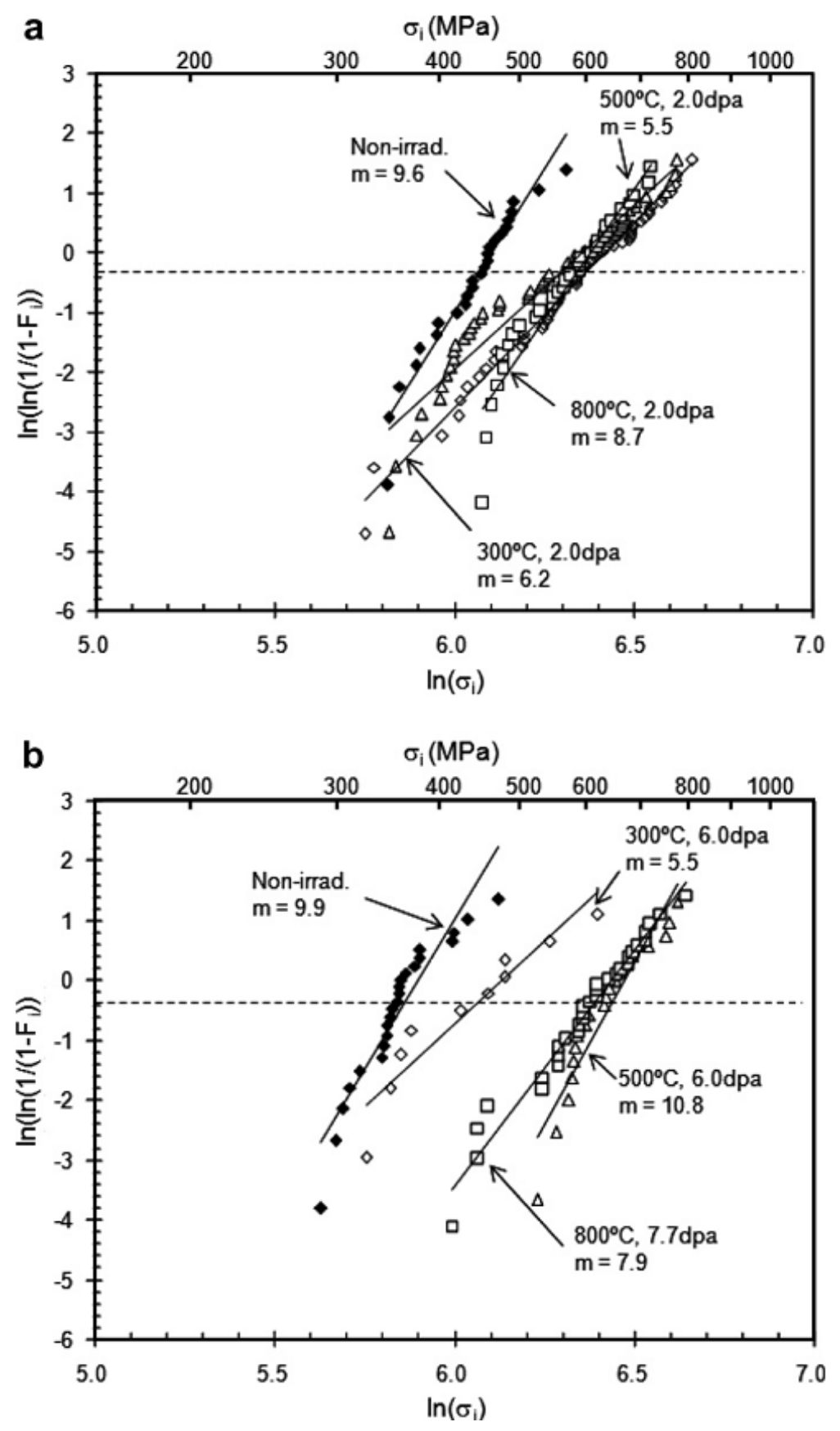

Figure 13: Effect of neutron irradiation on statistical fracture strength of high purity CVD SiC. $[43,58]$

For additional information, the effect of neutron irradiation on statistical flexural strength of the matrix material of the NITE $\mathrm{SiC} / \mathrm{SiC}$ is presented in Figure 14 [62]. The irradiation dose and temperature in that work were $0.6 \mathrm{dpa}$ and $750^{\circ} \mathrm{C}$, respectively. This result indicates minor yet statistically insignificant effect of radiation in this particular condition on the strength of the 
NITE matrix material. Further study will be required in order to assess the radiation effect on NITE matrix material.

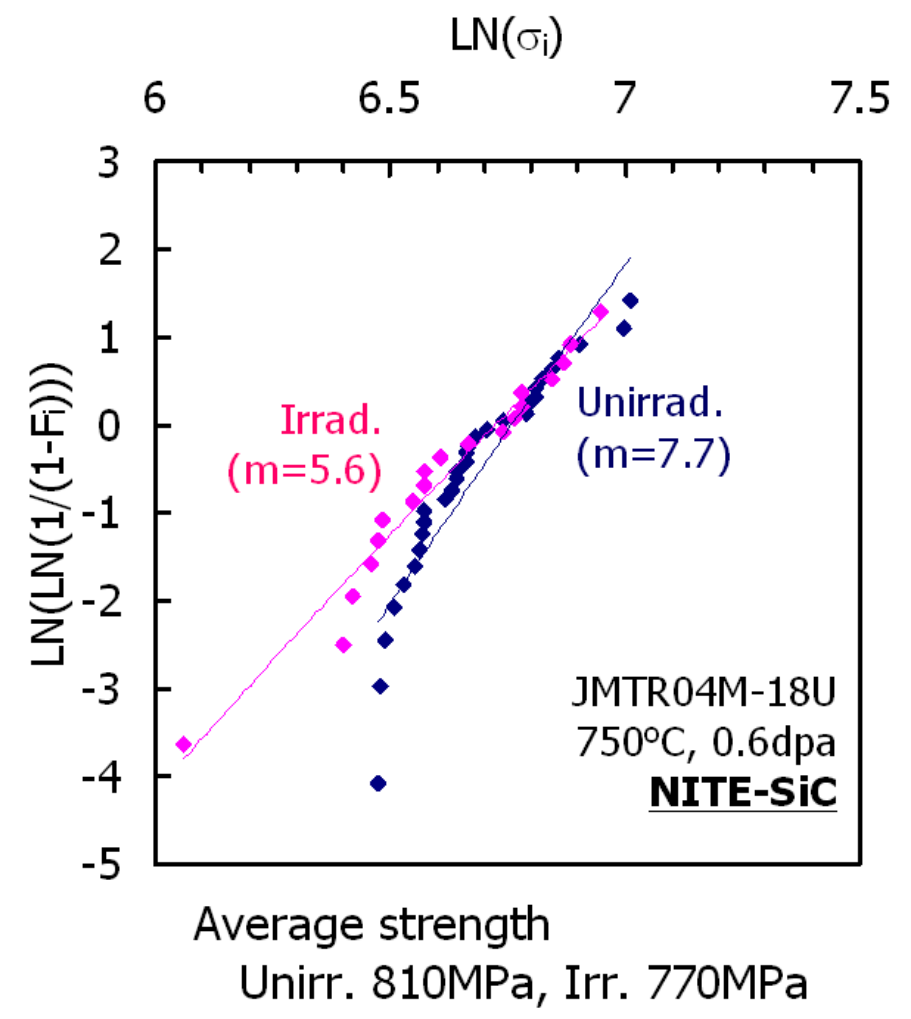

Figure 14: Effect of neutron irradiation on fracture strength of liquid phase sintered SiC. [62]

\subsubsection{Radiation effect on strength of $\mathrm{SiC} / \mathrm{SiC}$}

Published literature reporting the neutron irradiation effects on mechanical properties of the Generation III CVI SiC/SiC is summarized in Table 8 [25, 43, 63-67]. The first result was reported in 2000 by Snead et al. Recent work tends to involve a detailed properties evaluation by tensile testing and extended hysteresis analysis. 
Table 8: Summary of neutron irradiation effects on mechanical properties of advanced fiber CVI SiC/SiC. [25, 43, 63-66, 68]

\begin{tabular}{|c|c|c|l|}
\hline Reference & Material & $\begin{array}{c}\text { Irradiation } \\
\text { Condition }\end{array}$ & \multicolumn{1}{c|}{ Observation } \\
\hline $\begin{array}{c}\text { Snead et al, } \\
2000\end{array}$ & Hi-Nicalon S / CVI & $400^{\circ} \mathrm{C}, \sim 1 \mathrm{dpa}$ & - Slight increase or no change in flexural strength \\
\hline $\begin{array}{c}\text { Hinoki et al, } \\
2002\end{array}$ & $\begin{array}{c}\text { Hi-Nicalon S / CVI } \\
\text { Tyranno-SA1 / CVI }\end{array}$ & $\begin{array}{c}300^{\circ} \mathrm{C}, 6 \mathrm{dpa} \\
800^{\circ} \mathrm{C}, 7.7 \mathrm{dpa}\end{array}$ & $\begin{array}{l}\text { - Slight increase or no change in flexural strength } \\
\text { - Slight increase or no change in flexural PLS } \\
\text { - Slight decrease in flexural modulus }\end{array}$ \\
\hline $\begin{array}{c}\text { Nozawa et al, } \\
2004\end{array}$ & Hi-Nicalon S / CVI & $800^{\circ} \mathrm{C}, 7.7 \mathrm{dpa}$ & $\begin{array}{l}\text { - Slight increase in UTS } \\
\text { - Slight decrease in tensile PLS } \\
\text { - No significant change in tensile modulus }\end{array}$ \\
\hline $\begin{array}{c}\text { Hegeman et } \\
\text { al, 2005 }\end{array}$ & $\begin{array}{c}\text { SA-Tyrannohex } \\
\text { Hi-Nicalon S / CVI }\end{array}$ & $\begin{array}{c}600 / 900^{\circ} \mathrm{C}, \sim 2 \\
\mathrm{dpa}\end{array}$ & $\begin{array}{l}\text { - Little change in flexural strength } \\
\text { - No or slight decrease in dynamic modulus }\end{array}$ \\
\hline $\begin{array}{c}\text { Nozawa et al, } \\
2005\end{array}$ & Hi-Nicalon S / CVI & $\begin{array}{c}800 / 1000^{\circ} \mathrm{C}, 1 \\
\mathrm{dpa}\end{array}$ & $\begin{array}{l}\text { - Slight increase in UTS } \\
\text { - No or little change in tensile PLS } \\
\text { - Decrease in tensile modulus }\end{array}$ \\
\hline $\begin{array}{c}\text { Ozawa et al, } \\
2007\end{array}$ & $\begin{array}{c}\text { Hi-Nicalon S / CVI } \\
\text { Tyranno-SA3 / CVI }\end{array}$ & $\begin{array}{c}750^{\circ} \mathrm{C}, 12 \mathrm{dpa} \\
\text { - No change in UTS } \\
\text { - Slight increase or no change in tensile PLS } \\
\text { - Slight decrease in tensile modulus }\end{array}$ \\
\hline $\begin{array}{c}\text { Newsome et } \\
\text { al, 2007 }\end{array}$ & Hi-Nicalon S / CVI & $\begin{array}{c}300 / 500 / 800^{\circ} \mathrm{C}, \\
<~ 3.4 \mathrm{dpa}\end{array}$ & $\begin{array}{l}\text { - Slight decrease in flexural strength, flexural PLS, } \\
\text { and flexural modulus }\end{array}$ \\
\hline
\end{tabular}

The effect of neutron irradiation on strength of the Hi-Nicalon ${ }^{\mathrm{TM}}$ Type-S, PyC interphase, unidirectional CVI composites irradiated in High Flux Isotope Reactor (HFIR) and Japan Materials Test Reactor (JMTR) was recently evaluated [66, 69]. In the HFIR experiment, the previous preliminary conclusion that $\mathrm{SiC} / \mathrm{SiC}$ in this class likely maintains strength after neutron irradiation to $7.7 \times 10^{25} \mathrm{n} / \mathrm{m}^{2}\left(\mathrm{E}>0.1 \mathrm{MeV}\right.$ ) at $800^{\circ} \mathrm{C}$ obtained by four-point flexural tests appeared to hold true [69]. The effect of neutron irradiation in $200-800^{\circ} \mathrm{C}$ temperature range on flexural strength of the $\mathrm{SiC} / \mathrm{SiC}$ with fibers of the three generations is given in Figure 15, which shows no strength degradation for the Generation III materials. Whereas the previous flexural tests only indicated the lack of either the composite proportional limit stress (PLS) reduction or the severe fiber tensile strength degradation, the tensile tests revealed that in fact the composite UTS slightly increases while other properties such as PLS and modulus does not significantly degrade after irradiation. Moreover, the detailed analysis on the loading - unloading behavior provided insight into the effect of irradiation on the bonding and frictional properties of the fiber - matrix interface and the residual thermal stress. The result for the identical material irradiated in JMTR has shown that the irradiation effect at $1-2 \times 10^{25} \mathrm{n} / \mathrm{m}^{2}(\mathrm{E}>0.1 \mathrm{MeV})$ at 800 and $1000^{\circ} \mathrm{C}$ on tensile properties is essentially same as that at the higher dose and $800^{\circ} \mathrm{C}$ [66]. 


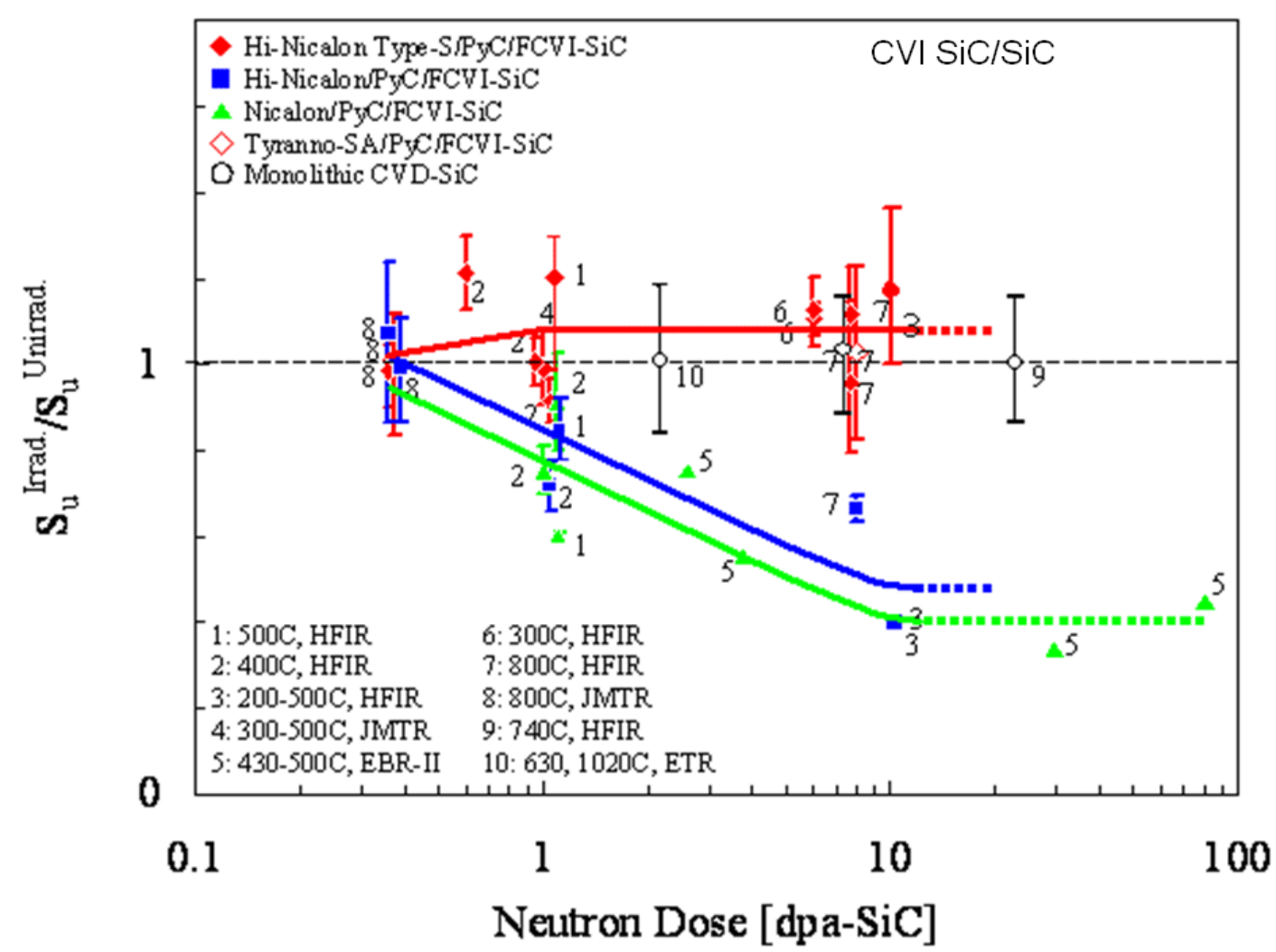

Figure 15: Effect of neutron irradiation on flexural strength of SiC/SiC. [70]

PIE of the Generation III SiC fiber composites neutron-irradiated to the highest dose so far has been completed in Japan. In that campaign, 2D Hi-Nicalon ${ }^{\mathrm{TM}}$ Type-S and Tyranno ${ }^{\mathrm{TM}}-\mathrm{SA} 3$, PyC interphase, CVI composites infiltrated at ORNL had been irradiated in JOYO (JOYO is not an acronym) fast breeder reactor (Japan Atomic Energy Agency, Oarai, Japan) to the maximum dose of $1.5 \times 10^{26} \mathrm{n} / \mathrm{m}^{2}(\mathrm{E}>0.1 \mathrm{MeV})$ at $750^{\circ} \mathrm{C}$ [67]. As seen in the representative stress - strain curves in Figure 16, the test result indicated no significant changes in tensile properties for composites with both types of fibers, demonstrating the competitiveness of Tyranno-SA3 fiber composites in terms of stability under neutron irradiation. The tensile hysteresis analysis and fractography did not imply a major degradation in interfacial frictional stress. However, as a major degradation of graphite strength is expected to take place at about this dose level, irradiation to even higher dose will be essential to determine the very high dose effect on the composite strength. 

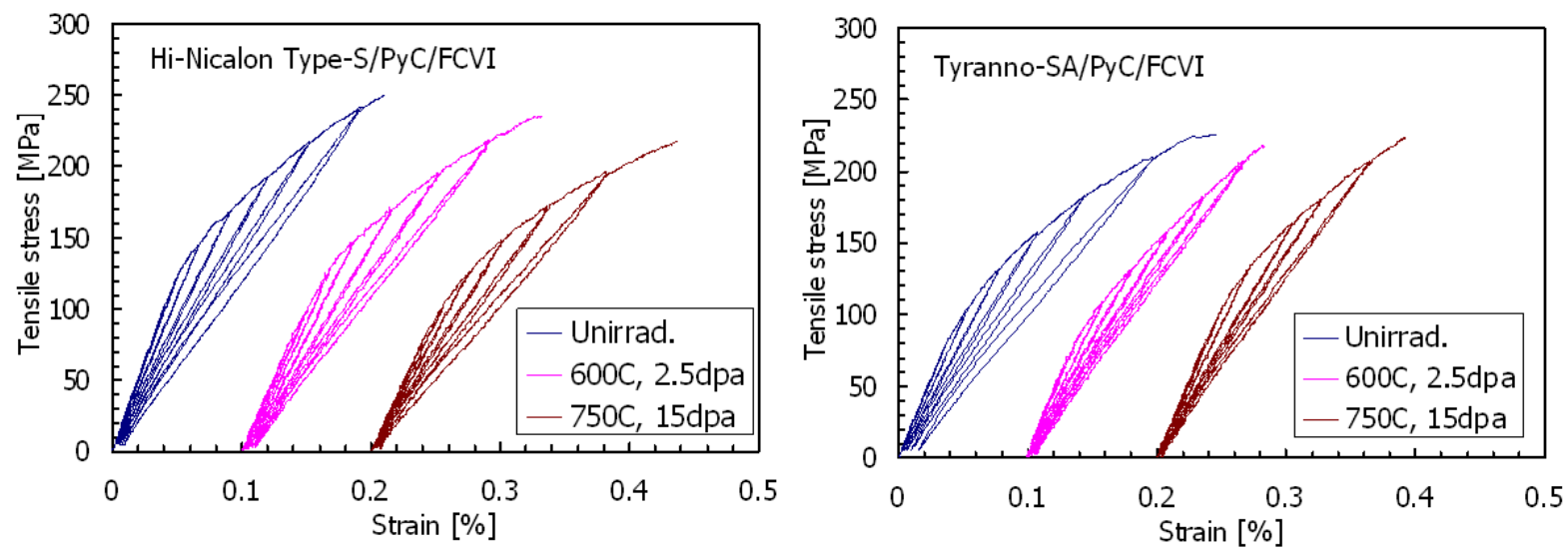

Figure 16: Effect of neutron irradiation on tensile properties of SiC/SiC. [68]

\subsubsection{Thermal conductivity}

Due to a low density of valence band electrons, thermal conductivity of most ceramic materials, $\mathrm{SiC}$ in particular, is based on phonon transport. For a ceramic at the relatively high temperature associated with nuclear applications the conduction heat can be generally described by the strength of the individual contributors to phonon scattering: grain boundary scattering $\left(1 / \mathrm{K}_{\mathrm{gb}}\right.$ ), phonon-phonon interaction (or Umklapp scattering $1 / \mathrm{K}_{\mathrm{u}}$ ), and defect scattering $\left(1 / \mathrm{K}_{\mathrm{d}}\right)$. Because scattering for each of these elements occurs at differing phonon frequencies and can be considered separable, the summed thermal resistance for a material can be simply described as the summation of the individual elements; i.e., $1 / \mathrm{K}=1 / \mathrm{K}_{\mathrm{gb}}+1 / \mathrm{K}_{\mathrm{u}}+1 / \mathrm{K}_{\mathrm{d}}$. The non-irradiated thermal conductivity of $\mathrm{SiC}$ is highly dependent on the nature of the material (grain size, impurities, etc.) and the temperature. While materials can be optimized for low intrinsic defect, impurity, and grain boundary scattering, the temperature dependent phonon scattering cannot be altered and tends to dominate at high temperature (above about $673 \mathrm{~K}$ for $\mathrm{SiC}$ ).

The effect of irradiation on $\mathrm{SiC}$ in the temperature range of $\sim 423-1073 \mathrm{~K}$ (the point defect regime discussed in Section 2.5.4) is to produce simple defects and defect-clusters that very effectively scatter phonons. For ceramics possessing high thermal conductivity the irradiationinduced defect scattering quickly dominates, with saturation thermal conductivity typically achieved by a few dpa (or a few $\times 10^{25} \mathrm{n} / \mathrm{m}^{2}$ of fast fluence). Moreover, as the irradiation-induced defect scattering exceeds the phonon-phonon scattering, the temperature dependence of thermal conductivity is much reduced or effectively eliminated. In recent work by Snead [71], the degradation in thermal conductivity has been analyzed in terms of the added thermal resistance caused by the neutron irradiation. CVD $\mathrm{SiC}$ was shown to have a similar accumulation of 
thermal defect resistance as a hot-pressed form of $\mathrm{SiC}$ with substantially lower $(\sim 90 \mathrm{~W} / \mathrm{m} \cdot \mathrm{K})$ non-irradiated thermal conductivity. The utility of this finding is that if the thermal defect resistance is mapped as a function of irradiation temperature and dose for a form of high purity CVD SiC it can be applied to determine the thermal conductivity to any high-purity CVD SiC, independent of starting thermal conductivity.

The thermal conductivity degradation discussed to this point has been for the point defect regime. For irradiation above this temperature (the non-saturatable void swelling regime), the thermal properties are not expected to saturate (at least at low dpa). The primary reason for this is that the formation of voids and other complex defects in the high temperature regime contribute to phonon scattering, and these defects will not saturate. The thermal conductivity degradation in the high temperature regimes is less dramatic. This is opposite to the behavior in the lower temperature, saturatable regime, where high swelling corresponds to extreme reduction in thermal conductivity. Unfortunately, the data on thermal conductivity reduction in the nonsaturatable regime is limited, and given the lack of knowledge of the specific defects governing the phonon scattering, it is not possible to predict behavior outside of the existing data-set.

The thermal conductivity of irradiated composites is determined by the irradiated thermal conductivity of the constituents in exactly the same manner with the non-irradiated thermal conductivity of composites. Examples of the measured thermal conductivities for high purity CVD SiC and Hi-Nicalon Type-S CVI SiC/SiC are shown as a function of irradiation dose in Figure 17. In this experiment, thermal conductivity was measured at room temperature. The data clearly indicate that the thermal conductivity degradation saturates by 1 or a few dpa in this temperature regime. It should be noted that the composite used represents the lowest thermal conductivity materials in this material class. Constitutive models described in Section 2.4.3 have successfully demonstrated their capability to explain the irradiated composite thermal conductivity.

Data presented thus far have been limited to measurement of thermal conductivity at roomtemperature. For non-irradiated ceramics, there is a dramatic dependence of thermal conductivity on measurement temperature. Temperature dependence of defect scattering is not presently understood. 


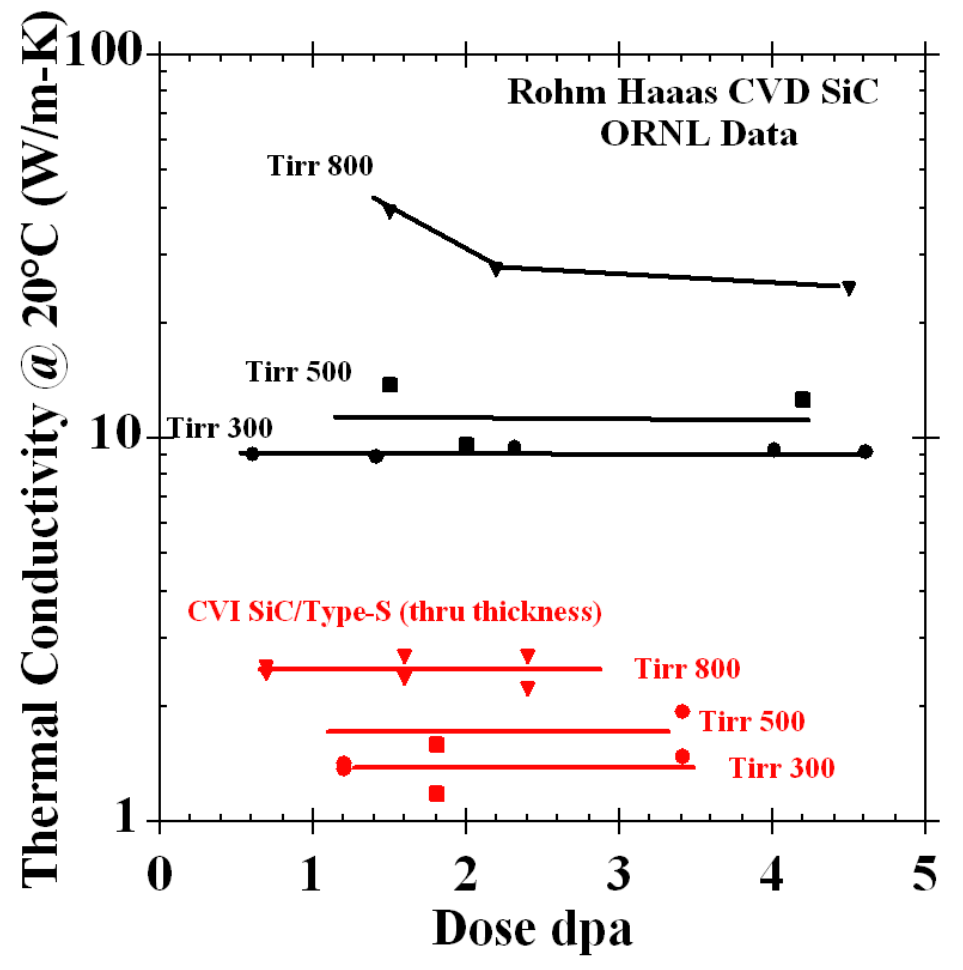

Figure 17: Effect of neutron irradiation on thermal conductivity of SiC/SiC. [72]

\subsubsection{Radiation-induced swelling and microstructure}

The neutron-induced swelling of $\mathrm{SiC}$ has been well studied for low and intermediate temperatures ( 293-1273 K). The irradiation-induced microstructural evolution of CVD SiC is to some extent understood and has been reviewed recently by Katoh et al. [73] However, the contribution of the defects themselves to the swelling in $\mathrm{SiC}$ is less understood. For irradiation temperatures less than about $423 \mathrm{~K}$, accumulation of strain due to the irradiation-produced defects can exceed a critical level above which the crystal becomes amorphous. This has been shown for both self-ion irradiation and under fast neutron irradiation [74-76]. As shown by Katoh et al., the swelling at $323 \mathrm{~K}$ under self-ion irradiation increases logarithmically with dose until amorphization occurs. The swelling of neutron- and ion-amorphized $\mathrm{SiC}$ has been reported to be $10.8 \%$ for $343 \mathrm{~K}$ irradiation. However, there is evidence that the density of amorphous SiC will depend on the conditions of irradiation (dose, temperature, etc.) [77].

For temperatures above the critical amorphization temperature $(423 \mathrm{~K})$ the swelling increases logarithmically with dose until it approaches saturation, with a steady decrease in the saturation swelling level with increasing irradiation temperature. The dose exponents of swelling during the logarithmical period are in many cases close to $2 / 3$ (until saturation is reached), as 
predicted by a kinetic model assuming planar geometry for interstitial clusters [78-79]. The saturation of swelling, in addition to other irradiation-induced phenomena such as thermal conductivity change and Young's modulus decrease, is believed to be due to the strong sink effect provided by self defects that homogeneously accumulate in the matrix at extremely high densities. This temperature regime is generally referred to as the point-defect swelling regime and can be roughly set between 423 and $1273 \mathrm{~K}$. Swelling in this range approaches the saturation before a few dpa is reached. The saturated swelling in CVD SiC is plotted in Figure 18 as a function of irradiation temperature. The swelling of $\mathrm{SiC}$ is highly temperature dependent. For the data given in Figure 18, the saturation values of swelling at $473 \mathrm{~K}$ are several times that for 1073 $\mathrm{K}$ irradiation. This reduced swelling with increasing irradiation temperature is primarily attributed to enhanced recombination of cascade produced Frenkel defects due to lower interstitial clustering density for higher temperatures. The second characteristic swelling behavior to note is that the swelling saturates at a relatively low dose. For damage levels of a few dpa (typically months in a fission power core) the swelling in the point-defect recombination range has found its saturation value. The significant scatter of the data points for $>1473 \mathrm{~K}$ in Figure 18 implies the onset of fluence-dependent swelling at around that temperature.

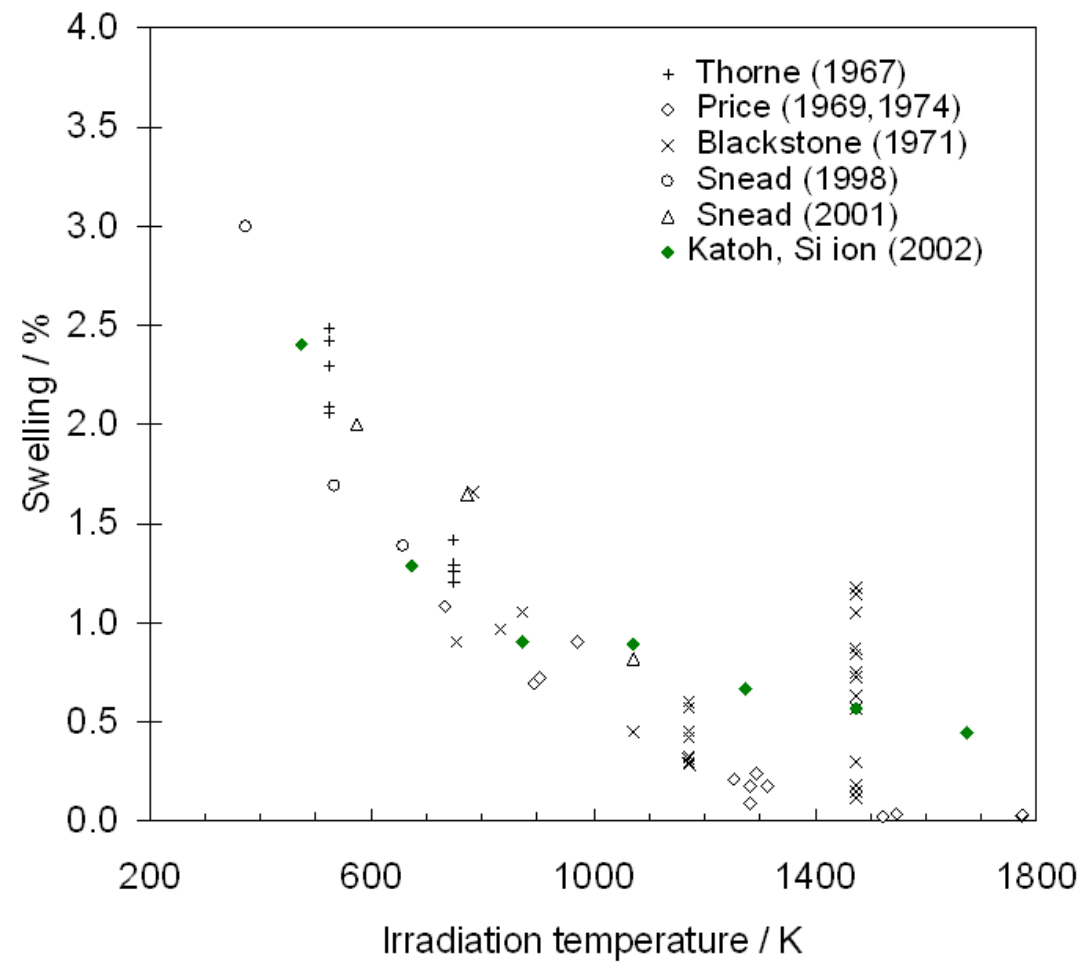

Figure 18: Effect of neutron irradiation on saturatable swelling of SiC/SiC. [80] 
At higher temperatures such as 1173-1673 K [81-82], Frank faulted loops of interstitial type become the dominant defects observed by transmission electron microscopy. It has also been reported that Frank faulted loops appear for lower temperature neutron irradiation at extremely high doses approaching 200 dpa [83]. At temperatures where vacancies are sufficiently mobile, vacancy clusters can be formed. Three-dimensional cavities (or voids) are the only vacancy clusters known to commonly develop in irradiated SiC. Positron annihilation and electron paramagnetic resonance studies have shown that the silicon vacancy in cubic SiC becomes mobile at 1073-1173 K [84-85]. Therefore, it would not be surprising for void swelling to take place at as low as $\sim 1273 \mathrm{~K}$ at high doses, particularly for low damage rate irradiations.

Recent work has been carried out in the $\sim 1173-1773 \mathrm{~K}$ range for high purity CVD SiC irradiated in HFIR. Of particular significance to that experiment is the confidence in irradiation temperature owing to the melt-wire passive thermometry. Recent TEM imaging by Kondo [86] clearly shows the evolution of complex defects, e.g., significant growth of voids commences at $1723 \mathrm{~K}$, well faceted voids appeared to be tetrahedrally bounded by $\{111\}$ planes, which likely provides the lowest surface energy in cubic SiC. In many cases, voids appeared to be aligned on stacking faults at all temperatures. However, intragranular voids unattached to stacking faults were also commonly observed at $1723 \mathrm{~K}$. Evolution of the dislocation loops into dislocation networks was confirmed for irradiation at $1723 \mathrm{~K}$.

Figure 19 plots both historical data and published and previously unpublished data from a recent high-temperature irradiation study [87]. A divergence from point-defect "saturated" swelling to non-saturated swelling is observed in the 1073-1473 K range, though additional data in this temperature range as a function of fluence would be required to precisely define such behavior. Above $1273 \mathrm{~K}$, there exists a clear non-saturated swelling behavior for CVD SiC. The two divergent curves drawn in Figure 19 represent data taken at nominally $\sim 2$ and $\sim 5 \times 10^{25} \mathrm{n} / \mathrm{m}^{2}$ $(\mathrm{E}>0.1 \mathrm{MeV}$ ) (assumed 2 and $5 \mathrm{dpa}$ ). In the 1373-1473 $\mathrm{K}$ temperature range, volumetric swelling is apparently at a minimum though it likely increases with dose. Clearly the swelling in this temperature range has not saturated by $5 \mathrm{dpa}$. This finding is somewhat surprising given the apparent mobility of the silicon vacancy above $1273 \mathrm{~K}$ found experimentally in cubic SiC (the CVD SiC of this study is highly faulted FCC). Above this minimum in swelling the data indicates a continual swelling increase to the highest irradiation temperature of $\sim 1773-1873 \mathrm{~K}$. It was also noted in the study by Snead et al. [87] that for $\sim 1773 \mathrm{~K}$ surface reaction between $\mathrm{SiC}$ and the graphite holder had taken place. Though, a loss of silicon from the surface can not be ruled out. 


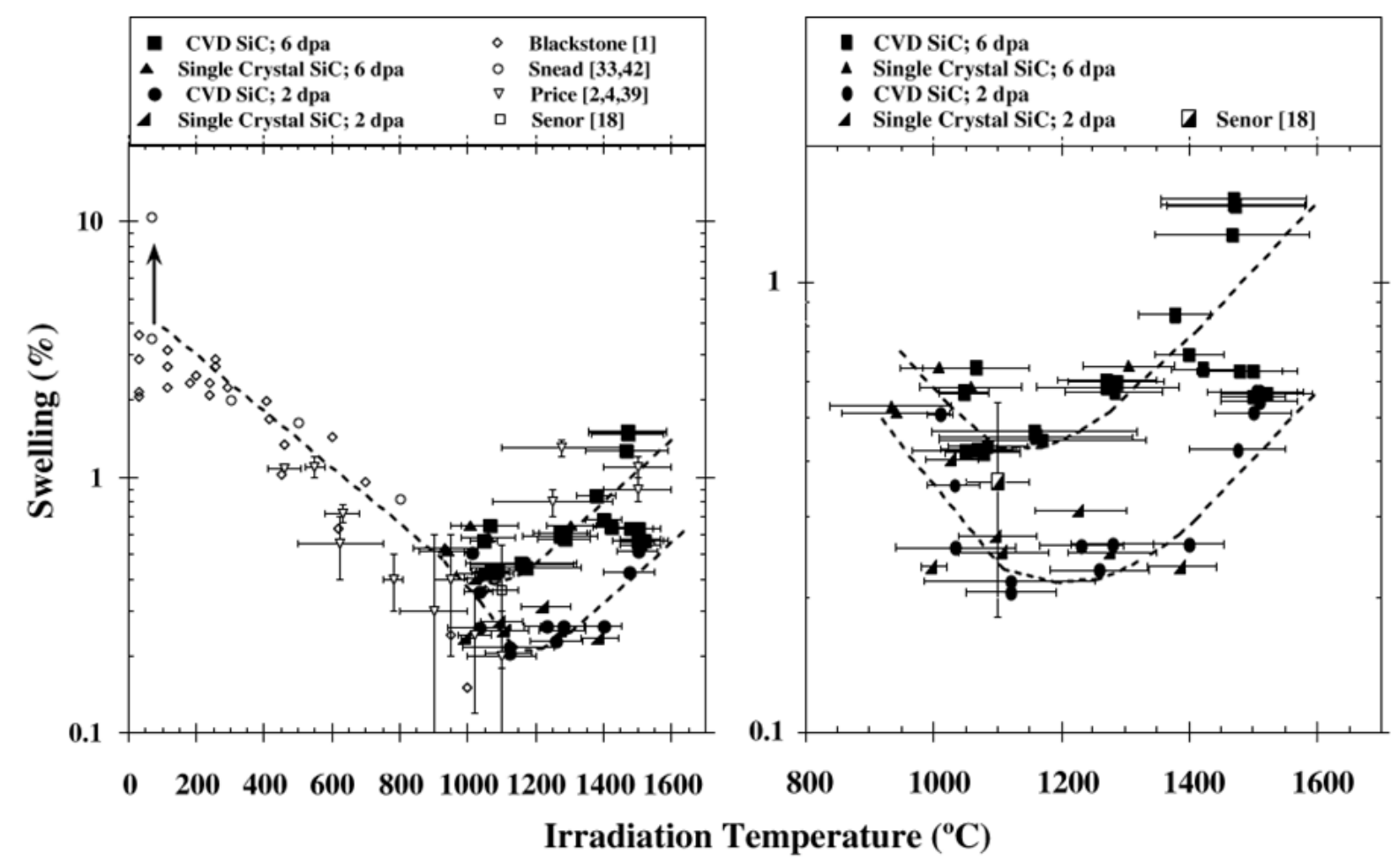

Figure 19: Effect of neutron irradiation on unstable swelling of SiC/SiC. [87]

As mentioned earlier, the microstructural evolution of irradiated $\mathrm{SiC}$ is to limited extent understood, at least for temperatures up to $\sim 1373 \mathrm{~K}$ for neutron irradiation and up to $\sim 1673 \mathrm{~K}$ for self ion irradiation. The swelling near the critical amorphization temperature $(\sim 23 \mathrm{~K})$ is classically described as the differential strain between the single interstitial, or tiny interstitial clusters, immobile vacancies, and antisite defects. As the temperature increases above the critical amorphization temperature the number of defects surviving the cascade are reduced and the mobility of both silicon and carbon interstitials becomes significant. For temperatures exceeding $\sim 1273 \mathrm{~K}$ microstructural studies have noted the presence of both Frank loops and tiny voids indicating limited mobility of vacancies.

A map of microstructural development in high purity CVD SiC during irradiation is presented in Figure 20.[59] The map shows the summary of microstructural features observed after neutron and self ion irradiation as a function of irradiation temperature and fluence. Note that this compilation is intended to present a general trend rather than results of strict interpretation of detailed microstructural examination, and will be subject to future revision when more data are made available. It should be noted that 1) Price claimed small dislocation loops produced at $<1000^{\circ} \mathrm{C}$ to be Frank loops but did not present an explicit evidence. Price reported only voids for 
$>1200^{\circ} \mathrm{C}$, which does not mean that no dislocation features were observed; 2) Irradiation temperatures for $>50$ dpa data in Yano et al work is highly uncertain; 3) Senor, et al., speculated small dislocation loops produced at $1100^{\circ} \mathrm{C}$ to be Frank loops but did not present evidence; and 4) Self ion irradiated microstructures may have been influenced by the dose rate effect, particularly at very high temperatures.

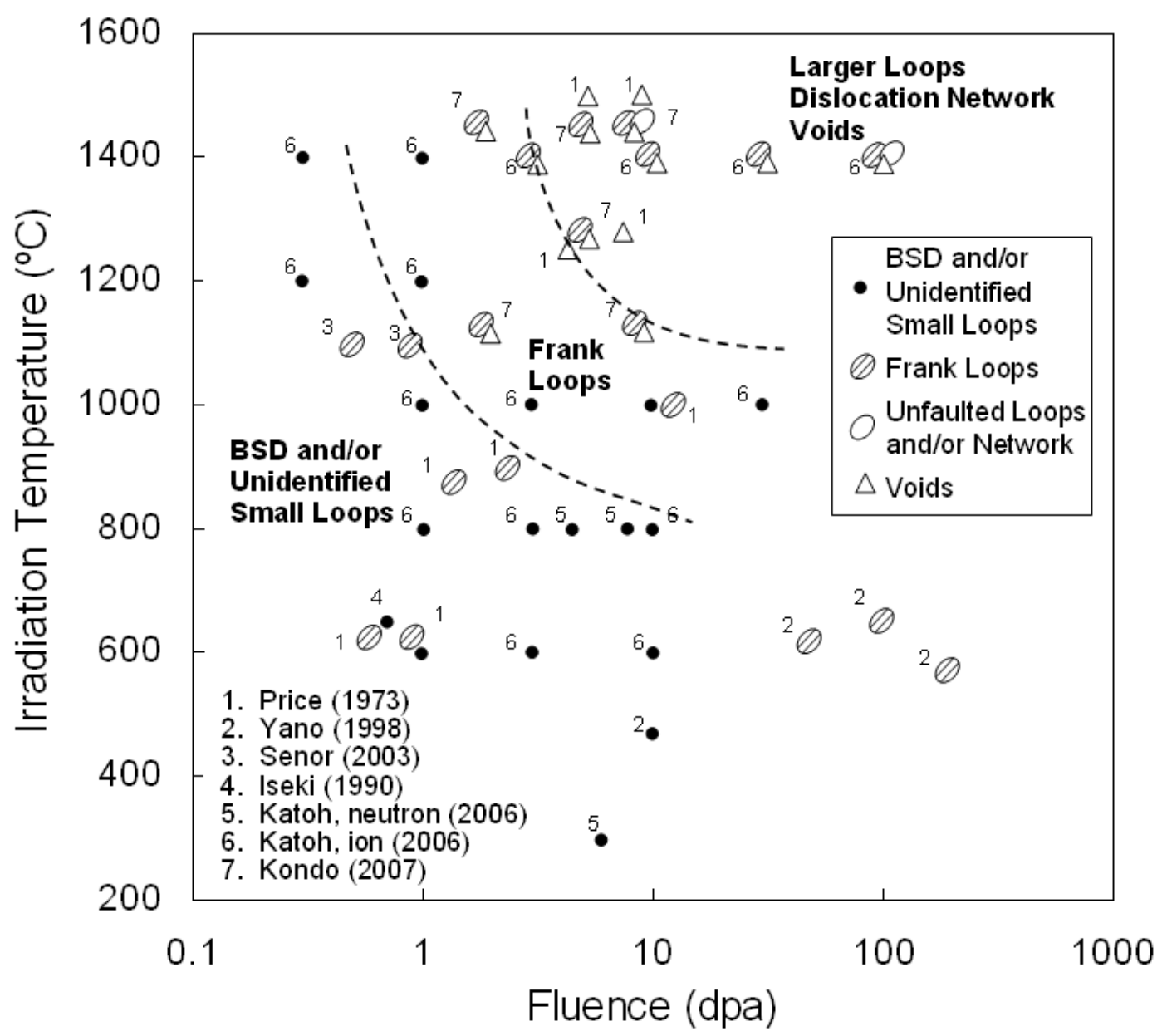

Figure 20: Microstructural development in high purity CVD SiC during neutron irradiation. [59]

\subsubsection{Irradiation Creep}

The definition of irradiation creep is the difference in dimensional changes between a stressed and an unstressed sample irradiated under identical conditions. Irradiation creep is important for 
structural materials for nuclear services since it is a major contributor to the dimensional instability of irradiated materials at temperatures where thermal creep is negligible. However, studies on irradiation creep of $\mathrm{SiC}$ (-based materials) have so far been very limited, though it is of high importance for understanding the behavior of load-bearing components.

Price published the result of the irradiation creep study on CVD SiC in 1977 [88]. In that work, elastically bent strip samples of CVD SiC were irradiated in a fission reactor, and the steady-state creep compliance was estimated to be in the order of $10^{-38}\left[\mathrm{~Pa} \cdot \mathrm{dpa} / \mathrm{m}^{2}(\mathrm{E}>0.18\right.$ $\mathrm{MeV})]^{-1}$ at 1053-1403 K. Scholz and co-workers measured the transient creep deformation of SCS-6 CVD SiC-based fiber, which was torsionally loaded under penetrating proton or deuteron beam irradiation [89-92]. They reported several important observations including the linear stress and flux dependency of the tangential primary creep rate at $873 \mathrm{~K}$, and the negative temperature dependence of primary creep strain at the same dose. Recently, Katoh et al. determined the bend stress relaxation (BSR) creep in Rohm and Haas CVD SiC and Hoya monocrystalline 3C-SiC during irradiation in HFIR and JMTR at 673-1353 K [93].

In the BSR irradiation creep experiment by Katoh et al., creep strain for CVD SiC exhibited weak temperature dependence at $<0.7 \mathrm{dpa}$ in the $\sim 673-\sim 1303 \mathrm{~K}$ temperature range, whereas a major transition at higher doses likely exists between $\sim 1223$ and $\sim 1353 \mathrm{~K}$. Below $\sim 1223 \mathrm{~K}$, the creep strain appeared highly non-linear with neutron fluence due to the early domination of the transient irradiation creep. The transient creep was speculated to have been caused by the rapid development of defect clusters and the structural relaxation of as-grown defects during early stages of irradiation damage accumulation. At $\sim 1353 \mathrm{~K}$, irradiation creep mechanisms which are common to metals are likely operating.

In metals, steady-state irradiation creep rates are generally proportional to the applied stress and neutron (or other projectiles) flux, $\phi$ [94-95], and therefore irradiation creep compliance, $B$, has been conveniently introduced: $\dot{\varepsilon}_{\text {ic }}=\sigma(B \phi+D \dot{S})$, where $S$ is void swelling and $D$ is a coefficient of swelling-creep coupling. Ignoring the swelling-creep coupling term, preliminary estimations of the steady-state irradiation creep compliance of CVD SiC were given to be $2.7 \pm$ $2.6 \times 10^{-7}$ and $1.5 \pm 0.8 \times 10^{-6}(\mathrm{MPa}-\mathrm{dpa})^{-1}$ at $\sim 873-1223 \mathrm{~K}$ and $\sim 1353 \mathrm{~K}$, respectively. If linear-averaged, creep compliances of $1-2 \times 10^{-6}(\mathrm{MPa}-\mathrm{dpa})^{-1}$ were obtained for doses of 0.6-0.7 dpa at all temperatures. Monocrystalline 3C SiC samples exhibited significantly smaller transient creep strain by $0.7 \mathrm{dpa}$ and greater subsequent deformation when loaded along $<011>$ direction.

To better define the irradiation creep behavior of $\mathrm{SiC}$ and the underlying physical mechanisms, it will be essential to further examine the stress dependence, dose dependence, effect of 
crystallographic orientation, microstructures of the crept samples, and the coupling between irradiation creep and swelling.

\subsubsection{Summary of radiation effect issues}

As the summary, irradiation effect issues for $\mathrm{SiC} / \mathrm{SiC}$ composites and their constituents are listed in Table 9 along with the present status of studies and assessment. All the issues are relevant to application of $\mathrm{SiC} / \mathrm{SiC}$ to salt-cooled reactor fuel assembly; some of them are likely linked with the critical feasibility and/or critical design issues.

Finally, the synergistic effects of neutron irradiation and chemical environment in salt-cooled reactors are unknown. This issue will also have to be examined. 
Table 9: Irradiation effect issues in SiC-based ceramics and composites and present status of assessment activities.

\begin{tabular}{|c|c|}
\hline Issue & Status of Assessment \\
\hline $\begin{array}{l}\text { Irradiation effect } \\
\text { on strength }\end{array}$ & $\begin{array}{l}\text { - No significant strength degradation confirmed up to } 12 \mathrm{dpa} \text { at } 750^{\circ} \mathrm{C} \text { or } 5 \mathrm{dpa} \text { at } 1100^{\circ} \mathrm{C} \text {. } \\
\text { - High dose ( }>10 \mathrm{dpa} \text { ) irradiation effect on intrinsic mechanical properties of high purity } \\
\mathrm{SiC} \text { has not been confirmed. } \\
\text { - Potential mechanical property issue exists due to anticipated structural instability of } \\
\text { carbon interphase at high doses. } \\
\text { - Constitutive models for mechanical properties of irradiated } \mathrm{SiC} / \mathrm{SiC} \text { are being developed. }\end{array}$ \\
\hline $\begin{array}{l}\text { Thermal } \\
\text { conductivity } \\
\text { degradation }\end{array}$ & $\begin{array}{l}\text { - Fairly comprehensive experimental data for intrinsic thermal conductivity of irradiated } \\
\text { high purity } \mathrm{SiC} \text { have been published and/or available for low dose }(<10 \mathrm{dpa}) \text { at } 200-1500^{\circ} \\
\mathrm{C} \text {. } \\
\text { - High dose ( }>10 \mathrm{dpa}) \text { data are not available. } \\
\text { - Constitutive models for thermal conductivity of irradiated } \mathrm{SiC} / \mathrm{SiC} \text { are being developed. } \\
\text { - Origin of thermal conductivity degradation is not exactly known. }\end{array}$ \\
\hline $\begin{array}{l}\text { Point-defect } \\
\text { swelling }\end{array}$ & $\begin{array}{l}\text { - Fairly comprehensive experimental data for irradiated high purity } \mathrm{SiC} \text { have been } \\
\text { published and/or available for low dose }(<\sim 4 \mathrm{dpa}) \text { at } 200-1000^{\circ} \mathrm{C} \text {. } \\
\text { - Higher dose data are not available. } \\
\text { - Point-defect swelling is anticipated to cause secondary stress and/or deformation when } \\
\text { significant temperature gradient exists. } \\
\text { - Source of point-defect swelling is not exactly known. }\end{array}$ \\
\hline Void swelling & $\begin{array}{l}\text { - High-purity, beta-phase CVD SiC has been confirmed to develop significant void swelling } \\
\text { at }>1200^{\circ} \mathrm{C} \text { at }<10 \text { dpa. } \\
\text { - Fairly comprehensive data available from neutron and ion irradiation experiments. } \\
\text { - Little is known about driving/control mechanisms, effect of microstructures, high dose } \\
\text { phenomena, etc. }\end{array}$ \\
\hline Irradiation creep & $\begin{array}{l}\text { - Very little is known about irradiation creep phenomena and mechanisms for high purity } \\
\text { SiC. Steady-state irradiation creep is particularly unknown. } \\
\text { - Study on transient irradiation creep in } \mathrm{SiC} \text { has recently been initiated. }\end{array}$ \\
\hline $\begin{array}{l}\text { Irradiation- } \\
\text { enhanced slow } \\
\text { crack growth }\end{array}$ & $\begin{array}{l}\text { - Slow crack growth in } \mathrm{SiC} / \mathrm{SiC} \text { in oxidative, non-irradiation environment is being studied. } \\
\text { - Recent modeling work suggests that fiber irradiation creep may dictate slow crack growth } \\
\text { in } \mathrm{SiC} / \mathrm{SiC} \text {. }\end{array}$ \\
\hline
\end{tabular}

\subsection{TEST STANDARDS AND NON-DESTRUCTIVE EVALUATION}

Compared to structural metallic alloys, $\mathrm{SiC} / \mathrm{SiC}$ are relatively new materials. Although highstrength $\mathrm{SiC}$ fibers first became available in the 1960's, today's $\mathrm{SiC} / \mathrm{SiC}$ composites are the result of significant $R \& D$ efforts during the last 20 years in the aerospace and power generation industries. Unlike other structural materials, initial standardization efforts for $\mathrm{SiC} / \mathrm{SiC}$ composites were concurrent with their development because it was recognized that their commercial diffusion and industrial acceptance could be hampered by lack of standard test methods, databases or design codes [96]. 
Numerous standardized mechanical testing methodologies have been developed for characterizing the mechanical properties of engineering materials. Noteworthy are the standards of the ASTM International. Typically these standards are based on testing experience including both independent research and round-robin evaluations. Such standards, so developed, are the result of consensus on the part of ASTM participants and therefore address the needs of the participants at the time the standards are developed.

In the United States, sub-committee C28.07 on Ceramic Matrix Composites of the ASTM International has spearheaded the widespread introduction of standard test methods for $\mathrm{SiC} / \mathrm{SiC}$ and other ceramic matrix composites [96]. These standards have primarily concentrated on the evaluation of test coupons to determine the intrinsic mechanical properties of these materials and little work has been focused on the development of standards for the evaluation of ceramic matrix composite components. Table 10 lists the standardized test methods developed by ASTM's subcommittee C28.07 on Ceramic Matrix Composites.

Table 10: ASTM test standards for ceramic matrix composites.

\begin{tabular}{|c|c|}
\hline Standard & Title \\
\hline C1275-00 & $\begin{array}{l}\text { Standard Test Method for Monotonic Tensile Behavior of Continuous Fiber-Reinforced } \\
\text { Advanced Ceramics with Solid Rectangular Cross-Section Test Specimens at Ambient } \\
\text { Temperature }\end{array}$ \\
\hline C1292-00 & $\begin{array}{l}\text { Standard Test Method for Shear Strength of Continuous Fiber-Reinforced Advanced } \\
\text { Ceramics at Ambient Temperatures }\end{array}$ \\
\hline C1337-96 & $\begin{array}{l}\text { Standard Test Method for Creep and Creep Rupture of Continuous Fiber-Reinforced } \\
\text { Ceramic Composites under Tensile Loading at Elevated Temperatures }\end{array}$ \\
\hline C1341-06 & $\begin{array}{l}\text { Standard Test Method for Flexural Properties of Continuous Fiber-Reinforced Advanced } \\
\text { Ceramic Composites }\end{array}$ \\
\hline C1358-05 & $\begin{array}{l}\text { Standard Test Method for Monotonic Compressive Strength Testing of Continuous Fiber- } \\
\text { Reinforced Advanced Ceramics with Solid Rectangular Cross-Section Test Specimens at } \\
\text { Ambient Temperatures }\end{array}$ \\
\hline C1359-05 & $\begin{array}{l}\text { Standard Test Method for Monotonic Tensile Strength Testing of Continuous Fiber- } \\
\text { Reinforced Advanced Ceramics With Solid Rectangular Cross-Section Test Specimens at } \\
\text { Elevated Temperatures }\end{array}$ \\
\hline C1360-01 & $\begin{array}{l}\text { Standard Practice for Constant-Amplitude, Axial, Tension-Tension Cyclic Fatigue of } \\
\text { Continuous Fiber-Reinforced Advanced Ceramics at Ambient Temperatures }\end{array}$ \\
\hline C1425-05 & $\begin{array}{l}\text { Standard Test Method for Interlaminar Shear Strength of 1-D and 2-D Continuous Fiber- } \\
\text { Reinforced Advanced Ceramics at Elevated Temperatures }\end{array}$ \\
\hline C1468-06 & $\begin{array}{l}\text { Standard Test Method for Transthickness Tensile Strength of Continuous Fiber-Reinforced } \\
\text { Advanced Ceramics at Ambient Temperature }\end{array}$ \\
\hline C1469-00 & $\begin{array}{l}\text { Standard Test Method for Shear Strength of Joints of Advanced Ceramics at Ambient } \\
\text { Temperature }\end{array}$ \\
\hline
\end{tabular}


The design rules will likely involve the mandatory use of non-destructive evaluation (NDE) for fuel cladding. There have been substantial efforts for developing and applying various NDE techniques for $\mathrm{SiC} / \mathrm{SiC}$ composites. However, $\mathrm{NDE}$ scheme for $\mathrm{SiC} / \mathrm{SiC}$ has not been seriously considered for specific applications in nuclear services. Table 11 lists the typical NDE modalities for the continuous fiber composites and their attributes [97].

Table 11: NDE techniques for SiC/SiC: candidate modalities and main attributes. [97]

\begin{tabular}{cc}
\hline Modalities & Attributes \\
\hline Ultrasonics & Non-invasive \\
Infrared thermography & Direct spatial imaging \\
Eddy currents & Spatial resolution in 2D/3D \\
X-ray computed tomography & 3D volumetric discrimination \\
X-ray tomosynthesis & Virtual sectioning and segmentation \\
Digital X-rays & Cognitive visualization \\
(Proof testing) & Quantitative metrology \\
& Volumetric damage mapping \\
\end{tabular}

\subsection{ONGOING PROGRAMS}

$\mathrm{R} \& \mathrm{D}$ of $\mathrm{SiC} / \mathrm{SiC}$ composite materials and their application technologies are conducted for various nuclear and fusion energy applications, in small to medium scales, in the US, the Generation IV International Forum (GIF) parties, and the international fusion energy research communities. The recent interests attracted to $\mathrm{SiC} / \mathrm{SiC}$ from nuclear energy programs are based on the successful development of radiation-resistant composites in the US and Japanese fusion materials program. Table 12 lists the ongoing and recently finished programs involving R\&D of $\mathrm{SiC} / \mathrm{SiC}$ technologies for nuclear and fusion applications. 
Table 12: Ongoing SiC/SiC R\&D activities for nuclear applications and their focuses.

\begin{tabular}{|c|c|c|l|}
\hline $\begin{array}{c}\text { Envisioned system } \\
\text { (component) }\end{array}$ & Country & Lead contacts & Main focuses \\
\hline $\begin{array}{c}\text { VHTR } \\
\text { (control rod, etc) }\end{array}$ & $\begin{array}{c}\text { US } \\
\text { (France, } \\
\text { etc.) }\end{array}$ & $\begin{array}{c}\text { L.L. Snead (US) } \\
\text { C. Colin (FR) }\end{array}$ & $\begin{array}{l}\text { - Proof-of-principle irradiation } \\
\text { - Test standard development }\end{array}$ \\
\hline $\begin{array}{c}\text { LMR, VHTR } \\
\text { (IHX) }\end{array}$ & Japan & S. Konishi (JP) & $\begin{array}{l}\text { - Liquid metal loop compatibility testing } \\
\text { - Production / shaping technology development for } \\
\text { compact HX }\end{array}$ \\
\hline $\begin{array}{c}\text { GFR } \\
\text { (core assemnly) }\end{array}$ & $\begin{array}{c}\text { France, } \\
\text { Japan }\end{array}$ & $\begin{array}{c}\text { M. Le Flem (FR) } \\
\text { A. Kohyama (JP) }\end{array}$ & $\begin{array}{l}\text { - Material processing and fundamental properties } \\
\text { - Near-net shaping development } \\
\text { - Conceptual core design } \\
\text { - Irradiation effects }\end{array}$ \\
\hline $\begin{array}{c}\text { GFR } \\
\text { (fuel matrix) }\end{array}$ & Japan & T. Hinoki (JP) & $\begin{array}{c}\text { - Fundamental technology development for SiC } \\
\text { composite-matrix nitride fuel production }\end{array}$ \\
\hline $\begin{array}{c}\text { LWR } \\
\text { (fuel cladding) }\end{array}$ & US & H. Feinroth (US) & $\begin{array}{c}\text { - Feasibility assessment of SiC composite cladding } \\
\text { nitride fuel for advanced LWR }\end{array}$ \\
\hline $\begin{array}{c}\text { Fusion } \\
\text { (blanket) }\end{array}$ & $\begin{array}{c}\text { Internation } \\
\text { al }\end{array}$ & $\begin{array}{c}\text { H. Hegeman (EU) } \\
\text { A. Hasegawa (JP) } \\
\text { Y. Katoh (US) }\end{array}$ & $\begin{array}{c}\text { - Fundamental aspects of irradiation effects in SiC } \\
\text { ceramics and composites, both experimental and } \\
\text { theoretical modeling } \\
\text { - Evaluation of SiC composite as Pb-Li flow channel } \\
\text { insert material }\end{array}$ \\
\hline
\end{tabular}

\subsubsection{Fusion}

$\mathrm{SiC} / \mathrm{SiC}$ composites have been considered for application to the fusion blanket/first wall structures since early 1990's [98]. These components consisted typically of panels with coolant channels in them, requiring resistance against very high-fluence neutron irradiation, high thermal stress, low induced radioactivity, low tritium permeation/retention, and other demanding attributes [99]. Presently, $\mathrm{SiC} / \mathrm{SiC}$ composites are among the three competing candidate material classes for this application, together with the reduced-activation ferritic/martensitic steels (mostly for near-term applications) and the vanadium alloys [100]. SiC/SiC composites stand out among the candidates in terms of the anticipated energy cost competitiveness and favorable safety features associated with the high operating temperature and low activation.

The proposed blanket designs in which the use of $\mathrm{SiC} / \mathrm{SiC}$ composites is assumed are listed in Table 13 and are based on either self-cooled lead-lithium (SCLL) or helium-cooled ceramic breeder (HCCB) concepts [99, 101]. Design studies of EU Power Plant Conceptual Study (PPCS) Model D [102] and the US ARIES (Advanced Reactor Innovation and Evaluation Study)-AT [103], which are the latest SCLL conceptual designs, assume the highest operating temperatures for $\mathrm{SiC} / \mathrm{SiC}$ structures of $\sim 1000^{\circ} \mathrm{C}$, yielding a power conversion efficiency of $\sim 60 \%$ for the blanket circuit. The DREAM (stands for "DRastically EAsy Maintenance") HCCB 
blanket concept of Japan assumes outlet helium temperatures of $\sim 900^{\circ} \mathrm{C}$ with a gross thermal efficiency of $\sim 50 \%$ [104].

Table 13: Fusion blanket designs assuming use of SiC/SiC. [99, 101-104]

\begin{tabular}{|c|c|c|c|c|c|}
\hline & ARIES-AT & $\begin{array}{c}\text { EU PPCS } \\
\text { Model D }\end{array}$ & DREAM & $\begin{array}{c}\text { EU PPCS } \\
\text { Model C }\end{array}$ & ARIES-ST \\
\hline Component & $\begin{array}{c}\mathrm{FW} / \text { blanket } \\
\text { structure }\end{array}$ & $\begin{array}{c}\mathrm{FW} / \text { blanket } \\
\text { structure }\end{array}$ & $\begin{array}{c}\text { FW/blanket } \\
\text { structure }\end{array}$ & $\begin{array}{c}\text { Flow channel } \\
\text { insert }\end{array}$ & $\begin{array}{c}\text { Flow channel } \\
\text { insert }\end{array}$ \\
\hline Coolant & $\mathrm{Pb}-\mathrm{Li}$ & $\mathrm{Pb}-\mathrm{Li}$ & $\mathrm{He}$ & $\mathrm{He} / \mathrm{Pb}-\mathrm{Li}$ & $\mathrm{He} / \mathrm{Pb}-\mathrm{Li}$ \\
\hline Breeder & $\mathrm{Pb}-\mathrm{Li}$ & $\mathrm{Pb}-\mathrm{Li}$ & $\begin{array}{c}\text { Lithium } \\
\text { ceramics }\end{array}$ & $\mathrm{Pb}-\mathrm{Li}$ & $\mathrm{Pb}-\mathrm{Li}$ \\
\hline $\begin{array}{c}\text { Max. temperature of } \\
\text { SiC/SiC component }\end{array}$ & $\sim 1000^{\circ} \mathrm{C}$ & $\sim 1000^{\circ} \mathrm{C}$ & $\sim 900^{\circ} \mathrm{C}$ & $\sim 700^{\circ} \mathrm{C}$ & $\sim 700^{\circ} \mathrm{C}$ \\
\hline $\begin{array}{c}\text { Coolant or Pb-Li } \\
\text { pressure }\end{array}$ & $1 \mathrm{MPa}$ & $1.5 \mathrm{MPa}$ & $10 \mathrm{MPa}$ & $15 \mathrm{MPa}$ & $\mathrm{Not}$ specified \\
\hline Cycle efficiency & $59 \%$ & $60 \%$ & $45 \%$ & $42 \%$ & $45 \%$ \\
\hline $\begin{array}{c}\text { Neutron wall load, } \\
\text { average }\end{array}$ & $3.2 \mathrm{MW} / \mathrm{m}^{2}$ & $2.2 \mathrm{MW} / \mathrm{m}^{2}$ & $3.0 \mathrm{MW} / \mathrm{m}^{2}$ & $2.4 \mathrm{MW} / \mathrm{m}^{2}$ & $4.2 \mathrm{MW} / \mathrm{m}^{2}$ \\
\hline
\end{tabular}

Figure 21 depicts the US and the European examples of blanket designs assuming the use of $\mathrm{SiC} / \mathrm{SiC}$ as the structural material. Key properties for $\mathrm{SiC} / \mathrm{SiC}$ assumed in these conceptual studies are summarized and compared with typical values for materials through the two most promising processing routes in Table 14. It is noted that many of the assumed base-line property requirements are already satisfied or addressed for the design solutions. 

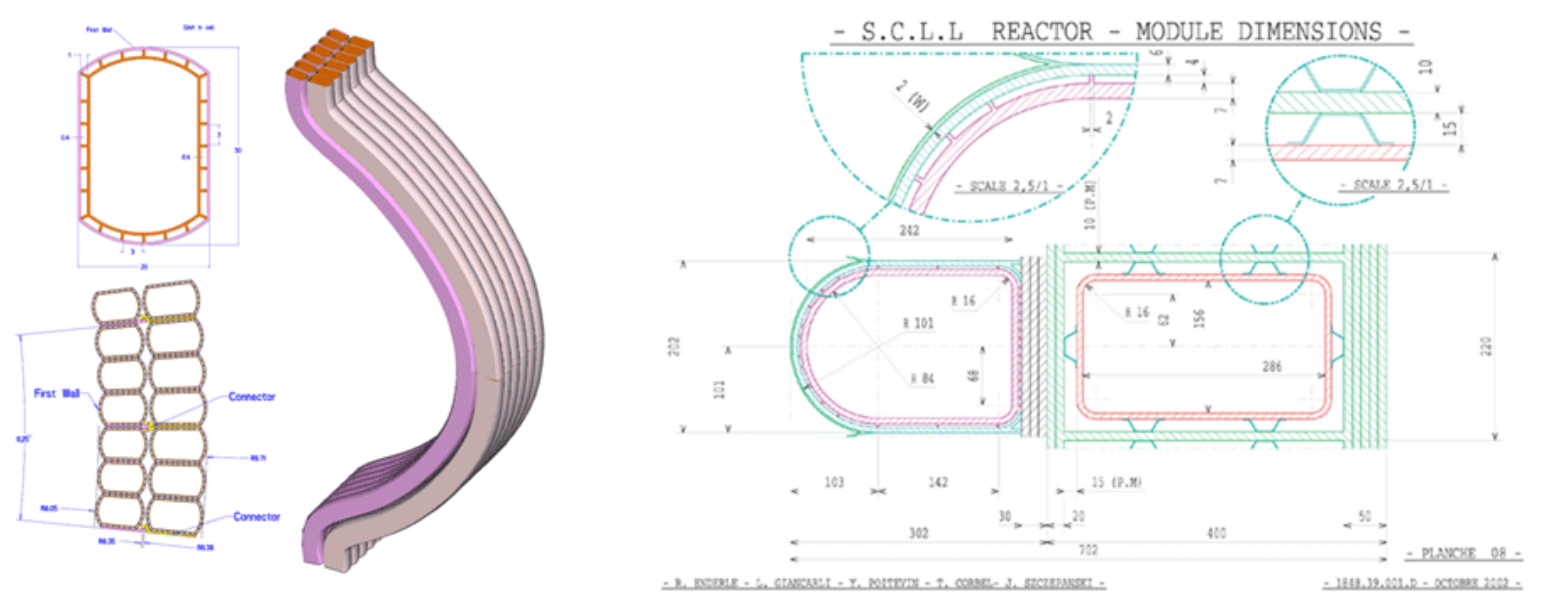

Figure 21: Example of blanket designs assuming use of $\mathrm{SiC} / \mathrm{SiC}$ as structural material. [99, 103]

Table 14: Key requirements for $\mathrm{SiC} / \mathrm{SiC}$ for blanket structural and functional applications in fusion reactors. [3]

\begin{tabular}{|c|c|c|c|}
\hline \multicolumn{2}{|l|}{ Key properties } & Blanket structure & Flow channel insert \\
\hline \multicolumn{4}{|c|}{ Thermal conductivity, through-thickness $[\mathrm{W} / \mathrm{m}-\mathrm{K}]$} \\
\hline Non-irradiated, $500^{\circ} \mathrm{C}$ & & $>\sim 20$ & $<2$ \\
\hline Non-irradiated, $1000^{\circ} \mathrm{C}$ & & $>\sim 20$ & - \\
\hline Irradiated, $500^{\circ} \mathrm{C}$ & & $>\sim 20$ & $<2$ \\
\hline Irradiated, $1000^{\circ} \mathrm{C}$ & & $>\sim 20$ & - \\
\hline \multicolumn{4}{|l|}{ Electrical conductivity } \\
\hline Non-irradiated, $500-1000^{\circ} \mathrm{C}$ & & $<\sim 500$ & $<\sim 100$ \\
\hline Irradiated, $500-1000^{\circ} \mathrm{C}$ & & $<\sim 500$ & $<\sim 100$ \\
\hline \multicolumn{4}{|l|}{ Tensile properties } \\
\hline Ultimate tensile stress, $500-1000^{\circ} \mathrm{C}$ & {$[\mathrm{MPa}]$} & 300 & - \\
\hline Matrix cracking stress, $500-1000^{\circ} \mathrm{C}$ & [MPa] & - & $>\sim 100$ \\
\hline Modulus, $500-1000^{\circ} \mathrm{C}$ & [GPa] & $200-300$ & $200-300$ \\
\hline
\end{tabular}

In a very different way from the structural application, the use of $\mathrm{SiC} / \mathrm{SiC}$ as the insulating lining material for lead-lithium (Pb-Li) flow channels (flow channel insert; FCI) has been proposed in the EU advanced lead-lithium blanket concept [105] and US ARIES-ST blanket design [106]. In this application, an FCI serves as an electrical and thermal insulator in order to mitigate the MHD pressure drop and to allow a significantly higher coolant outlet temperature than the upper temperature limit for the metallic duct structure. The dual-cooled $\mathrm{Pb}-\mathrm{Li}$ blanket concept (DCLL), in which Pb-Li supplies the tritium fuel while conveying a certain fraction of 
heat, has been adopted by the proposed US TBM and Chinese late-stage TBM for the ITER [7, 107]. The design illustrations showing the proposed use of $\mathrm{SiC} / \mathrm{SiC} \mathrm{FCI}$ in the $\mathrm{EU} \mathrm{Pb}-\mathrm{Li}$ blanket concept and the US DCLL TBM are presented in Figure 22. The design inlet/outlet Pb-Li temperatures for the EU PPCS Model C DCLL blanket are $480 / 700^{\circ} \mathrm{C}$. The outlet temperature corresponds approximately to the inside temperatures for the FCI, whereas the outside temperature will be maintained to be compatible with the ferritic steel structure [108].
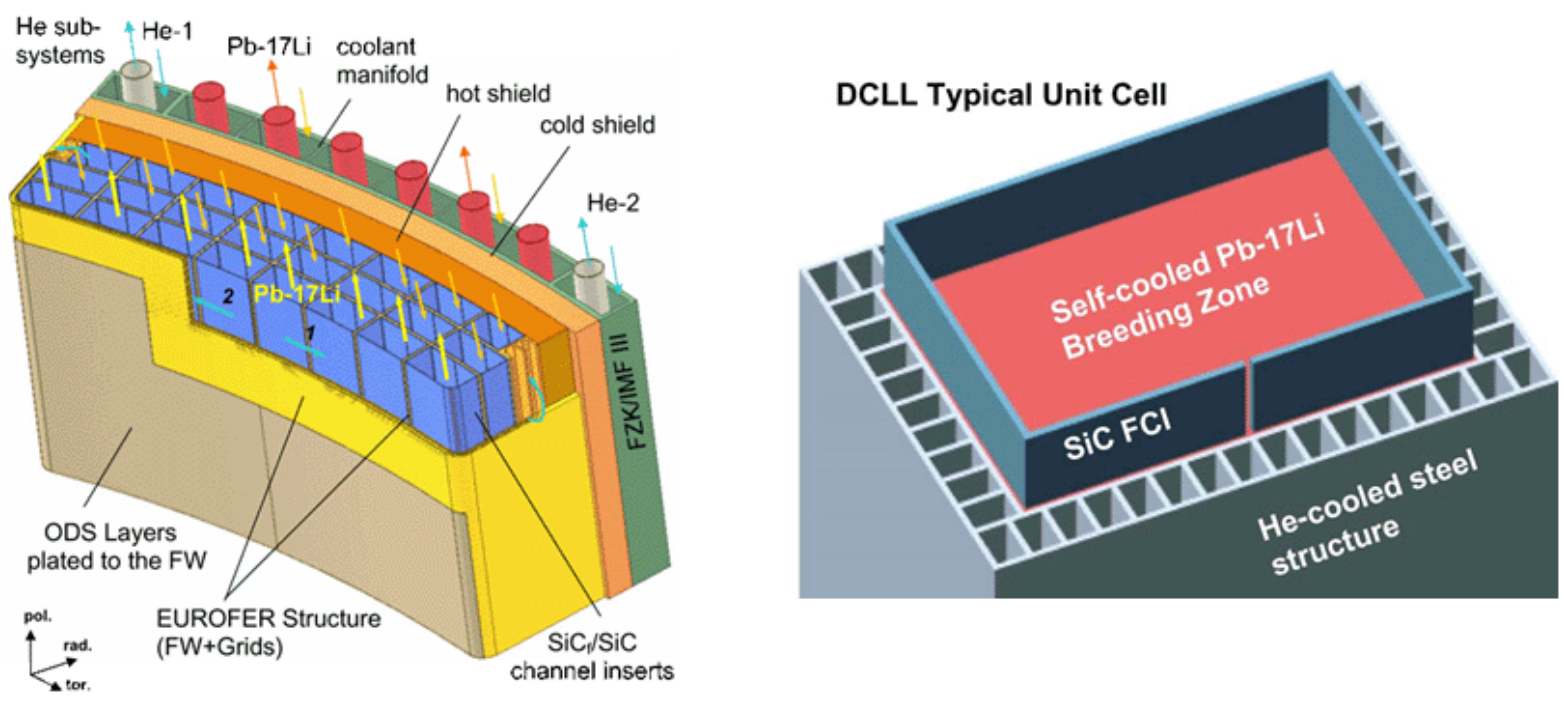

Figure 22: Examples of blanket designs assuming use of SiC-based flow channel inserts. [23, 109]

\subsubsection{NGNP / VHTR}

Most of the international partners in the GIF consider $\mathrm{SiC} / \mathrm{SiC}$ composites as viable materials for control rod sleeves and intermediate heat exchangers (IHX) of very high temperature reactor (VHTR) and potentially for gas-cooled fast reactors (GFR) and other advanced reactor concepts. Table 15 lists the R\&D task items to which individual GIF parties presently perform or plan R\&D activities. 
Table 15: Elements of US NGNP Composite R\&D program and comparison with international $R \& D$ plans.

\begin{tabular}{|l|c|c|c|c|c|c|c|c|}
\hline & US & France & $\begin{array}{c}\text { South } \\
\text { Africa }\end{array}$ & Canada & $\begin{array}{c}\text { Switzer- } \\
\text { land }\end{array}$ & Korea & Japan & EU/JRC \\
\hline Ceramic IHX & & & & & & & & \\
\hline Design & $\mathrm{x}$ & $\mathrm{x}$ & $\mathrm{x}$ & $\mathrm{x}$ & & & & \\
\hline Baseline test & $\mathrm{x}$ & $\mathrm{x}$ & $\mathrm{x}$ & & $\mathrm{x}$ & $\mathrm{x}$ & & \\
\hline Environmental test & $\mathrm{x}$ & $\mathrm{x}$ & $\mathrm{x}$ & $\mathrm{x}$ & $\mathrm{x}$ & & & \\
\hline Modeling & $\mathrm{x}$ & & $\mathrm{x}$ & $\mathrm{x}$ & & & & \\
\hline Acceptability test & & & $\mathrm{x}$ & & & & & \\
\hline Composite Control Rod & & & & & & & & \\
\hline Design and manufacture & $\mathrm{x}$ & $\mathrm{x}$ & $\mathrm{x}$ & & $\mathrm{x}$ & $\mathrm{x}$ & $\mathrm{x}$ & $\mathrm{x}$ \\
\hline Baseline properties & $\mathrm{x}$ & $\mathrm{x}$ & $\mathrm{x}$ & & $\mathrm{x}$ & $\mathrm{x}$ & $\mathrm{x}$ & $\mathrm{x}$ \\
\hline Environmental test & $\mathrm{x}$ & $\mathrm{x}$ & $\mathrm{x}$ & & $\mathrm{x}$ & $\mathrm{x}$ & $\mathrm{x}$ & $\mathrm{x}$ \\
\hline Irradiation test & $\mathrm{x}$ & $\mathrm{x}$ & $\mathrm{x}$ & & $\mathrm{x}$ & $\mathrm{x}$ & $\mathrm{x}$ & $\mathrm{x}$ \\
\hline Modeling & $\mathrm{x}$ & $\mathrm{x}$ & $\mathrm{x}$ & & $\mathrm{x}$ & & & \\
\hline Acceptability test & & & $\mathrm{x}$ & & & & $\mathrm{x}$ & \\
\hline
\end{tabular}

The VHTR is one of the six advanced nuclear reactor concepts presently pursued in the Generation IV (Gen-IV) nuclear power programs. The U.S. Department of Energy has selected VHTR for the NGNP Project, which will demonstrate the use of nuclear power for electricity and hydrogen production without greenhouse gas emission [8]. In the Gas Turbine-Modular Helium Reactor (GT-MHR, Figure 23) design from General Atomics, which is a type of VHTR, the control rod cladding and guide tubes receive fast neutrons up to $\sim 1 \times 10^{25} \mathrm{n} / \mathrm{m}^{2} /$ year at the maximum in a temperature range $600-1100^{\circ} \mathrm{C}$ during the normal operation, whereas the mechanical loading will not be very significant [110-111]. In the scenario of a depressurized conduction cool-down accident, i.e. a complete loss of the forced coolant flow, the maximum temperature may reach $\sim 1500^{\circ} \mathrm{C}$. Since it is very likely that refractory composites will need to be used for these applications, the U.S. NGNP Composite Program conducts R\&D for qualification and testing of the $\mathrm{SiC} / \mathrm{SiC}$ composites, as the primary option, and carbon fiber / carbon matrix $(\mathrm{C} / \mathrm{C})$ composites. 


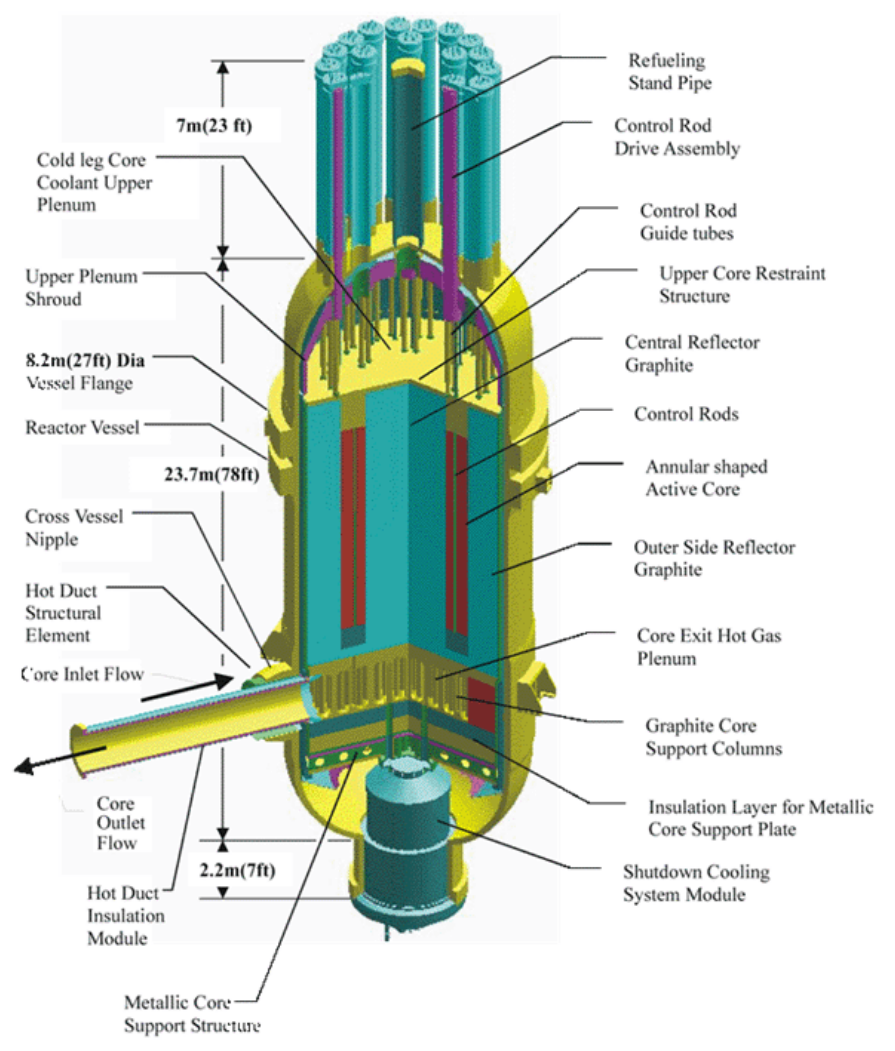

Figure 23: Illustration of reactor vessel and components for GT-MHR. [8]

The program comprises specific tasks for 1) confirmative feasibility issues for $\mathrm{SiC} / \mathrm{SiC}$ including irradiation effect and fabricability, 2) key technical issues governing the lifetime envelope such as irradiation creep and time-dependent fracture, and 3) providing support to test standards and design code development in the framework of ASTM International and American Society of Mechanical Engineers (ASME) [110].

Figure 24 illustrates an example concept of proposed control rod segment, namely tubular sleeve, end caps, and an articulating joint segment) to be made of composite materials. This example assumes the use of $\mathrm{C} / \mathrm{C}$ composite and of approximate dimensions $1 \mathrm{~m}$-long x $10 \mathrm{~cm}$ diameter. The NGNP program activity has identified a potentially very severe irradiationinduced dimensional instability issue for $\mathrm{C} / \mathrm{C}$ control rod. Because of this, it is unlikely that $\mathrm{C} / \mathrm{C}$ can be used as the control rod material except for the location where very small neutron dose is anticipated. For $\mathrm{SiC} / \mathrm{SiC}$ control rods, mechanical designs employing structural spines are considered as well as designs with cylindrical sleeve for both structure and containment of the neutron absorbing material. The spine approach is generally advantageous in that it enables simpler articulating joint structures and less significant secondary loading to structural 
components, whereas the bending strength of spine-based control rods may be inferior to that of structural sleeves. The Japanese High Temperature Test Reactor (HTTR) employs the spine concept (Figure 25).

Figure 24: An example of proposed control rod segment (tubular sleeve, end caps, and articulating joint) made of composite materials. This example assumes the use of $\mathrm{C} / \mathrm{C}$ composite and approximate dimensions of $1 \mathrm{~m}$-long x $10 \mathrm{~cm}$-diameter.

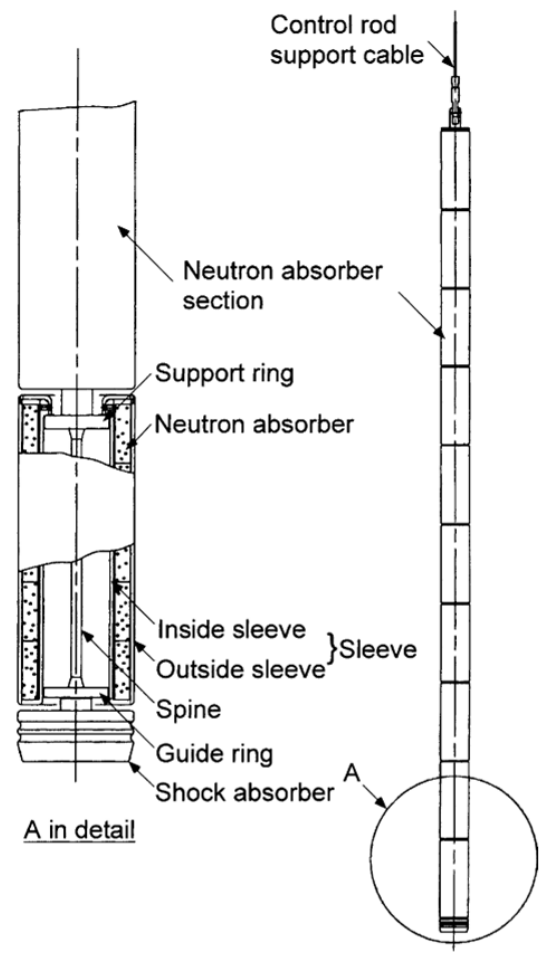

Figure 25: Spine-based design approach for control rod in Japanese HTTR. [112] 


\subsubsection{GFR}

$\mathrm{SiC}$ and $\mathrm{SiC} / \mathrm{SiC}$ are studied as the candidate materials for fuel cladding and core structures for the GFR, which is also one of the six Gen-IV concepts and features a fast-neutron spectrum, helium-cooled reactor and closed fuel cycle [113]. General feasibility issues still exist for SiCbased materials for use in the GFR environment, including the effect of very high-fluence neutron irradiation at temperatures far exceeding $1000^{\circ} \mathrm{C}$. Among the GIF countries, France and Japan are particularly active in $R \& D$ of selected technical elements to establish feasibility of GFR concept. Preliminary specifications for the Japanese conceptual GFR core design with $\mathrm{SiC} / \mathrm{SiC}$ structures are shown in Table 16. Fabrication of $\mathrm{SiC} / \mathrm{SiC}$ components with attributes implied by Table 16 is feasible with existing facilities at most venders. However, as shown in Table 17, the operating temperature of fuel cladding which is presently assumed to be in 1300 $1600^{\circ} \mathrm{C}$ imposes a major challenge to $\mathrm{SiC} / \mathrm{SiC}$. Overall, the operating environment presently envisioned in the GFR core is very challenging for any existing material.

Table 16: Preliminary specifications for Japanese conceptual GFR core with SiC composite structures. [113]

\begin{tabular}{|c|c|c|}
\hline Component & Attribute & Specification \\
\hline Fuel pellet & Material & Enriched nitride \\
\hline Cladding & Material & SiC/SiC \\
\hline & Outer diameter & $9.15 / 9.5 \mathrm{~mm}$ (inner/outer core regions) \\
\hline & Inner diameter & $7.15 / 7.5 \mathrm{~mm}$ \\
\hline & Wall thickness & $1 \mathrm{~mm}$ \\
\hline & Column length & $950 \mathrm{~mm}$ \\
\hline Fuel pin & Smear density & SiC/SiC \\
\hline Spacer & Material & Grid mesh \\
\hline & Type & 10 \\
\hline & Number of stages & SiC/SiC \\
\hline Wrapper tube & Material & $94.15 \mathrm{~mm}$ \\
\hline & Outer apothem & $5 \mathrm{~mm}$ \\
\hline & Wall thickness & 271 \\
\hline Fuel assembly & Number of fuel pins & $10.7 \mathrm{~mm}$ \\
\hline & Fuel pin interval & $5.5 \mathrm{~mm}$ \\
\hline
\end{tabular}


Table 17: Operating conditions and assumed thermal properties for cladding material for nominally $1300^{\circ} \mathrm{C}$ GFR core design. [114]

\begin{tabular}{|c|c|}
\hline Coolant outlet / inlet temperatures & $1300^{\circ} \mathrm{C} / 460^{\circ} \mathrm{C}$ \\
\hline Maximum clad temperature, nominal / hot spot & $1600^{\circ} \mathrm{C} / 1760^{\circ} \mathrm{C}$ \\
\hline Linear power density and clad temperature, assumed thermal conductivity & \\
\hline (upper core) & $150 \mathrm{~W} / \mathrm{cm}, 1600^{\circ} \mathrm{C}, 13.9 \mathrm{~W} / \mathrm{m}-\mathrm{K}$ \\
\hline (midplane) & $250 \mathrm{~W} / \mathrm{cm}, 1030^{\circ} \mathrm{C}, 15.6 \mathrm{~W} / \mathrm{m}-\mathrm{K}$ \\
\hline (lower core) & $200-250 \mathrm{~W} / \mathrm{cm}, 460^{\circ} \mathrm{C}, 5.1 \mathrm{~W} / \mathrm{m}-\mathrm{K}$ \\
\hline
\end{tabular}

There are two other programs related with the opportunity for $\mathrm{SiC} / \mathrm{SiC}$ primarily in GFR in Japan. One is a program for the $\mathrm{SiC}$ composite inert fuel matrix. [114] The program develops the fabrication technologies for the mixed nitride fuel pellet made of high density $\mathrm{SiC}$ with submillimeter cylindrical holes which accommodate fuel material surrounded by a porous $\mathrm{SiC}$ buffer layer (Figure 26). The fuel pellet specifications which were identified optimum in the Japanese program are presented in Table 18.

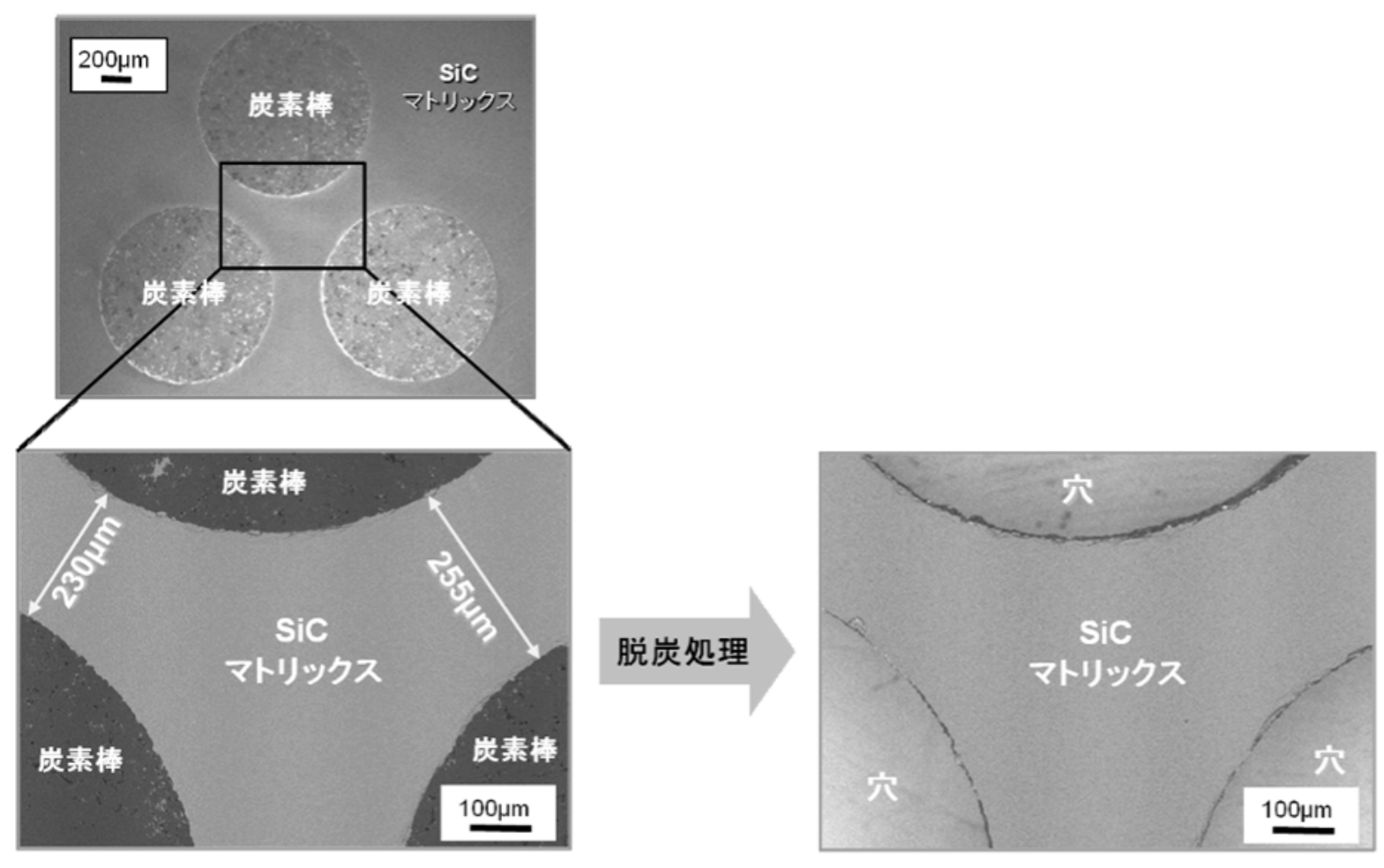

Figure 26: Sintered SiC fuel matrix element with submillimeter fuel containing channels developed in Japanese NERI program on GFR fuel R\&D.In this figure, process for producing sintered $\mathrm{SiC}$ matrix with axial penetrating holes to accommodate fuel microrods is shown. [114] 
Table 18: Optimum specifications determined for mixed nitride fuel in Japanese GFR fuel program. [114]

\begin{tabular}{|c|c|}
\hline Fuel pellet diameter & $9 \mathrm{~mm}$ \\
\hline Fuel pellet height & $10 \mathrm{~mm}$ \\
\hline Fuel core diameter & $1.2 \mathrm{~mm}$ \\
\hline Pu enrichment & $28 \mathrm{wt} . \%$ \\
\hline SiC buffer layer thickness & $0.42 \mathrm{~mm}$ \\
\hline SiC buffer layer density & $20 \% \mathrm{TD}$ \\
\hline Fuel core interspacing & $0.2 \mathrm{~mm}$ \\
\hline
\end{tabular}

In the other Japanese program, development of IHX made of NITE $\mathrm{SiC} / \mathrm{SiC}$ is being attempted [115]. The program assumes the maximum IHX operating temperature of $\sim 900^{\circ} \mathrm{C}$ and various coolant media including helium, carbon dioxide, and liquid metals. The major R\&D elements include development of fabrication technologies, fabrication of prototypical heat exchanger units, testing in coolant loop facilities, conceptual designing of thermal systems, and identification of adequate NDE schemes. The conceptual illustrations of the IHX assembly and the heat exchange element studied in the Japanese ceramic IHX program are shown in Figure 27.

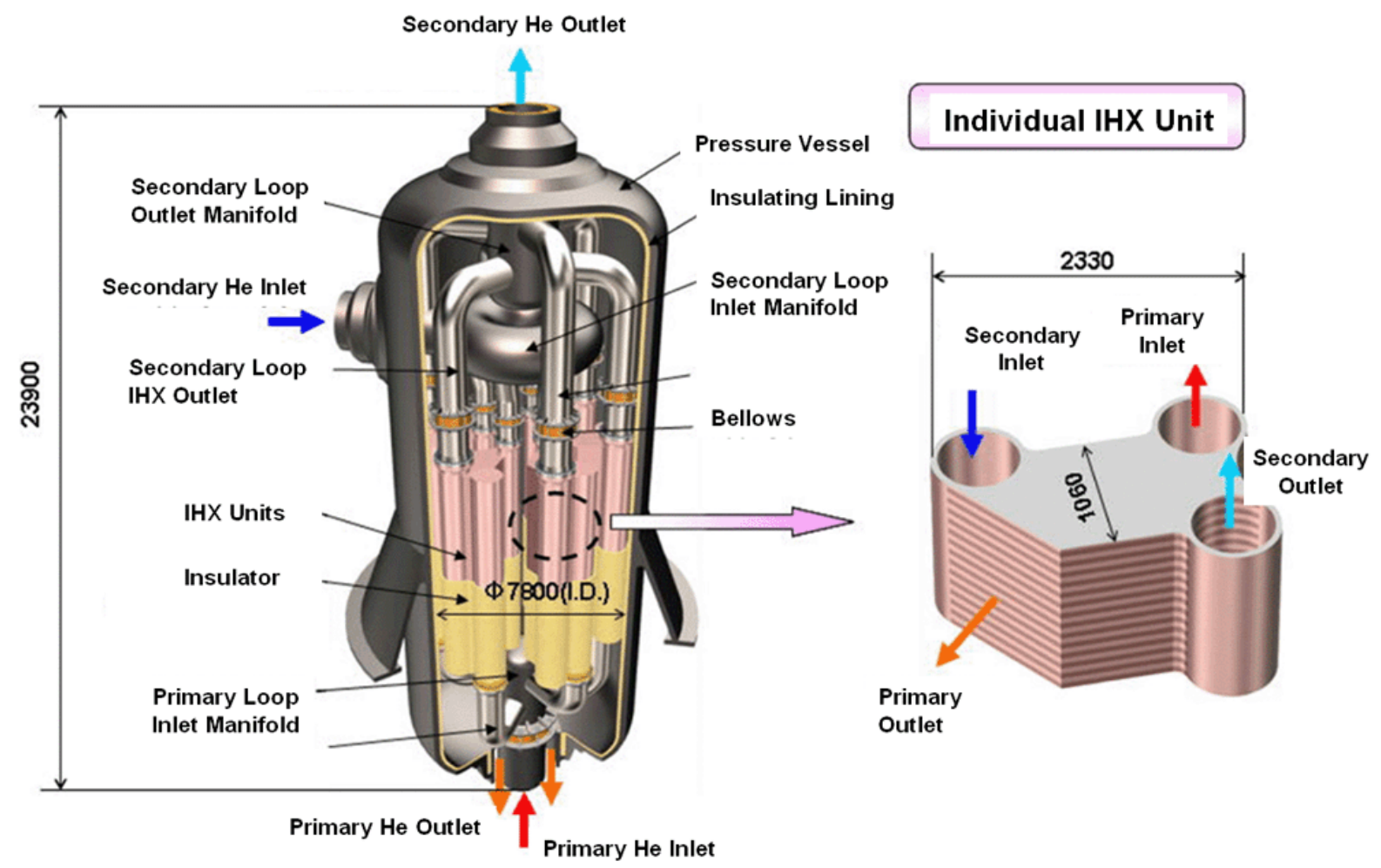

Figure 27: Conceptual illustration of intermediate heat exchanger and heat exchange element studied in Japanese ceramic IHX program. [115] 


\subsubsection{Advanced LWR cladding}

$\mathrm{SiC}$ and $\mathrm{SiC} / \mathrm{SiC}$ are considered as attractive materials to supplement or replace zirconium alloy cladding presently used for LWR fuels [116]. The chemical inertness and strength of SiC at elevated temperatures are expected to offer improved safety features, reduced contamination of the primary circuit, and a simplified disposal process. Key issues for SiC-based cladding for LWR include the fabrication of very long, thin-walled tubes, irradiated effects (generally more pronounced dimensional and strength change at low temperatures of water reactor), hermeticity, and corrosion by water environment and fission products. Research on the key issues is being conducted in several countries, including the U.S. [117] 


\section{SiC/SiC FOR AHTR: ANALYSIS OF ISSUES}

In this chapter, analysis of issues associated with the potential use of $\mathrm{SiC} / \mathrm{SiC}$ (or any other forms of SiC-based materials) in Advanced High Temperature Reactor (AHTR) core components. The AHTR is a liquid-salt-cooled high-temperature reactor [1, 118-120] that uses the coated-particle graphite-matrix fuel. The optically transparent liquid-salt coolant is a mixture of fluoride salts with atmospheric boiling points $>1200^{\circ} \mathrm{C}$. The reactor operates at nearatmospheric pressure, and at operating conditions, the liquid-salt heat-transfer properties are similar to those of water. Several different salts can be used as the primary coolant, including lithium-beryllium, sodium-beryllium, and sodium-zirconium fluoride salts. The peak coolant operating temperatures are envisioned to be in between 700 and $950^{\circ} \mathrm{C}$, with reactor outputs up to $4000 \mathrm{MW}(\mathrm{t})$.

The AHTR fuel is basically the same fuel that has been developed for high-temperature gascooled reactors. All of the proposed high-temperature fuel assemblies use coated-particle fuels where the uranium oxide or carbide is in the form of small microspheres coated with multiple layers that provide the cladding. The microspheres are then incorporated into some type of graphite matrix. The graphite matrix can be formed into different geometries. The result is a fuel that can operate under normal conditions with peak temperatures up to $1250^{\circ} \mathrm{C}$. Under accident conditions, peak temperatures can approach $\sim 1600^{\circ} \mathrm{C}$ for limited periods of time without significant fuel failure.

Three fuel-assembly geometries, namely 1) prismatic, 2) pebble bed, and 3) stringer, are being considered to optimize fuel performance $[2,120]$. A detailed comparison of the three fuel type options provided elsewhere concludes that the choice of fuel assembly design involves complex design trade-offs [118]. The prismatic core requires very long fuel pin with thin-walled cladding, which means a very challenging feasibility issue in terms of fabrication technology in addition to technical issues common to three options. Pebble may be excluded because it is unique in terms of fabrication requirement for cladding. It should be noted that there recently was a DOE-funded Phase-I SBIR project for development of fabrication technology for CVI $\mathrm{SiC} / \mathrm{SiC}$ fuel cladding for the pebble bed concept. Hereafter in this report, the stringer core is discussed as the primary option. The fuel assembly and main components for the stringer core option are illustrated in Figure 28. Critical components for the stringer core are mostly of simple shapes, such as straight cylinders and flat plates, and the pins and wrapper tubes are assumed to be of length of $\sim 1 \mathrm{~m}$, hence no serious critical issue is anticipated regarding fabrication and refueling operation (except for the tie bars). 

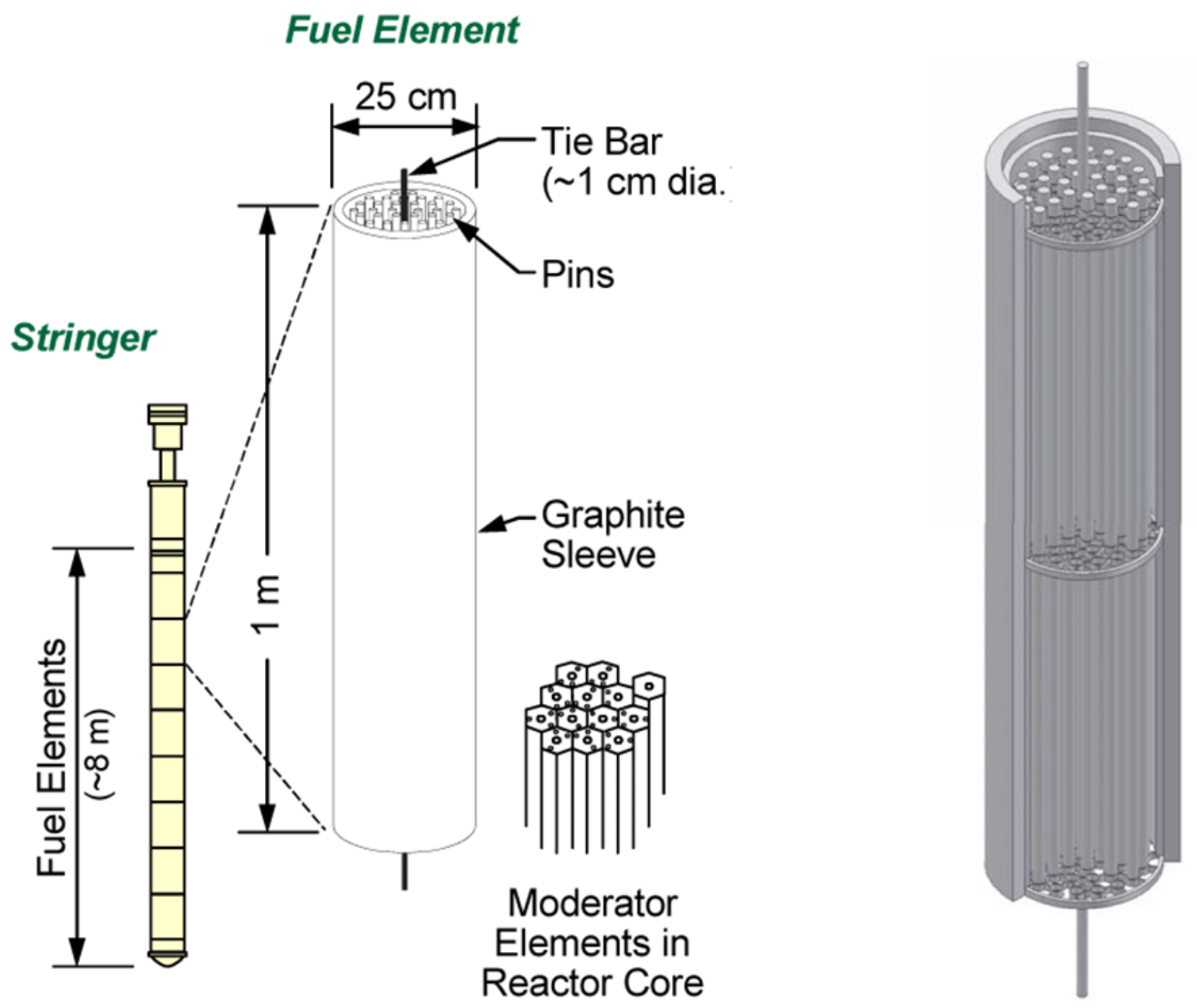

Figure 28: Illustrations of stringer type core and fuel assembly proposed for LS-VHTR. [2]

\subsection{AHTR STRINGER FUEL COMPONENTS AND REQUIREMENTS}

\subsubsection{Fuel cladding}

The main functions of fuel rod cladding are to confine radioactive materials within the fuel element, to maintain structural and dimensional integrity of the fuel rod, and to transfer heat generated within the fuel to the cooling medium. Therefore, the primary requirements to the cladding materials are 1) to maintain mechanical integrity and hermeticity, 2) to maintain dimensional stability, 3) to be sufficiently corrosion resistant to both the fission products and the coolant material, and 4) to maintain sufficient thermal conductivity, throughout the service life. Radiation governs or influences properties of cladding materials related with all of these requirements in one way or another. Requirements for the fuel rod cladding application are generally most demanding to materials among various fuel assembly components. 


\subsubsection{Other fuel assembly components}

Other fuel assembly components for the string core option include the sleeve, the grid disk, and the tie bar. These components will be required to 1) maintain mechanical integrity, 2) maintain dimensional stability, and 3) be sufficiently corrosion resistant to the coolant. Requirement of radiation resistance will be similar to that for fuel rod cladding. Other requirements for cladding such as hermeticity, corrosion resistance against fission products, and thermal conductivity may not apply to these components.

Figure 28 assumes the use of graphite as the material for the sleeve. Also, preliminary conceptual work on AHTR anticipates that graphite or carbon composite may be used for the tie bar. However, viability of carbon-based materials for use in AHTR core is questionable. The coolant temperature in AHTR is anticipated to be higher than $700^{\circ} \mathrm{C}$ and approaching $1000^{\circ} \mathrm{C}$ in an aggressive option. Although the neutron dose anticipated to be received by these components is not exactly known, it may be reasonable to assume equivalent with or greater than the typical dose $\left(\sim 6 \times 10^{25} \mathrm{n} / \mathrm{m}^{2}, \mathrm{E}>0.1 \mathrm{MeV}\right)$ for TRISO fuel coatings. With such doses at the anticipated operation temperatures, carbon-based materials may undergo very substantial dimensional changes accompanied with major modification in other physical and mechanical properties, in particular when mechanical stress is applied. Since the sleeves and the grid disks presumably require dimensional stability, SiC-based materials will be the prime candidate for those components.

\subsubsection{Reaction control system}

The reaction control systems, in particular for the components which stay in the reactor core region for a long period, will likely be operated in a condition similar to that for the fuel assembly. Examples of such components are the near-edge segments and joints of the control rods. For the same reasons with the fuel assembly components, those control rod components will require the use of $\mathrm{SiC}$-based composites provided the specific feasibility issues for $\mathrm{SiC}$ are resolved.

For the VHTR control rods, $\mathrm{SiC} / \mathrm{SiC}, \mathrm{C} / \mathrm{C}$, and a nickel-based superalloy Alloy $800 \mathrm{H}$ are the candidate materials for their structural components. However, the use of Alloy $800 \mathrm{H}$ has to be limited to the portion where the conditions of radiation exposure and off-normal maximum temperature are both mild, as the alloy almost completely loses rupture stress, life, and elongation at elevated temperatures after neutron irradiation. It is extremely unlikely for Alloy 
$800 \mathrm{H}$ to be qualified for use as the AHTR control rod, at temperatures higher than $700^{\circ} \mathrm{C}$ in a high radiation environment. On the other hand, $\mathrm{C} / \mathrm{C}$ composites are known to undergo severe dimensional instability as noted above. Recent irradiation campaign performed for the US NGNP program demonstrated that a high quality balanced weave graphite composite experiences anisotropic linear deformation on the order of $2 \%$ after neutron irradiation to $\sim 4 \times 10^{25} \mathrm{n} / \mathrm{m}^{2}$ (E > $0.1 \mathrm{MeV}$ ) at $800^{\circ} \mathrm{C}$. This result essentially rules out the possibility of using this particular material for the AHTR control rod, leaving SiC/SiC composites as the only option.

\subsection{FABRICATION}

\subsubsection{Fuel rod cladding}

Assuming that the fuel rod cladding of AHTR stringer core will be a straight cylindrical tube of $\sim 1 \mathrm{~m}$-long, $1 \mathrm{~cm}$-diameter, and $1 \mathrm{~mm}$-wall thickness, fabrication of the cladding itself will not be a critical issue for CVI processing of $\mathrm{SiC} / \mathrm{SiC}$. Fiber architectures such as braiding, filament winding, and pin-weave will be the candidates for fabricating the preform. Candidate preforming methods for small diameter tubes are listed in Table 19 [121]. However, other fiber architectures may have to be explored depending on the result of further detailed analysis of requirements.

Table 19: Common fabric architectures for fibrous ceramic composites. [121]

\begin{tabular}{cccc}
\hline Architecture & Fiber angles $^{(1)}$ & Typical $_{\mathrm{f}}^{(2)}$ & Remarks \\
\hline Jelly-roll & $\begin{array}{c}0^{\circ} / 90^{\circ} \\
\left(, \pm 45^{\circ}, \text { etc. }\right)\end{array}$ & $35 \%$ & Low cost \\
\hline Braid, bi-axial & $\pm \theta$ & $30 \%$ & $\begin{array}{c}\text { Freedom of diametral variation } \\
\text { Tailorable axial/hoop strength }\end{array}$ \\
\hline Braid, tri-axial & $0^{\circ} / \pm \theta$ & $25 \%$ & $\begin{array}{c}\text { Diametral variation possible } \\
\text { Tailorable axial/hoop strength } \\
\text { Added axial strength }\end{array}$ \\
\hline Filament-winding & $\pm \theta$ & $30 \%$ & Tailorable axial/hoop strength \\
\hline Pin-weave & $0^{\circ} / \sim 90^{\circ}$ & $35 \%$ & Diametral variation possible
\end{tabular}

(1) Fiber angle from tube axis, (2) Fiber volume fraction, $\theta$ : braid or screw angle, arbitrary to a limited extent 
Requirement of hermeticity or gas tightness is an obvious challenge and critical for $\mathrm{SiC} / \mathrm{SiC}$, because $\mathrm{SiC} / \mathrm{SiC}$ has not been industrially used where gas tightness is required, within the knowledge of the authors. It is possible that an additional measure for securing gas tightness is needed. Such measures include but are not limited to the additional CVD SiC coating and metal lining inside the tube. Hermetic sealing at the both ends of the cladding tube is an additional technical issue that has to be addressed. The hermeticity requirement imposes not only the fabrication issue but all the irradiation and environmental effect issues applicable to the additional materials or interface elements.

There will be trade-offs among the architectures, in terms of strength, thermal conductivity, life time properties, anisotropy, surface smoothness, and compatibility with the potential additional processes to provide/secure hermeticity. It is preferable that such trade-offs are thoroughly studied in order to identify the best optimized fabrication processes.

With the hermeticity requirement being such a challenging issue, it is recommended to consider alternative fuel design options which incorporate inert matrix (such as $\mathrm{SiC}$ ) fuel pellets or compacts retaining the fission products and non-hermetic fuel cladding.

\subsubsection{Other fuel assembly components}

There has been no critical fabricability issue identified for the grid and the sleeve to be made of $\mathrm{CVI} \mathrm{SiC/SiC}$, provide that the grid is a flat round plate with a number of circular holes in it, and the sleeve is a straight cylindrical tube of $\sim 1 \mathrm{~m}$-long and $\sim 25 \mathrm{~cm}$-diameter.

Fabricating a long (e.g., $\sim 8 \mathrm{~m}$ ) single rod component which is assumed for the tie bar in the preconceptual stringer core design will be very difficult for $\mathrm{SiC} / \mathrm{SiC}$. $\mathrm{R} \& \mathrm{D}$ of such fabrication is being planned in the advanced LWR fuel program; however, the technical feasibility has not been established. In this case it appears that the tie bar has to be made of a SiC-based material, other design options will likely need to be considered. Such design options may include a series of shorter rods interconnected or different ways to hold the sleeves together.

\subsubsection{Control rod}

Assuming that the requirements for control rod materials are not too dissimilar between VHTR and AHTR, there has been no critical issue identified associated with the fabrication of 
control rod components with CVI SiC/SiC. However, in case that intrusion of liquid salt to inside the control rod sheath is strictly prohibited, hermeticity becomes an issue.

\subsection{CORROSION}

The extent of the corrosion behavior of materials in liquid fluoride salts is related, to some extent, to the acid-base chemistry of the salt. An explanation of this Lewis acid-base effect is presented in ORNL/TM-2006/140 [120]. Thus, while materials' corrosion performance may be ranked in the same order in different liquid fluoride salts, the extent of corrosion of a particular material can be significantly different in different liquid fluoride salts. Overall, because the dependence on a stable, compact, very slowly growing surface layer for corrosion protection does not obtain in liquid fluoride salts due to the fluxing nature of these salts, structural containment materials must be as near as possible in equilibrium with the fluoride salts. An additional factor that must be considered for heat transfer loops is the change in oxidation state with temperature for species that are redox sensitive, which can provide impetus for compatibility issues. However, it has been shown that control of the liquid salt oxidation potential can significantly reduce the extent of compatibility associated issues [122]. While there is a large body of work that can be drawn upon to understand the compatibility issues associated with metallic materials in liquid fluoride salts, especially below $750^{\circ} \mathrm{C}$ [123], there is very little information available on the behavior of silicon carbide in liquid fluoride salts. However, it is anticipated that the need for thermodynamic equilibrium and redox control will hold true for silicon carbide in the presence of liquid fluoride salts at high temperature and under flow conditions. Alas, while there is a significant body of thermodynamic information on fluoride systems associated with the liquid salt reactor fuels [124], there is a need to extend this information to include other fluoride salts of interest and nonmetallic materials such as silicon carbide.

While a significant amount of work has been performed on the behavior of silicon carbide at high temperatures in various environments, there is a dearth of information on the compatibility of silicon carbide in fluoride salts. The fusion energy community has shown some interest in the behavior of silicon carbide in $\mathrm{LiF}_{-\mathrm{BeF}_{2}}(\mathrm{FLiBe})$ (ratio of $2 \mathrm{LiF}$ to $\left.1 \mathrm{BeF}_{2}\right)$ [125]. Nishimura et al. [126], evaluated the performance of silicon carbide in $\mathrm{FLiBe}$ at $550^{\circ} \mathrm{C}$ in a nickel crucible. Neither the purity of the $\mathrm{FLiBe}$, formed by mixing $\mathrm{LiF}$ and $\mathrm{BeF}_{2}$, nor that of the flowing cover gas, argon, was provided.[126] Also, the authors did not indicate any pretest cleaning procedure for the nickel crucible. Nishimura et al., did observe "black deposits," identified as $\mathrm{Ni}_{31} \mathrm{Si}_{12}$, on 
the surface of the silicon carbide specimens after exposures for three and ten days. The nickel silicide, $\mathrm{Ni}_{31} \mathrm{Si}_{12}$, was postulated as forming from a reaction between nickel and silicon carbide. Such a reaction would give rise to a second reaction product, carbon, and an implied degradation of the silicon carbide. As a result of this sparsity of data, the behavior of silicon carbide in liquid fluoride salts can only be inferred from its behavior in other environments.

Tressler et al. [127] evaluated the behavior of hot pressed and reaction bonded silicon carbide in sodium sulfate, sodium chloride, and a $63 \% / 37 \%$ mixture of said materials in a fused silica crucible at $1000^{\circ} \mathrm{C}$ in air for times up to $120 \mathrm{~h}$. The silicon carbide specimens experienced a slight increase in weight that was attributed to the formation of a silicon dioxide surface layer. It was stated that the silicon dioxide layer was not affected by the liquid sodium chloride because the melt was not sufficiently basic (the free-oxide ion activity was not high enough). This interfacial oxidation control of the corrosion of alpha-silicon carbide (surface layer formation of silicon dioxide) and dissolution of the silicon dioxide layer have been demonstrated also by Pickrell et al.,[128] at 950 to $1100^{\circ} \mathrm{C}$ in dry air with 0.98 vol.\% sodium nitrate. In these tests, in the presence of sodium oxide, the silicon dioxide reacts to form a sodium silicate (liquid) and the overall reaction kinetics is linear.

The work cited previously indicates the formation of silicon dioxide. The work of Gulbransen and Jansson [129] has demonstrated a critical oxygen pressure for the transition from active (formation of silicon oxide and carbon monoxide with linear oxidation kinetics) at low oxygen potentials to passive (formation of self-healing silicon dioxide with parabolic oxidation kinetics) oxidation of silicon carbide. Antila and Warburton[130] demonstrated the active to passive oxidation of beta-silicon carbide occurs below $10^{-6}$ atm at $1000^{\circ} \mathrm{C}$. Ervin [131] has presented eight possible reactions between silicon carbide and oxygen to produce silicon dioxide, silicon oxide, and silicon that have negative free energy changes within the temperature range of interest and are, therefore, thermodynamically possible. Hence, unless the silicon carbide is thermodynamically stable in the liquid fluoride salt, control of the oxygen partially pressure is critical to long-term performance of silicon carbide.

Song et al.,[132] reported on the corrosion of alpha-silicon carbide in the presence of sodium sulfate under flowing argon ( $\geq 99.9999 \%)$ and argon-oxygen ( $\geq 99.99$ [sic]). The weight loss in sodium sulfate under flowing argon (oxygen partial pressure of $1.01 \times 10^{-6} \mathrm{~atm}$ ) followed linear kinetics and the surface of the specimens showed significant pitting. It was also reported that the corrosion in argon was more severe than in the argon-oxygen mixture (oxygen partial pressure of $0.20 \mathrm{~atm})$. This significant change with oxygen partial pressure was also reported by McKee and Chatterji [133] who examined the behavior of beta-silicon carbide in the presence of air, $\mathrm{O}_{2}$, 
$\mathrm{Na}_{2} \mathrm{SO}_{4}, \mathrm{Na}_{2} \mathrm{SO}_{4}+\mathrm{Na}_{2} \mathrm{CO}_{3}, \mathrm{Na}_{2} \mathrm{SO}_{4}+\mathrm{Na}_{2} \mathrm{O}, \mathrm{Na}_{2} \mathrm{SO}_{4}+\mathrm{NaNO}_{3}$, and $\mathrm{Na}_{2} \mathrm{SO}_{4}+\mathrm{Na}_{2} \mathrm{~S}$, among other environments at $900^{\circ} \mathrm{C}$. Their work concluded that in the presence of liquid salts, corrosion occurred at high oxygen partial pressures in the presence of basic salt melts and at very low oxygen partial pressures regardless of the basicity/acidity of the salt melts, and little corrosion (passivation) occurred at high oxygen partial pressures and in the presence of acidic or neutral salt melts. These modes of corrosion are presented in Figure 29. This effect for silicon carbide with respect to basic salts is consistent with the conclusions presented for metallic materials in ORNL/TM-2006/140 [120], which concludes that FLiNaK, a strongly basic salt, supports a higher degree of corrosion as compared to the other fluoride salts evaluated.

$\mathrm{SiO}_{2}-\frac{\mathrm{HIGH} \mathrm{P} \mathrm{O}_{2}}{\text { T/T/SiC T/TT }}$

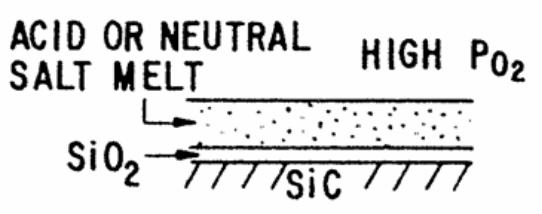

FORMS PROTECTIVE $\mathrm{SiO}_{2}$ SCALE, ALMOST INERT

PASSIVATION TO SALT MELT

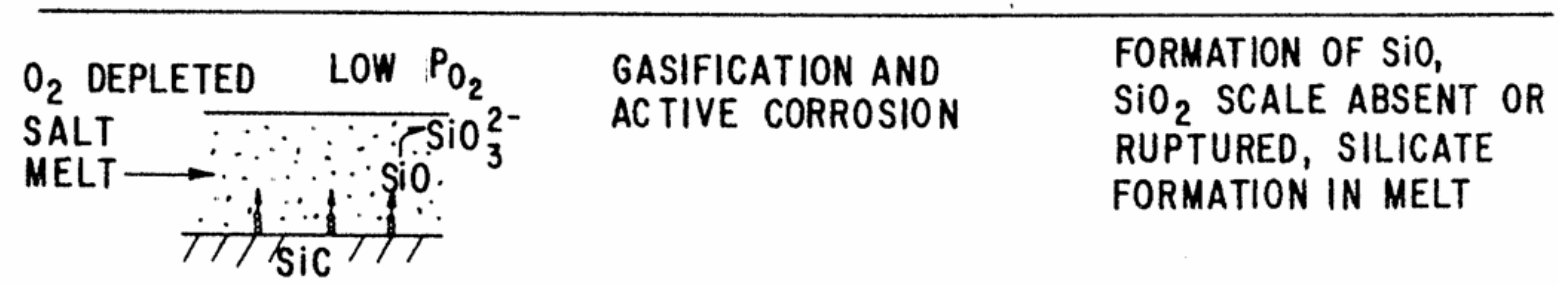

Figure 29: Three modes of silicon carbide corrosion in liquid salts. Based on McKee and Chatterji information. [133]

While the majority of work in the literature on silicon carbide corrosion in liquid salts is with salts other than halides, the sodium sulfate corrosion information in combination with the information from the two papers on halides, raise issues that must be evaluated for the use of liquid fluoride salts with silicon carbide. Work needs to be performed to create a good thermodynamic foundation for the evaluation of silicon carbide in liquid fluoride salts with 
respect to the basicity/acidity of the salt and low partial oxygen pressures that are to be expected in reactor systems. Experimental data need to be generated to support the thermodynamic analyses and to shed light on the corrosion effects in systems with varying temperatures.

\subsection{MECHANICAL INTEGRITY}

As mentioned in Section 2.4.4, it is likely that the static fatigue dictates the mechanical integrity of $\mathrm{SiC} / \mathrm{SiC}$ components during a long term service, as the static fatigue limit stress may be substantially lower than the fast fracture PLS. The states and magnitudes of stresses anticipated in the fuel rod cladding (and other components) are not defined but will be determined by the contributions from the fuel swelling, internal gas pressure, thermal gradient, swelling of cladding itself, and any other external loading. In case any of the anticipated stress component may reach 30 to $50 \%$ of the PLS in the corresponding failure mode, mechanical integrity may become a critical feasibility/design issue. These are also strongly related with the radiation effects on $\mathrm{SiC} / \mathrm{SiC}$ including radiation creep, radiation-assisted/enhanced static fatigue, thermal conductivity change, and radiation-induced strength modification.

\subsection{RADIATION EFFECTS}

As reviewed in Section 2.5, effects on radiation on materials integrity are many-fold and related each other as well as related with non-radiation effect issues. The Generation III CVI SiC/SiC is considered highly tolerant against neutron irradiation at temperatures of current interest, however, the highest dose those materials have ever been irradiated to and tested is so far slightly more than $10 \mathrm{dpa}[3,68]$. This fluence may be marginal for cladding of the thermal spectrum reactor fuel but will be far short of dose anticipated for the fast spectrum reactors. Moreover, it is likely that most of the core components will need to stay in service for substantial periods for economic reasons. Therefore, it will be important to confirm the fundamental radiation stability to doses far beyond $10 \mathrm{dpa}$, in order to assess the feasibility of $\mathrm{SiC} / \mathrm{SiC}$ for the AHTR core applications.

The long-term radiation effect issues for fuel cladding are irradiation creep and irradiationenhanced/assisted static fatigue. Assuming the internal pressurization by fuel swelling and/or fission gas production as the primary source of mechanical loading onto the fuel cladding, irradiation creep and static fatigue may lead to unacceptable extents of diametral swelling and/or uneven cross-sectional deformation. Moreover, the static fatigue failure may lead to a loss of 
fission product confinement. Therefore, understanding irradiation creep and irradiated static fatigue are both critically important technical issues. There has not been a study conducted for addressing high dose creep or static fatigue behavior of $\mathrm{SiC}$ ceramics or composites during irradiation $[3,23]$. These issues are also design issues as the thermomechanical design effort may be able to reduce the extent of criticalness.

Thermal conductivity change is unavoidable for ceramics in nuclear environments. This means that the effectiveness of material development effort to further increase the in-service thermal conductivity of $\mathrm{SiC} / \mathrm{SiC}$ will be rather limited $[50,134]$. The thermal conductivity degradation issue of fuel cladding is at least three-fold: 1) reduced thermal conductivity results in increased fuel and fuel/cladding interface temperatures, 2) reduced thermal conductivity causes thermal stress within cladding, and 3) temperature gradient within cladding imposes new issues associated with differential swelling.

In Figure 30, the approximately estimated relationship among the cladding thermal conductivity, the linear power density, and the temperature drop across the cladding wall is plotted. For the estimation in Figure 30, fuel power density of $10 \mathrm{~W} / \mathrm{cm}^{3}$ corresponds to linear power density for fuel assembly of $250 \mathrm{~W} / \mathrm{cm}$ in this calculation. It was also conservatively assumed that all the generated power is transferred as heat from inside to outside cladding across the cladding wall. Thermal conductivity of two-dimensional or braided $\mathrm{SiC} / \mathrm{SiC}$ through the wall is anticipated to be $2-3 \mathrm{~W} / \mathrm{m}-\mathrm{K}$ at $700^{\circ} \mathrm{C}$ and $\sim 5 \mathrm{~W} / \mathrm{m}-\mathrm{K}$ at $1000^{\circ} \mathrm{C}$ during and after irradiation [50]. The calculation implies that the combination of $250 \mathrm{~W} / \mathrm{cm}$ linear power density and thermal conductivity $3 \mathrm{~W} / \mathrm{m}-\mathrm{K}$ will results in temperature drop by $\sim 50 \mathrm{~K}$. The maximum thermal stress in a thin-walled tube with the trans-wall temperature drop $\Delta T$ can be approximated as $\sigma=\alpha E \Delta T / 2(1-v)$ where $\alpha=$ coefficient of thermal expansion (CTE), $E=$ Young's modulus, $v=$ Poisson's ratio. With appropriate values for these parameters, the maximum thermal stress is estimated to be $\sim 70 \mathrm{MPa}$ for $\Delta T=50 \mathrm{~K}$. The preliminary estimation here implies that the thermal stress, in particular when combined with stresses from other sources, may be a critical issue for the assumed conditions. 


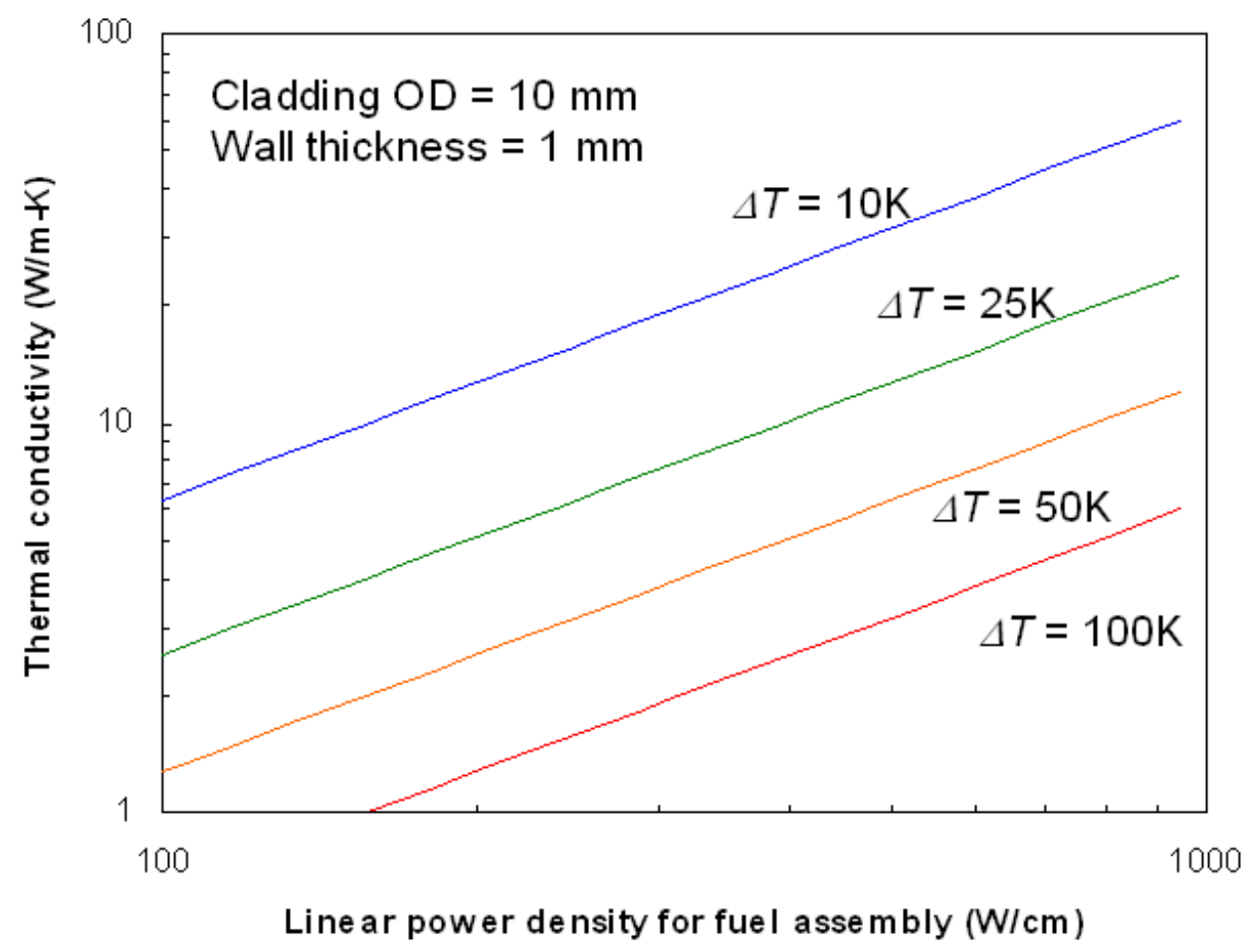

Figure 30: Influences of heat flux and thermal conductivity on magnitude of temperature drop across $\mathrm{SiC} / \mathrm{SiC}$ clad wall with given thickness.

Another issue related with the temperature gradient is associated with differential swelling. As shown in Figures 18 and 19, SiC undergoes saturatable swelling in the temperature range of interest and the magnitude of the swelling is dependent on irradiation temperature. The existing data implies the temperature coefficient for linear swelling for $\mathrm{SiC}$ to be $\sim-6 \mathrm{ppm} / \mathrm{K}$ at $700^{\circ} \mathrm{C}$, which magnitude is slightly greater than the $\mathrm{CTE} \sim 5 \mathrm{ppm} / \mathrm{K}$ at the same temperature. In this case, if irradiation creep does not at all mitigate the differential swelling-induced stress, it will be slightly greater than the thermal stress in magnitude. The contribution from irradiation creep to the swelling-induced stress can not be estimated because of the complete lack of relevant irradiation creep data. However, in Figure 31, the evolutions of swelling-induced stress for three extreme irradiation creep cases estimated in the fusion FCI are presented [135]. This estimation implies that the swelling-induced stress may possibly be mitigated to a large extent when the likely creep-swelling coupling mechanism operates. 


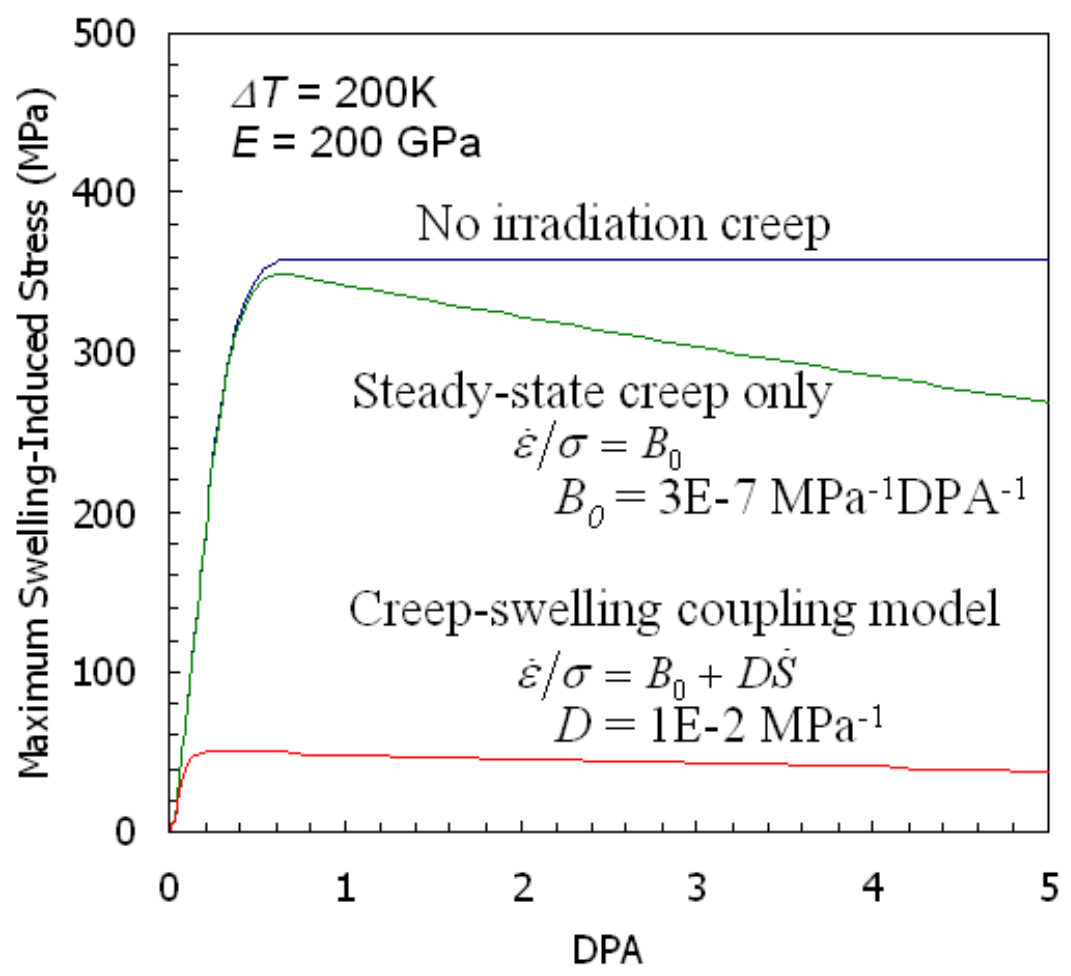

Figure 31: Influence of temperature drop by $200 \mathrm{~K}$ across clad wall on evolution of maximum swelling-induced internal stress in fully constrained clad during operation with three extreme hypothetical irradiation creep cases. Stress magnitude is roughly estimated for Young's modulus $200 \mathrm{GPa}$. Note that understanding of irradiation creep behavior of SiC-based materials is presently very insufficient. [136]

Finally, radiation effect issues are again very complex themselves and, moreover, are related with other typically non-nuclear material issues in a complex manner. As SiC ceramics and composites are not sufficiently experienced in nuclear service, it will have to be admitted that there may be radiation effect issues which are not known yet.

\subsection{COATING}

Coating is a common engineering solution for corrosion and other environmental compatibility issues for materials for non-nuclear applications. In case $\mathrm{SiC}$ appears unacceptably corrosive in the candidate salt systems for AHTR, it is natural to consider applying corrosion barrier coating on the surface of SiC-based components. In particular, carbon is a refractory material and is 
generally considered to be chemically compatible with liquid salt at elevated temperatures. Hence, carbon-based materials are the prime candidate for the coating system.

Techniques and capacity to apply pyrolytic carbon onto the $\mathrm{SiC} / \mathrm{SiC}$ surfaces are industrially available. The microstructures and properties of the carbon coating may be adjusted to a certain extent. Such adjustment may be performed for CTE matching with the SiC substrate and to minimize porosity in the coating. It is even feasible to produce a functionally graded coating in which a transition of chemical composition from SiC to carbon occurs in the coating layer. The functionally graded coating is an ideal coating technique, when available, which minimizes the CTE mismatch issue.

Main issues for the carbon coating include the radiation effect and the effectiveness as the corrosion barrier. The radiation effects issue is rather obvious because the carbon-based materials are susceptive to neutron irradiation damage at relatively low doses at high temperatures [137-146]. Under neutron irradiation, carbon materials initially densify, and then after a certain dose, start swelling. Once swelling initiates, it continues until the material completely loses integrity in an unstable manner. The dose at which the transition from densification to swelling occurs is often considered the life time, and is lower at a higher temperature. An approximate life time of isotropic graphite at $700-1000^{\circ} \mathrm{C}$ is $\sim 10 \mathrm{dpa}$.

As for the effectiveness as the corrosion barrier, carbon is generally highly porous as fabricated, incorporating numerous micro- and submicro-pores and cracks. Highly graphitized carbon contains the minimal porosity but is highly anisotropic and consequently its radiation-induced dimensional instability also is highly anisotropic. Pyrolytic carbon is in general substantially permeable by helium and other gas media. Permeability of liquid salts in carbon materials is not known within the authors' knowledge.

\subsection{TEST STANDARDS AND DESIGN CODIFICATION}

The potential use of $\mathrm{SiC} / \mathrm{SiC}$ composites in the AHTR fuel assembly will require the existence of: 1) design codes, which list "rules" and guidelines for designing and testing $\mathrm{SiC} / \mathrm{SiC}$ composite components and incorporating them into advanced designs; 2) design codes which regulate the certification procedures for processing materials, fabricating components, and assembling final designs and 3) databases that provide statistically significant and complete material properties and performance. Appropriate full-consensus test standards will be needed for all the design properties. Additionally, the design rules will likely involve the mandatory use 
of non-destructive evaluation (NDE) for fuel cladding. The design codes will have to be very significantly different from those for metallic alloys due to the need for brittle failure criteria. 


\section{PATH-FORWARD}

This chapter defines the prioritized efforts which are required to establish technical feasibility of the liquid salt-cooled AHTR fuel assembly with the $\mathrm{SiC} / \mathrm{SiC}$ composite as the primary material for the components. The critical feasibility issues identified in the previous chapter are first listed in Table 20 along with the evaluation of relative importance. The evaluation in Table 20 assumes the operating temperature and the maximum neutron dose of $800^{\circ} \mathrm{C}$ and $30 \mathrm{dpa}$, respectively, which may correspond to a relatively less severe condition regime for the AHTR core. A similar evaluation is provided for the provisional operating temperature significantly higher than $800^{\circ} \mathrm{C}$ in Table 21, which is a subset of Table 20. Explanations for the individual feasibility study items are given below. As the conclusion, the suggested directions of the nearterm proof-of-principle study for application of $\mathrm{SiC} / \mathrm{SiC}$ to AHTR fuel cladding is summarized in Table 22. 
Table 20: Critical issues and their relative importance for application of $\mathrm{SiC} / \mathrm{SiC}$ to saltcooled high temperature reactor fuel cladding. Application temperature and maximum neutron fluence are assumed to be $800^{\circ} \mathrm{C}$ and $30 \mathrm{dpa}$, respectively.

\begin{tabular}{|c|c|c|c|}
\hline Issue & Description & $\begin{array}{l}\text { Relative Importance in } \\
\text { Feasibility Study Phase }\end{array}$ & $\begin{array}{l}\text { Work in Other } \\
\text { Programs }\end{array}$ \\
\hline $\begin{array}{l}\text { Corrosion of } \mathrm{SiC} \text { with } \\
\text { or without } \mathrm{C} \text {-coating } \\
\text { in molten salt }\end{array}$ & $\begin{array}{l}\text { Published data on corrosion of } \mathrm{SiC} \\
\text { and SiC-based materials in molten } \\
\text { salt are extremely limited and } \\
\text { incomplete. }\end{array}$ & $\begin{array}{l}\text { Very high: critical } \\
\text { feasibility / design issue }\end{array}$ & None known \\
\hline $\begin{array}{l}\text { Effects of high dose } \\
\text { irradiation on } \\
\text { fundamental properties }\end{array}$ & $\begin{array}{l}\text { High dose neutron irradiation may } \\
\text { affect mechanical properties. } \\
\text { Credible data available only up to } \\
10+\text { dpa. }\end{array}$ & $\begin{array}{l}\text { High: critical feasibility } \\
\text { / design issue }\end{array}$ & $\begin{array}{l}\text { Very limited work in } \\
\text { fusion and Gen-IV } \\
\text { VHTR / GFR } \\
\text { programs }\end{array}$ \\
\hline $\begin{array}{l}\text { Static fatigue failure of } \\
\text { composite under } \\
\text { loading }\end{array}$ & $\begin{array}{l}\text { Ceramic composites may fail due } \\
\text { to slow crack growth under stress } \\
\text { in corrosive and/or radiation } \\
\text { environment, in a highly } \\
\text { architecture-dependent manner. }\end{array}$ & $\begin{array}{l}\text { High: critical feasibility } \\
\text { / design issue }\end{array}$ & $\begin{array}{l}\text { Very limited work in } \\
\text { fusion and Gen-IV } \\
\text { VHTR program }\end{array}$ \\
\hline $\begin{array}{l}\text { Irradiation creep at } \\
\text { medium temperatures }\end{array}$ & $\begin{array}{l}\text { Irradiation creep may impose } \\
\text { dimensional instability issue, but } \\
\text { also may mitigate thermal stress } \\
\text { issue. }\end{array}$ & $\begin{array}{l}\text { High: critical feasibility } \\
\text { / design issue }\end{array}$ & $\begin{array}{l}\text { Low dose, } \\
\text { fundamental study in } \\
\text { fusion program }\end{array}$ \\
\hline Fabrication technology & $\begin{array}{l}\text { Long, small diameter, thin wall } \\
\text { tube fabrication with SiC-based } \\
\text { materials does not have sufficient } \\
\text { industrial experience. Hermeticity } \\
\text { requirement adds challenge. }\end{array}$ & $\begin{array}{l}\text { Medium: important } \\
\text { engineering issue }\end{array}$ & $\begin{array}{l}\text { Limited work } \\
\text { proposed for } \\
\text { advanced LWR } \\
\text { cladding } \\
\text { development } \\
\end{array}$ \\
\hline $\begin{array}{l}\text { Radiation effect on } \\
\text { thermal conductivity }\end{array}$ & $\begin{array}{l}\text { Radiation-induced thermal } \\
\text { conductivity reduction may limit } \\
\text { core power density. }\end{array}$ & $\begin{array}{l}\text { Low: design issue but } \\
\text { unlikely imposes severe } \\
\text { limitation }\end{array}$ & $\begin{array}{l}\text { Some work in US } \\
\text { fusion program }\end{array}$ \\
\hline $\begin{array}{l}\text { Test standards and } \\
\text { design codification }\end{array}$ & $\begin{array}{l}\text { Licensing process will require } \\
\text { design codes. Design codification } \\
\text { drives test standard development. }\end{array}$ & $\begin{array}{l}\text { Low: important } \\
\text { qualification issue in } \\
\text { later phase }\end{array}$ & $\begin{array}{l}\text { Limited tube strength } \\
\text { test standardization } \\
\text { work in Gen-IV } \\
\text { VHTR program }\end{array}$ \\
\hline $\begin{array}{l}\text { Non-destructive } \\
\text { evaluation }\end{array}$ & $\begin{array}{l}\text { Licensing process will require } \\
\text { NDE scheme established. }\end{array}$ & $\begin{array}{l}\text { Low: important } \\
\text { qualification issue in } \\
\text { later phase }\end{array}$ & $\begin{array}{l}\text { Work proposed in } \\
\text { Gen-IV VHTR } \\
\text { program }\end{array}$ \\
\hline
\end{tabular}


Table 21: Critical issues and their relative importance for application of $\mathrm{SiC} / \mathrm{SiC}$ to saltcooled high temperature reactor fuel cladding at temperatures significantly higher than $8^{800} \mathrm{C}$.

\begin{tabular}{|l|l|l|l|}
\hline \multicolumn{1}{|c|}{ Issue } & \multicolumn{1}{|c|}{ Description } & $\begin{array}{l}\text { Relative Importance in } \\
\text { Feasibility Study Phase }\end{array}$ & \multicolumn{1}{c|}{$\begin{array}{c}\text { Work in Other } \\
\text { Programs }\end{array}$} \\
\hline $\begin{array}{l}\text { Irradiation creep at } \\
\text { high temperatures }\end{array}$ & $\begin{array}{l}\text { Irradiation creep may impose } \\
\text { dimensional instability issue, but } \\
\text { also may mitigate thermal stress } \\
\text { issue. }\end{array}$ & $\begin{array}{l}\text { Medium: critical issue } \\
\text { if temperature exceeds } \\
1000^{\circ} \mathrm{C} \text { with significant } \\
\text { stress applied }\end{array}$ & $\begin{array}{l}\text { Work in US/Japan } \\
\text { fusion programs }\end{array}$ \\
\hline Void swelling & $\begin{array}{l}\text { Void swelling may become } \\
\text { significant at T }>\sim 1100^{\circ} \mathrm{C} .\end{array}$ & $\begin{array}{l}\text { Low: critical feasibility } \\
\text { issue if temperature } \\
\text { largely exceeds } 1100^{\circ} \mathrm{C}\end{array}$ & $\begin{array}{l}\text { Work in US fusion } \\
\text { program }\end{array}$ \\
\hline $\begin{array}{l}\text { Corrosion by fission } \\
\text { products }\end{array}$ & $\begin{array}{l}\text { Corrosion by fission produces may } \\
\text { be significant at very high } \\
\text { temperatures }\end{array}$ & $\begin{array}{l}\text { Medium: critical } \\
\text { feasibility issue if fuel } \\
\text { temperature exceeds } \\
\text { typical HTGR TRISO } \\
\text { temperatures }\end{array}$ & $\begin{array}{l}\text { Fair amount of work } \\
\text { in previous HTGR } \\
\text { fuel programs }\end{array}$ \\
\hline
\end{tabular}

Table 22: Suggested directions of near-term proof-of-principle study for application of SiCbased materials to salt-cooled high temperature reactor fuel cladding.

\begin{tabular}{|l|l|c|c|}
\hline \multicolumn{1}{|c|}{ Subject } & \multicolumn{1}{|c|}{ Description } & Priority & $\begin{array}{c}\text { Relation with } \\
\text { Other Programs }\end{array}$ \\
\hline $\begin{array}{l}\text { Corrosion of SiC in } \\
\text { candidate molten salt }\end{array}$ & $\begin{array}{l}\text { Perform thermodynamics assessment for SiC - salt } \\
\text { systems and experimental validation work for } \\
\text { candidate systems. }\end{array}$ & 1 & None \\
\hline $\begin{array}{l}\text { Prototypical } \\
\text { demonstration }\end{array}$ & $\begin{array}{l}\text { ldentify appropriate architectures methods to secure } \\
\text { hermeticity. Produce prototypical components and } \\
\text { evaluate. Fabricate prototype components and } \\
\text { evaluate for static fatigue both in inert and simulated } \\
\text { environments. }\end{array}$ & 2 & None \\
\hline $\begin{array}{l}\text { Hetermine fundamental properties of candidate } \\
\text { effect issues }\end{array}$ & $\begin{array}{l}\text { materials after irradiation in relevant conditions. } \\
\text { Design and perform in-pile creep and static fatigue } \\
\text { experiment. }\end{array}$ & $\begin{array}{l}\text { Complement fusion } \\
\text { and Gen-IV works }\end{array}$ \\
\hline
\end{tabular}




\subsection{CORROSION OF SIC IN LIQUID SALTS}

Work needs to be performed to create a good thermodynamic foundation for the evaluation of silicon carbide in liquid fluoride salts with respect to the basicity/acidity of the salt and low partial oxygen pressures that are to be expected in reactor systems. Experimental data need to be generated to support the thermodynamic analyses and to shed light on the corrosion effects in systems with varying temperatures.

Task 1: Thermodynamic Stability Assessment

Work needs to be performed to create a good thermodynamic foundation for the evaluation of silicon carbide in liquid fluoride salts with respect to the basicity/acidity of the salt and low partial oxygen pressures that are to be expected in reactor systems. This would extend the formula of Bates [124].

\section{Task 2: Experimental Assessment of Silicon Carbide for Liquid-Salt Service}

Experimental data need to be generated to support the thermodynamic analyses. In addition, corrosion effects of silicon carbide for liquid salt service must be evaluated so that: the identity and concentration of material element(s) migrating (thermodynamic stability effects) into the salt can be ascertained; the effect of oxygen partial pressure and other impurities on corrosion with respect to acid, basic or neutral salts can be determined; and the effect of activity gradients of dissimilar materials in the salt on corrosion can be ascertained.

\section{Task 3: Assessment of Temperature-Gradient-Assisted Corrosion Effects}

Because an operating reactor system is not isothermal, corrosion reactions driven by thermodynamic considerations or impurity reactions, which can have different solubility limits at various temperatures, or for which a change in oxidation state with temperature for species that are redox sensitive, can result in significant differential mass transport. This is particularly detrimental to piping and heat exchangers. 


\subsection{PROTOTYPICAL DEMONSTRATION}

Task 1: Design and fabricate prototypical fuel rod cladding

Designing an adequate composite cladding takes substantial trade-off study among various candidate architectures. In other words, the tube architecture will influence various fundamental properties of the cladding. Moreover, without defining the tube architecture, realistic design consideration associated with mechanical, thermal, and life time properties of the materials will be extremely limited. Therefore, the reference cladding architecture should be defined during the early period of the project. Once the reference component is designed, prototypical component should be fabricated and evaluated for fundamental characteristics.

Task 2: Stress rupture / static fatigue evaluation

Tubular components of $\mathrm{SiC} / \mathrm{SiC}$ do not have industrial experience to serve for a prolonged period in conditions relevant to the AHTR fuel cladding, e.g., with internal pressurization or other mechanical loading. Therefore, a prototypical component will need to be tested for its ability to withstand the mechanical loading in prototypical conditions. The testing will likely be a stressrupture type experiment in order to evaluate primarily the static fatigue behavior. The next stage of this task will be the same testing in the candidate salt environment.

\subsection{EFFECTS OF HIGH DOSE IRRADIATION ON FUNDAMENTAL PROPERTIES OF SIC/SIC}

Task 1: High dose radiation effect on strength of $\mathrm{SiC} / \mathrm{SiC}$

Experimental data need to be generated to study if $\mathrm{SiC} / \mathrm{SiC}$ components maintain fundamental integrity to doses and at temperatures relevant to the AHTR fuel cladding and other fuel assembly components. The ongoing irradiation campaign in the NGNP Composite R\&D program will cover up to $30 \mathrm{dpa}$ at $800^{\circ} \mathrm{C}$. In case the NGNP irradiation condition appears insufficient, the AHTR project may have to consider its own irradiation program.

Task 2: Radiation effect on thermal conductivity of $\mathrm{SiC} / \mathrm{SiC}$

Transverse thermal conductivity of $\mathrm{SiC} / \mathrm{SiC}$ fuel cladding under irradiation is of crucial importance both for fuel temperature control and secondary stress issues within the cladding itself. The phenomenological understanding of neutron irradiation-induced thermal conductivity 
degradation in $\mathrm{SiC}$ ceramics and the constitutive modeling of composite thermal conductivity have matured, however, they have not reached the status so that the model estimation may be used to quantitatively evaluate the fuel temperature and the magnitude of secondary stresses. Moreover, there are no experimental data at doses greater than a few dpa. As the studies on thermal conductivity issues are ongoing in the US fusion materials program, it is suggested to advance those studies in collaboration with the fusion program.

Task 3: Irradiation creep and in-pile static fatigue

Both the irradiation creep and the in-pile static fatigue behaviors of $\mathrm{SiC}$ ceramics and composites in the medium to high dose regimes are completely unknown. Fortunately, a low-cost irradiation technique for studying both phenomena is being developed in naval reactor materials and fusion materials program primarily for metallic materials research. It is highly preferable to perform a small experiment on high dose irradiation creep at $800^{\circ} \mathrm{C}$, as the first step, to determine if serious irradiation creep issue may exist or not at the temperature. 


\section{REFERENCES}

[1] C.W. Forsberg, The Advanced High-Temperature Reactor: High-Temperature Fuel, Liquid Salt Coolant, and Liquid-Metal-Reactor Plant, Progress in Nuclear Energy, 47 (2005) 32-43.

[2] C.W. Forsberg, D.T. Ingersoll, P. Peterson, H. Zhao, J.E. Cahalan, T. Taiwo, J.A. Enneking, R.A. Kochendafer, P.E. MacDonald, Refueling Options and Considerations for Liquid-Salt-Cooled Very High-Temperature Reactors, ORNL/TM-2006/92, in, Oak Ridge National Laboratory, Oak Ridge, Tennessee, 2006.

[3] Y. Katoh, L.L. Snead, C.H. Henager, A. Hasegawa, A. Kohyama, B. Riccardi, J.B.J. Hegeman, Current status and critical issues for development of $\mathrm{SiC}$ composites for fusion applications, J. Nucl. Mater., 367-370 (2007) 659-671.

[4] B. Riccardi, L. Giancarli, A. Hasegawa, Y. Katoh, A. Kohyama, R.H. Jones, L.L. Snead, Issues and advances in $\mathrm{SiCf} / \mathrm{SiC}$ composites development for fusion reactors, J. Nucl. Mater., 329-33 (2004) 56-65.

[5] R.H. Jones, L. Giancarli, A. Hasegawa, Y. Katoh, A. Kohyama, B. Riccardi, L.L. Snead, W.J. Weber, Promise and challenges of $\mathrm{SiCf} / \mathrm{SiC}$ composites for fusion energy applications, J. Nucl. Mater., 307 (2002) 1057-1072.

[6] L.L. Snead, R.H. Jones, A. Kohyama, P. Fenici, Status of silicon carbide composites for fusion, J. Nucl. Mater., 233-237 (1996) 26-36.

[7] M. Abdou, D.-K. Sze, C. Wong, M. Sawan, A. Ying, N.B. Morley, S. Malang, U.S. Plans and Strategy for ITER Blanket Testing, Fusion Sci. Tech., 47 (2005) 475-487.

[8] G.O. Hayner, E.L. Shaber, R.E. Mizia, R.L. Bratton, W.K. Sowder, R.N. Wright, W.E. Windes, T.C. Totemeier, K.A. Moore, W.R. Corwin, T.D. Burchell, J.M. Corum, J.W. Klett, R.K. Nanstad, L.L. Snead, P.L. Rittenhouse, R.W. Swindeman, D.F. Wilson, T.E. McGreevy, R.H. Jones, F. Gardner, Next Generation Nuclear Plant Materials Research and Development Program Plan, in, Idaho National Engineering and Environmental Laboratory, Idaho Falls, Idaho, 2004.

[9] T. Ishikawa, S. Kajii, K. Matsunaga, T. Hogami, T. Kohtoku, T. Nagasawa, A tough, thermally conductive silicon carbide composite with high strength up to $1600 \mathrm{C}$ in air, Science, 282 (1998) 1295-1297.

[10] R. Naslain, Design, preparation and properties of non-oxide CMCs for application in engines and nuclear reactors: an overview, Composites Science and Technology, 64 (2004) 155-170.

[11] Y. Katoh, A. Kohyama, T. Nozawa, M. Sato, SiC/SiC composites through transient eutectic-phase route for fusion applications, J. Nucl. Mater., 329-33 (2004) 587-591.

[12] A. Kohyama, S.M. Dong, Y. Katoh, Development of SiC/SiC Composites by NanoInfiltration and Transient Eutectoid (NITE) Process, Ceram. Eng. Sci. Proc., 23 (2002) 311-318. 
[13] Y. Katoh, S.M. Dong, A. Kohyama, Thermo-mechanical properties carbide composites fabricated and microstructure of silicon by nano-infiltrated transient eutectoid process, Fusion Eng. Design, 61-2 (2002) 723-731.

[14] S. Suyama, Y. Itoh, A. Kohyama, Y. Katoh, Development of high strength reactionsintered silicon carbide, Journal of the Ceramic Society of Japan, 109 (2001) 315-321.

[15] Y. Katoh, M. Kotani, H. Kishimoto, W. Yang, A. Kohyama, Properties and radiation effects in high-temperature pyrolyzed PIP-SiC/SiC, J. Nucl. Mater., 289 (2001) 42-47.

[16] Y. Katoh, A. Kohyama, T. Hinoki, L.L. Snead, Progress in SiC-based ceramic composites for fusion applications, Fusion Sci. Tech., 44 (2003) 155-162.

[17] R.J. Price, G.R. Hopkins, Flexural strength of proof-tested and neutron-irradiated silicon carbide, J. Nucl. Mater., 108\&109 (1982) 732-738.

[18] A.M. Carey, F.J. Pineau, C.W. Lee, J.C. Corelli, Radiation response of reaction-bonded and sintered SiC: effects of boron isotopes, J. Nucl. Mater., 103\&104 (1981) 789-794.

[19] L.L. Snead, S.J. Zinkle, D. Steiner, Radiation induced microstructure and mechanical property evolution of $\mathrm{SiC} / \mathrm{C} / \mathrm{SiC}$ composite material, J. Nucl. Mater., 191-194 (1992) $560-565$.

[20] L.L. Snead, O.J. Schwarz, Advanced SiC composites for fusion applications, J. Nucl. Mater., 219 (1995) 3-14.

[21] S.M. Dong, Y. Katoh, A. Kohyama, Preparation of SiC/SiC composites by hot pressing, using Tyranno-SA fiber as reinforcement, J. Ameri. Ceram. Soc., 86 (2003) 26-32.

[22] A. Kohyama, T. Hinoki, J.S. Park, M. Sato, Materials design of NITE-SiC/SiC for VHTR/GFR and fusion, Journal of Nuclear Materials, (submitted).

[23] Y. Katoh, L.L. Snead, T. Nozawa, W.E. Windes, N.B. Morley, Advanced RadiationResistant Ceramic Composites, Advances in Science and Technology, 45 (2006) 19151924.

[24] R.B. Matthews, Irradiation damage in reaction-bonded silicon carbide, J. Nucl. Mater., 51 (1974) 203-208.

[25] J.B.J. Hegeman, J.G. van der Laan, M. van Kranenburg, M. Jong, D.S. d'Hulst, P. ten Pierick, Mechanical and thermal properties of $\mathrm{SiCf} / \mathrm{SiC}$ composites irradiated with neutrons at high temperatures, Fusion Eng. Design, 75-59 (2005) 789-793.

[26] M. Kotani, Y. Katoh, A. Kohyama, M. Narisawa, Fabrication and oxidation-resistance property of allylhydridopolycarbosilane-derived $\mathrm{SiC} / \mathrm{SiC}$ composites, Journal of the Ceramic Society of Japan, 111 (2003) 300-307.

[27] Y. Katoh, T. Nozawa, M. Kotani, K. Ozawa, A. Kohyama, Microstructures and flexural properties of high temperature-pyrolyzed PIP-SiC/SiC composites, Key Engineering Materials, 287 (2005) 346-351.

[28] S.P. Lee, J.O. Jin, J.S. Park, A. Kohyama, Y. Katoh, H.K. Yoon, D.S. Bae, I.S. Kim, High temperature characterization of reaction sintered $\mathrm{SiC}$ based materials, J. Nucl. Mater., 329-33 (2004) 534-538. 
[29] A. Kohyama, T. Hinoki, J.S. Park, M. Sato, Materials design of NITE-SiC/SiC for VHTR/GFR and fusion, J. Nucl. Mater., (accepted for publication).

[30] M.C. Halbig, M. Singh, T.P. Shpargel, J.D. Kiser, Diffusion bonding of silicon carbide ceramics using titanium interlayers, Ceram. Eng. Sci. Proc., 27 (2006) 133-143.

[31] B.V. Cockeram, Flexural Strength and Shear Strength of Silicon Carbide to Silicon Carbide Joints Fabricated by a Molybdenum Diffusion Bonding Technique, J. Ameri. Ceram. Soc., 88 (2005) 1892-1899.

[32] T. Hinoki, N. Eiza, S.J. Son, K. Shimoda, J.K. Lee, A. Kohyama, Development of joining and coating tehnique for $\mathrm{SiC}$ and $\mathrm{SiC} / \mathrm{SiC}$ Composites utilizing NITE processing, Ceram. Eng. Sci. Proc., 26 (2005) 399-405.

[33] S. Harrison, H.L. Marcus, Gas-phase selective area laser deposition (SALD) joining of SiC, Materials and Design, 20 (1999) 147-152.

[34] Y. Katoh, M. Kotani, A. Kohyama, M. Montorsi, M. Salvo, M. Ferraris, Microstructure and mechanical properties of low-activation glass-ceramic joining and coating for $\mathrm{SiC} / \mathrm{SiC}$ composites, J. Nucl. Mater., 283 (2000) 1262-1266.

[35] S. Yajima, J. Hayashi, Development of a silicon carbide fibre with high tensile strength, Nature, 261 (1976) 683-685.

[36] T. Ishikawa, Recent developments of the SiC fiber Nicalon and its composites, including properties of the $\mathrm{SiC}$ fiber hi-Nicalon for ultra-high temperature, Composite Sci. Tech., 51 (1994) 135-144.

[37] M. Takeda, A. Saeki, J. Sakamoto, Y. Imai, H. Ichikawa, Effect of hydrogen atmosphere on pyrolysis of cured polycarbosilane fibers, J. Ameri. Ceram. Soc., 83 (2000) 1063-1069.

[38] T. Ishikawa, Y. Kohtoku, K. Kumagawa, T. Yamamura, T. Nagasawa, High-strength alkali-resistant sintered $\mathrm{SiC}$ fibre stable to $2,200^{\circ} \mathrm{C}$, Nature, 391 (1998) 773-775.

[39] G.N. Morscher, J. Martines-Fernandez, Fiber effects on minicomposite mechanical properties for several silicon carbide fiber-chemically vapor-infiltrated silicon carbide matrix systems, J. Ameri. Ceram. Soc., 82 (1999) 145-155.

[40] H. Ichikawa, Development of high performance $\mathrm{SiC}$ fibers derived from polycarbosilane using electron beam irradiation curing-a review, Journal of the Ceramic Society of Japan, 114 (2006) 455-460.

[41] T. Nakayasu, M. Sato, T. Yamamura, K. Okamura, Y. Katoh, A. Kohyama, Recent Advancement of Tyranno/SiC Composites R\&D, Ceram. Eng. Sci. Proc., 20 (1999) 301308.

[42] H.M. Yun, J.A. DiCarlo, Comparison of the tensile, creep, and rupture strength properties of stoichiometric SiC fibers, Ceram. Eng. Sci. Proc., 20 (1999) 259-272.

[43] G.A. Newsome, L.L. Snead, T. Hinoki, Y. Katoh, D. Peters, Evaluation of neutron irradiated silicon carbide and silicon carbide composites, J. Nucl. Mater., 371 (2007) 7689. 
[44] J.B. Davis, R.S. Hay, D.B. Marshall, P.E.D. Morgan, A. Sayir, Influence of interfacial roughness on fiber sliding in oxide composites with La-monazite interphases, J. Ameri. Ceram. Soc., 86 (2003) 305-316.

[45] Y. Katoh, T. Nozawa, L.L. Snead, Mechanical properties of thin pyrolitic carbon interphase SiC-Matrix composites reinforced with near-stoichiometric SiC fibers, J. Ameri. Ceram. Soc., 88 (2005) 3088-3095.

[46] Y. Katoh, L.L. Snead, T. Nozawa, T. Hinoki, A. Kohyama, N. Igawa, T. Taguchi, Mechanical properties of chemically vapor-infiltrated silicon carbide structural composites with thin carbon interphases for fusion and advanced fission applications, Materials Transactions, 46 (2005) 527-535.

[47] T. Nozawa, E. Lara-Curzio, Y. Katoh, R.J. Shinavski, Tensile Properties of Advanced $\mathrm{SiC} / \mathrm{SiC}$ Composites for Nuclear Control Rod Applications, in: E. Lara-Curzio (Ed.) Mechanical Properties and Performance of Engineering Ceramics and Composites III, Wiley, 2007, pp. 223-234.

[48] W. Yang, A. Kohyama, Y.T. Katoh, H. Araki, J.N. Yu, T. Noda, Effect of carbon and silicon carbide/carbon interlayers on the mechanical Behavior of tyranno-SA-fiberreinforced silicon carbide-matrix composites, J. Ameri. Ceram. Soc., 86 (2003) 851-856.

[49] A.G. Evans, J.-M. Domergue, E. Vagaggini, Methodology for relating the tensile constitutive behavior of ceramic-matrix composites to constituent properties, J. Ameri. Ceram. Soc., 77 (1994) 1425-1435.

[50] Y. Katoh, T. Nozawa, L.L. Snead, T. Hinoki, A. Kohyama, Property tailorability for advanced CVI silicon carbide composites for fusion, Fusion Eng. Design, 81 (2006) 937944.

[51] S. Zhu, M. Mizuno, Y. Kagawa, Y. Mutoh, Monotonic tension, fatigue and creep behavior of SiC-fiber-reinforced SiC-matrix composites: a review, Composite Sci. Tech., 59 (1999) 833-851.

[52] B. Riccardi, E. Trentini, M. Labanti, M. Leuchs, S. Roccella, E. Visca, Characterization of commercial grade Tyranno SA/CVI-SiC composites, J. Nucl. Mater., (accepted for publication).

[53] R.H. Jones, C.H. Henager, Subcritical crack growth processes in $\mathrm{SiC} / \mathrm{SiC}$ ceramic matrix composites, J. Eu. Ceram. Soc., 25 (2005) 1717-1722.

[54] M. Mizuno, S. Zhu, Y. Kagawa, H. Kaya, Stress, strain and elastic modulus behaviour of $\mathrm{SiC} / \mathrm{SiC}$ composites during creep and cyclic fatigue, J. Eu. Ceram. Soc., 18 (1998) 1869-1878.

[55] T. Nozawa, Y. Katoh, A. Kohyama, E. Lara-Curzio, Effect of Specimen Size and Fiber Orientation on the Tensile Properties of SiC/SiC Composites, in: 25th Annual International Conference on Advanced Ceramics \& Composites, Cocoa Beach, 2001.

[56] C. Cady, F.E. Heredia, A.G. Evans, In-Plane Mechanical Properties of Several CeramicMatrix Composites, J. Ameri. Ceram. Soc., 78 (1995) 2065-2078.

[57] W.A. Curtin, Theory of mechanical properties of ceramic-matrix composites, J. Ameri. Ceram. Soc., 74 (1991) 2837-2845. 
[58] Y. Katoh, L.L. Snead, Mechanical Properties of Cubic Silicon Carbide after Neutron Irradiation at Elevated Temperatures, J. ASTM. Int., 2 (2005) 12377-12371-12313.

[59] L.L. Snead, T. Nozawa, Y. Katoh, T.S. Byun, S. Kondo, D.A. Petti, Handbook on SiC Properties for Fuel Performance Modeling, J. Nucl. Mater., 371 (2007) 329-377.

[60] W. Dienst, T. Fett, R. Heidinger, H.D. Roehrig, B. Schulz, Investigation on ceramic materials for fusion technology, J. Nucl. Mater., 174 (1990) 102-109.

[61] B.E. Sheldon, UKAEA Report AERE-R8025, in, 1975.

[62] T. Hinoki, A. Kohyama, Y. Katoh, K. Ozawa, T. Nozawa, Irradiation Effect on NITE$\mathrm{SiC} / \mathrm{SiC}$ Composites, J. Nucl. Mater., (accepted for publication).

[63] L.L. Snead, Y. Katoh, A. Kohyama, J.L. Bailey, N.L. Vaughn, R.A. Lowden, Evaluation of neutron irradiated near-stoichiometric silicon carbide fiber composites, J. Nucl. Mater., 283-287 (2000) 551-555.

[64] T. Hinoki, L.L. Snead, Y. Katoh, A. Hasegawa, T. Nozawa, A. Kohyama, The effect of high dose/high temperature irradiation on high purity fibers and their silicon carbide composites, J. Nucl. Mater., 307 (2002) 1157-1162.

[65] T. Nozawa, T. Hinoki, L.L. Snead, Y. Katoh, A. Kohyama, Neutron irradiation effects on high-crystallinity and near-stoichiometry SiC fibers and their composites, J. Nucl. Mater., 329-33 (2004) 544-548.

[66] T. Nozawa, K. Ozawa, S. Kondo, T. Hinoki, Y. Katoh, L.L. Snead, A. Kohyama, Tensile, Flexural, and Shear Properties of Neutron Irradiated SiC/SiC Composites with Different Fiber-Matrix Interfaces, J. ASTM. Int., 2 (2005) 12884-12881-12813.

[67] K. Ozawa, T. Nozawa, Y. Katoh, T. Hinoki, A. Kohyama, Mechanical Properties and Microstructure of Advanced $\mathrm{SiC} / \mathrm{SiC}$ composites after Neutron Irradiation, Journal of Nuclear Materials, (submitted).

[68] K. Ozawa, T. Nozawa, Y. Katoh, T. Hinoki, A. Kohyama, Mechanical Properties and Microstructure of Advanced $\mathrm{SiC} / \mathrm{SiC}$ composites after Neutron Irradiation, J. Nucl. Mater., 367-370 (2007) 713-718.

[69] Y. Katoh, T. Nozawa, L.L. Snead, T. Hinoki, Effect of Neutron Irradiation on Tensile Properties of Unidirectional Silicon Carbide Composites, Journal of Nuclear Materials, (submitted).

[70] Y. Katoh, A. Kohyama, L.L. Snead, T. Hinoki, A. Hasegawa, Neutron Tolerance of Advanced SiC-Fiber / CVI-SiC Composites, in: 19th IAEA Fusion Energy Conference, 2002, pp. FT/P1-03.

[71] L.L. Snead, S.J. Zinkle, D.P. White, Thermal conductivity degradation of ceramic materials due to low temperature, low dose neutron irradiation, J. Nucl. Mater., 340 (2005) 187-202.

[72] L.L. Snead, Degradation in thermal conductivity of SiC and SiC composites, in: A. Kohyama, R.H. Jones, B. Riccardi (Eds.) The Sixth IEA International Workshop on SiC/SiC Ceramic Composites for Fusion Applications, Boston, 2004, pp. 197-208. 
[73] Y. Katoh, N. Hashimoto, S. Kondo, L.L. Snead, A. Kohyama, Microstructural Development in Cubic Silicon Carbide during Irradiation at Elevated Temperatures, J. Nucl. Mater., 351 (2006) 228-240.

[74] Y. Katoh, H. Kishimoto, A. Kohyama, The influences of irradiation temperature and helium production on the dimensional stability of silicon carbide, J. Nucl. Mater., 307 (2002) 1221-1226.

[75] L.L. Snead, S.J. Zinkle, J.C. Hay, M.C. Osborne, Amorphization of SiC under ion and neutron irradiation, Nucl. Inst. Meth. in Phys. Res. B, 141 (1998) 123-132.

[76] L.L. Snead, S.J. Zinkle, Structural relaxation in amorphous silicon carbide, Nucl. Inst. Meth. in Phys. Res. B, 191 (2002) 497-503.

[77] S.I. Golubov, A theoretical study of the kinetics of low-temperature irradiation of metals, Phys. Met. Metall., 60 (1985) 7-13.

[78] Y. Katoh, Modeling swelling and creep behavior of silicon carbide during irradiation, (to be submitted).

[79] T. Yano, H. Miyazaki, M. Akiyoshi, T. Iseki, X-ray diffractometry and high-resolution electron microscopy of neutron-irradiated $\mathrm{SiC}$ to a fluence of $1.9 \times 1027 \mathrm{n} / \mathrm{m} 2$, J. Nucl. Mater., 253 (1998) 78-86.

[80] Y. Katoh, H. Kishimoto, A. Kohyama, Low temperature swelling in beta-SiC associated with point defect accumulation, Materials Transactions, 43 (2002) 612-616.

[81] R.J. Price, Thermal conductivity of neutron-irradiated pyrolytic b-silicon carbide, J. Nucl. Mater., 46 (1973) 268-272.

[82] D.J. Senor, G.E. Youngblood, L.R. Greenwood, D.V. Archer, D.L. Alexander, M.C. Chen, G.A. Newsome, Defect structure and evolution in silicon carbide irradiated to 1 dpa-SiC at 1100C, J. Nucl. Mater., 317 (2003) 145-159.

[83] S. Kondo, K.H. Park, Y. Katoh, A. Kohyama, High temperature ion-irradiation effects on microstructural evolution in b-SiC, Fusion Sci. Tech., 44 (2003) 181-185.

[84] H. Itoh, N. Hayakawa, I. Nashiyama, E. Sakuma, Electron spin resonance in electronirradiated 3C-SiC, Journal of Applied Physics, 66 (1989) 4529-4531.

[85] A. Kawasuso, H. Itoh, N. Morishita, T. Ohshima, I. Nashiyama, S. Okada, H. Okumura, $\mathrm{S}$. Yoshida, Silicon vacancies in 3C-SiC observed by positron lifetime and electron spin resonance, Applied Physics, A 67 (1998) 209-212.

[86] S. Kondo, Y. Katoh, L.L. Snead, Microstructural defects in SiC neutron irradiated at very high temperatures, J. Nucl. Mater., (submitted).

[87] L.L. Snead, Y. Katoh, S. Connery, Swelling of SiC at Intermediate and High Irradiation Temperatures, J. Nucl. Mater., 367-370 (2007) 677-684.

[88] R.J. Price, Properties of silicon carbide for nuclear fuel particle coatings, Nucl. Tech., 35 (1977) 320-336.

[89] R. Scholz, Deuteron irradiation creep of chemically vapor deposited silicon carbide fibers, J. Nucl. Mater., 254 (1998) 74-77. 
[90] R. Scholz, Light ion irradiation creep of SiC fibers in torsion, J. Nucl. Mater., 258-263 (1998) 1533-1539.

[91] R. Scholz, G.E. Youngblood, Irradiation creep of advanced silicon carbide ®bers, J. Nucl. Mater., 283-287 (2000) 372-375.

[92] R. Scholz, R. Mueller, D. Lesueur, Light ion irradiation creep of Textron SCS-6 silicon carbide fibers, J. Nucl. Mater., 307-311 (2002) 1183-1186.

[93] Y. Katoh, L.L. Snead, T. Hinoki, S. Kondo, A. Kohyama, Irradiation Creep of Chemically Vapor Deposited Silicon Carbide as Estimated by Bend Stress Relaxation Method, J. Nucl. Mater., 367-370 (2007) 758-763.

[94] K. Ehrlich, Irradiation creep and interrelation with swelling in austenitic stainless steels, J. Nucl. Mater., 100 (1981) 149-166.

[95] J.R. Matthews, M.W. Finnis, Irradiation creep models - an overview, J. Nucl. Mater., 159 (1988) 257-285.

[96] E. Lara-Curzio, M.G. Jenkins, Development of test standards for continuous fiber ceramic composites in the United States, Composites Part A, 30 (1999) 561-567.

[97] J.M. Wells, On non-destructive evaluation techniques for ballistic impact damage in armor ceramics, Ceram. Eng. Sci. Proc., 26 (2005) 239-248.

[98] S. Sharafat, F. Najmabadi, C.P.C. Wong, T.A. Team, ARIES-I fusion-power-core engineering, Fusion Eng. Design, 18 (1991) 215-222.

[99] A.R. Raffray, R. Jones, G. Aiello, M. Billone, L. Giancarli, H. Golfier, A. Hasegawa, Y. Katoh, A. Kohyama, S. Nishio, B. Riccardi, M.S. Tillack, Design and material issues for high performance SiCf/SiC-based fusion power cores, Fusion Eng. Design, 55 (2001) 5595.

[100] S.J. Zinkle, Advanced materials for fusion technology, Fusion Eng. Design, 74 (2005) $31-40$.

[101] L. Giancarli, H. Golfier, S. Nishio, A.R. Raffray, C.P.C. Wong, R. Yamada, Progress in blanket designs using SiCf/SiC composites, Fusion Eng. Design, 61-62 (2002) 307-318.

[102] D. Maisonnier, I. Cook, P. Sardain, R. Andreani, L. Di Pace, R. Forrest, L. Giancarli, S. Hermsmeyer, P. Norajitra, N. Taylor, D. Ward, A conceptual study of commercial fusion power plants, in, European Fusion Development Agreement, 2005.

[103] A.R. Raffray, L. El-Guevaly, S. Gordeev, S. Malang, E. Mogahed, F. Najmabadi, I. Sviatoslavsky, D.-K. Sze, M.S. Tillack, X. Wang, A. Team, High performance blanket for ARIES-AT power plant, Fusion Eng. Design, 58-59 (2001) 549-553.

[104] S. Nishio, S. Ueda, I. Aoki, R. Kurihara, T. Kuroda, H. Miura, T. Kunugi, Y. Seki, T. Nagashima, M. Ohta, J. Adachi, S. Yamazaki, I. Kawaguchi, T. Hashimoto, K. Shinya, Y. Murakami, H. Takase, T. Nakamura, Improved tokamak concept focusing on easy maintenance, Fusion Eng. Design, 41 (1998) 357-364.

[105] P. Norajitra, e. al., The EU advanced lead lithium blanket concept using SiCf/SiC flow channel inserts as electrical and thermal insulators, in: 21st Symposium on Fusion Technology, Madrid, Spain, 2000. 
[106] D.-K. Sze, M.S. Tillack, L. El-Guevaly, Blanket system election for the ARIES-ST, Fusion Eng. Design, 48 (2000) 371-378.

[107] C.P.C. Wong, V. Chernov, A. Kimura, Y. Katoh, N.B. Morley, T. Muroga, K.W. Song, Y.C. Wu, M. Zmitko, ITER Test Blanket Module Functional Materials, Journal of Nuclear Materials, (submitted).

[108] P. Norajitra, L. Buehler, U. Fischer, S. Gordeev, S. Malang, G. Reimann, Conceptual design of the dual-coolant blanket in the frame of the EU power plant conceptual study, Fusion Eng. Design, 69 (2003) 669-673.

[109] P. Norajitra, L. Buhler, U. Fischer, K. Kleefeldt, S. Malang, G. Reimann, H. Schnauder, L. Giancarli, H. Golfier, Y. Poitevin, J.F. Salavy, The EU advanced lead lithium blanket concept using $\mathrm{SiCf} / \mathrm{SiC}$ flow channel inserts as electrical and thermal insulators, Fusion Eng. Design, 58-59 (2001) 629-634.

[110] W.R. Corwin, T.D. Burchell, W.G. Halsey, G.O. Hayner, Y. Katoh, J.W. Klett, T.E. McGreevy, R.K. Nanstad, W. Ren, L.L. Snead, R.E. Stoller, D.F. Wilson, Updated Generation IV Reactors Integrated Materials Technology Program Plan, Revision 2, ORNL/TM-2003/244/R2, in, Oak Ridge National Laboratory, 2005.

[111] H.D. Gougar, C.B. Davis, Reactor pressure vessel temperature analysis for prismatic and pebble-bed VHTR designs, in, Idaho National Laboratory, 2006.

[112] Y. Tachibana, S. Shiozawa, J. Fukakura, F. Matsumoto, T. Araki, Integrity assessment of the high temperature engineering test reactor (HTTR) control rod at very high temperatures, Nuclear Engineering and Design, 172 (1997) 93-102.

[113] M. Konomura, T. Mizuno, T. Saigusa, Y. Ohkubo, A Promising Gas-Cooled Fast Reactor Concept and Its R\&D Plan, in: GLOBAL 2003, New Orleans, 2003.

[114] A. Kohyama, Present status of NITE-SiC/SiC for advanced nuclear energy systems, in: 31st International Conference on Advanced Ceramics and Composites, Daytona Beach, 2007.

[115] S. Konishi, Technology development for compact intermediate heat exchangers made of advanced composite, in, Kyoto University, Kyoto, Japan, 2007.

[116] Z. Alkan, K. Kugeler, R. Kaulbarsch, C. Manter, Silicon carbide encapsulated fuel pellets for light water reactors, Progress in Nuclear Energy, 38 (2001) 411-414.

[117] H. Feinroth, A multi-layered ceramic composite for impermeable fuel cladding for commercial water reactors, in, Gamma Engineering, 2005.

[118] C. Forsberg, Fuel Geometry Options for Salt-Cooled Advanced High-Temperature Reactors, in: ICAPP 2007, Nice, France, 2007.

[119] C.W. Forsberg, Goals, Requirements, and Design Implications for the Advanced HighTemperature Reactor, in: 14th International Conference on Nuclear Energy, American Society of Mechanical Engineers, American Society of Mechanical Engineers, Miami, Florida, 2006. 
[120] D.T. Ingersoll, C.W. Forsberg, P.E. MacDonald, Trade Studies on the Liquid-SaltCooled Very High-Temperature Reactor: Fiscal Year 2006 Progress Report, ORNL/TM2006/140, in, Oak Ridge National Laboratory, Oak Ridge, Tennessee, 2006.

[121] Y. Katoh, L.L. Snead, E. Lara-Curzio, W.E. Windes, R.J. Shinavski, Summary of SiC Tube Architecture and Fabrication, in, Oak Ridge National Laboratory, 2005.

[122] J.R. Keiser, Status of Tellurium-Hastelloy N Studies in Molten Fluoride Salts, ORNL/TM-6002, in, Oak Ridge National Laboratory, Oak Ridge, Tennessee, 1997, pp. September.

[123] J.H. DeVan, R.B.I. Evans, Corrosion Behavior of Reactor Materials in Fluoride Salt Mixtures, ORNL/TM-328, in, Oak Ridge National Laboratory, Oak Ridge, Tennessee, 1962.

[124] C.F. Bates, The Chemistry and Thermodynamics of Molten Salt Reactor Fuels, J. Nucl. Mater., 51 (1974) 149-162.

[125] A. Sagara, T. Muroga, O. Motojima, T. Noda, S. Tanaka, T. Terai, A. Kohyama, H. Matsui, Materials Design and Related R\&D Issues for Force-free Helical Reactor (FFHR), J. Nucl. Mater., 258-263 (1998) 2079-2082.

[126] H. Nishimura, T. Terai, T. Yoneoka, S. Tanaka, A. Sagara, O. Motojima, Compatibility of Structural Candidate Materials with LiF-BeF2 Molten Salt Mixture, J. Nucl. Mater., 283-287 (2000) 1326-1131.

[127] R.E. Tressler, M.D. Meiser, T. Yonushonis, Molten Salt Corrosion of SiC and Si3N4 Ceramics, J. Ameri. Ceram. Soc., 59 (1976) 278-279.

[128] G.R. Pickrell, T. Sun, J.J.J. Brown, High Temperature Alkali Corrosion of SiC and Si3N4, Fuel Processing Technology, 44 (1995) 213-236.

[129] E.A. Gulbransen, S.A. Jansson, The High-Temperature Oxidation, Reduction, and Volatilization Reactions of Silicon and Silicon Carbide, Oxidation of Metals, 4 (1972) 181-201.

[130] J.E. Antill, J.B. Warburton, Active to Passive Transition in the Oxidation of SiC, Corrosion Science, 11 (1971) 337-342.

[131] G.J. Ervin, Oxidation Behavior of Silicon Carbide, J. Ameri. Ceram. Soc., 41 (1958) 347-352.

[132] D.Y. Song, S. Kitaoka, H. Kawamoto, Hot Corrosion of Chemical Vapour Deposited $\mathrm{SiC}$ and Si3N4 in Molten Na2SO4 Salt, Journal of Materials Science Letters, 33 (1998) 1031-1036.

[133] D.W. McKee, D. Chatterji, Corrosion of Silicon Carbide in Gases and Alkaline Melts, J. Ameri. Ceram. Soc., 59 (1976) 441-444.

[134] L.L. Snead, Limits on irradiation-induced thermal conductivity and electrical resistivity in silicon carbide materials, J. Nucl. Mater., 329-333 (2004) 524-529.

[135] Y. Katoh, SiC Flow Channel Inserts (FCI) for DCLL Test Blanket Module, in: USITER Test Blanket Module DOE External Review Meeting, Oak Ridge, Tennessee, 2006. 
[136] N.B. Morley, Y. Katoh, S. Malang, B.A. Pint, A.R. Raffray, S. Sharafat, S. Smolentsev, G.E. Youngblood, Recent US research and development for the dual coolant blanket concept, Fusion Eng. and Design, ((submitted)).

[137] L.L. Snead, T.D. Burchell, Y. Katoh, Swelling of Nuclear Graphite and High Quality Carbon Fiber Composite Under Very High Irradiation Temperature, J. Nucl. Mater., (submitted).

[138] Y. Katoh, L.L. Snead, Status of Irradiation of Multilayer SiC/SiC and FMI-222 Graphite Composites, ORNL/TM-2005/508, in, Oak Ridge National Laboratory, 2005.

[139] T. Tanabe, T. Maruyama, Graphite Materials for Fusion Reactor Applications, Journal of Plasma and Fusion Research, 69 (1993) 415-450.

[140] B.T. Kelly, The behavior of graphite under neutron irradiation, Journal of Vacuum Science and Technology, A 4 (1986) 1171-1178.

[141] B.T. Kelly, Irradiation behavior of fine-grain graphites, Fusion Technology, 16 (1989) 96-103.

[142] C.R. Kennedy, TSX graphite for extended use in the N-Reactor, ORNL/TM-9710, in, Oak Ridge National Laboratory, Oak Ridge, Tennessee, 1985.

[143] A.L. Pitner, Irradiation behavior of POCO graphites, Carbon, 9 (1971) 637-644.

[144] R.J. Price, G. Haag, Property changes in graphite irradiated at changing irradiation temperature, in, General Atomics, 1979.

[145] R.J. Price, High-temperature neutron irradiation of highly oriented carbons and graphites, Carbon, 12 (1974) 159-169.

[146] R.J. Price, J.C. Bokros, Mechanical properties of neutron-irradiated pyrolytic carbons, Journal of Nuclear Energy, 21 (1967) 158-174. 